
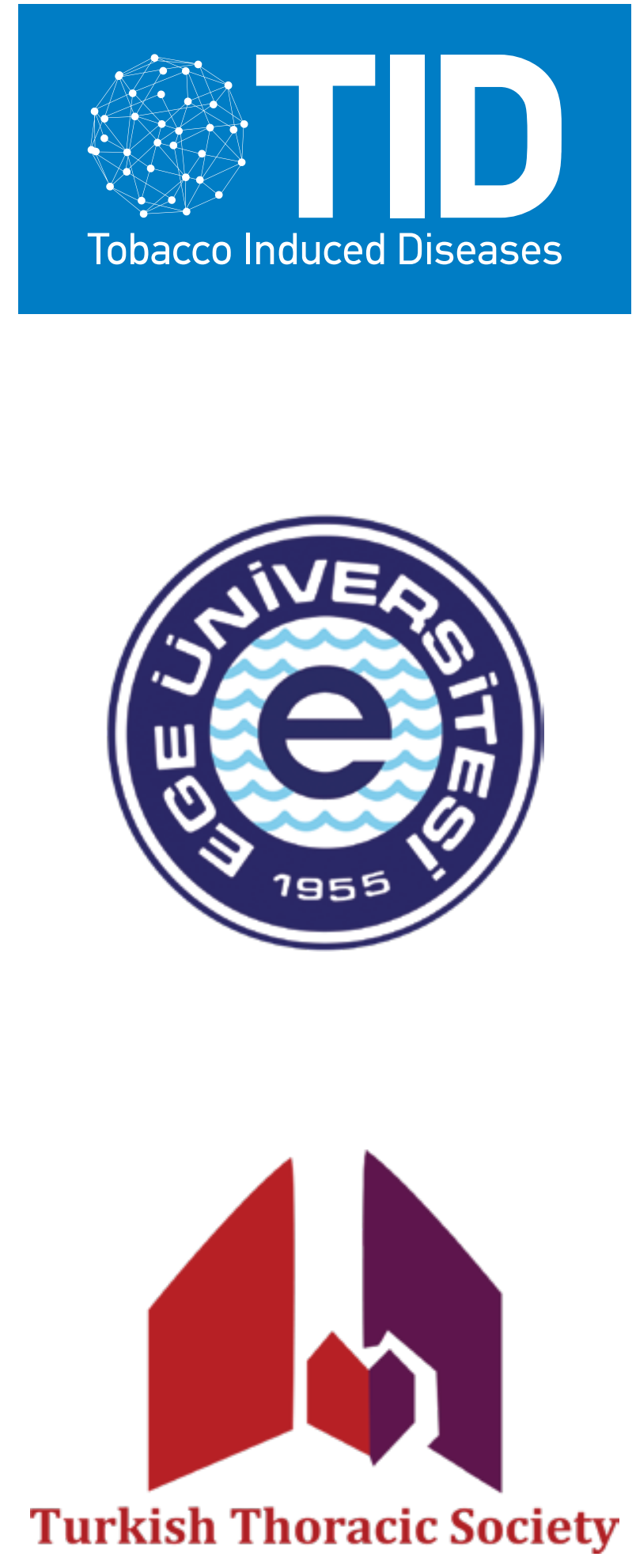

2
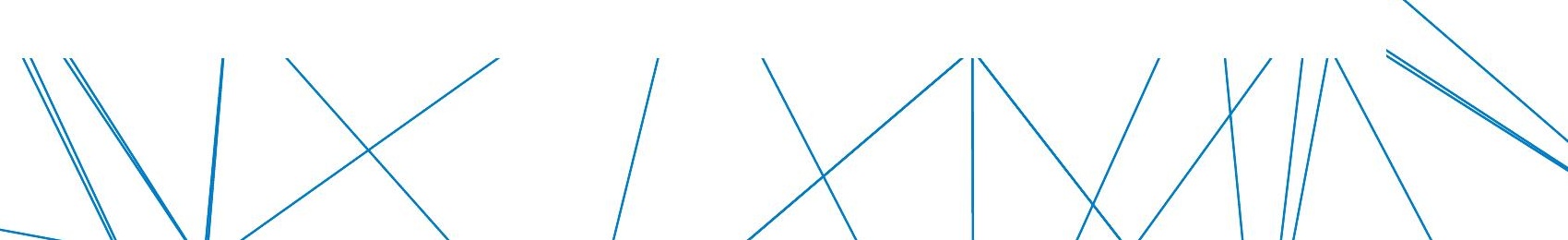


\section{Aims and Scope}

Tobacco Induced Diseases encompasses all aspects of research related to the prevention and control of tobacco use at a global level. Preventing diseases attributable to tobacco is only one aspect of the journal, whose overall scope is to provide a forum for the publication of research articles that can contribute to reducing the burden of tobacco induced diseases globally. To address this epidemic we believe that there must be an avenue for the publication of research/ policy activities on tobacco control initiatives that may be very important at a regional and national level. This approach provides a very important "hands on" service to the tobacco control community at a global scale - as common problems have common solutions. Hence, we see ourselves as "connectors" within this global community.

The journal hence encourages the submission of articles from all medical, biological and psychosocial disciplines, ranging from medical and dental clinicians, through health professionals to basic biomedical and clinical scientists.

Full Journal Title:

Tobacco Induced Diseases

Abbreviated Title:

Tob. Induc. Dis.

ISSN (electronic):

$1617-9625$

Publishing model:

Open Access

Society:

The International Society for the Prevention of Tobacco Induced Diseases

Publisher:

EUEP European Publishing

Publisher Address:

Science and Technological Park of Crete, Greece

Peer Review:

Double Blind

Impact factor 2017

1.539

Licenses:

$\mathrm{CC}-\mathrm{BY}$

Publication Frequency:

Continuous

Publication Medium:

Electronic Only

Publication website:

http://www.tobaccoinduceddiseases.org/

Disclaimer: All authors are responsible for the content of their abstracts and retain copyright of their abstract under an Open Access, Creative Commons License (CC-BY-4.0). Each abstract is citable and identifiable through its individual Digital Object Identifier (DOI)

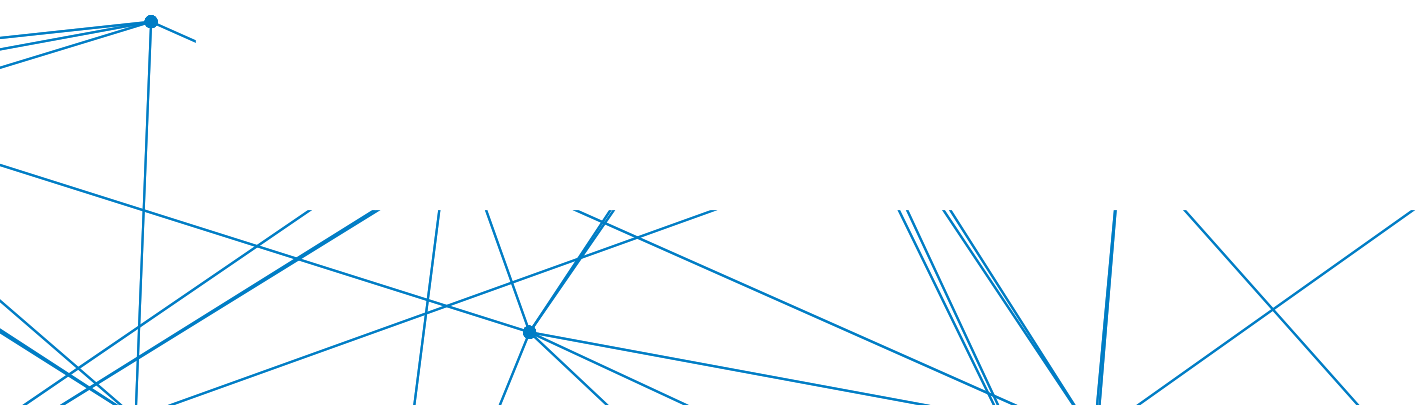




\section{Editorial Board}

Editors-in-Chief

James Elliott Scott, University of Manitoba, Canada Israel Agaku, Office of Smoking and Health, Center for Diseases Control (CDC), United States

\section{Associate Editors}

Parimal Chowdhury, University of Arkansas for Medical Sciences, United States Taru H. Kinnunen, Harvard University, United States David Scott, University of Louisville, United States Xing Li Wang, Baylor College of Medicine, United States Athanasios Zavras, Boston University, United States

\section{Editorial Board}

Olalekan Ayo-Yusuf, Sefako Makgatho Health Sciences University, South Africa Sophia S. Chan, The University of Hong Kong, Hong Kong Gregory Connolly, Northeastern University, United States

Elif Dagli, Turkish Thoracic Society, Turkey

Silvio De Flora, University of Genoa, Italy

Filippos Filippidis, Imperial College London, United Kingdom Geoffrey Fong, University of Waterloo, Canada

Erika S. Froelicher, University of California San Francisco, United States Stan Glantz, University of California, United States

Giuseppe Gorini, Cancer Research \& Prevention Institute, Italy

Prakash C. Gupta, Healis - Sekhsaria Institute of Public Health, India

Takashi Hanioka, Fukuoka Dental College, Japan

Wojciech Hanke, Nofer Institute of Occupational Medicine, Poland

Asgeir R. Helgason, Karolinska Institute, Sweden

DaeHyun Kim, Keimyung University Dongsan Medical Center, South Korea

Sungkyu Lee, National Tobacco Control Center, Korea Health Promotion Institute, South Korea Christos Lionis, University of Crete, Greece

Maria Jose Lopez, Public Health Agency of Barcelona, Spain

Karl E. Lund, Norwegian Institute for Alcohol and Drug Research, Norway

Toshitaka Nakahara, Kyoto University School of Medicine, Japan

Rima Nakkash, American University of Beirut, Lebanon

Evridiki Patelarou, Kings College London, United Kingdom

Kinga Polanska, Nofer Institute of Occupational Medicine, Poland

Lars Ramstrom, Institute for Tobacco Studies, Sweden

Hana Ross, University of Cape Town, South Africa Kazunari Satomura, Kyoto University, Japan

Steve Sussman, University of Southern California, United States

Tai Hing Lam, University of Hong Kong, Hong Kong

Witold Zatonski, The Maria Sklodowsska-Curie Memorial Cancer Center, Poland

\section{Development Editor}

Constantine Vardavas, Institute of Public Health, American College of Greece, Greece 


\section{TABLE OF CONTENTS}

THURSDAY 4 OCTOBER

YOUTH AND TOBACCO 1

What is the rate of tobacco usage among dental school students?....

Assessment of the joint approach of family, school and family physician in smoking and alcohol

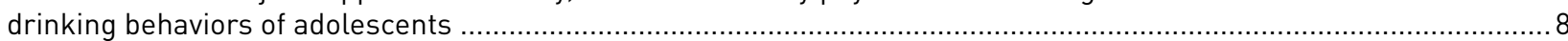

Social factors should not be underestimated in smoking behaviour among adolescents: A patriarchal

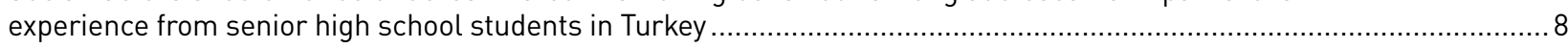

Smoke-free Ege: An attempt for an integrative prevention strategy for tobacco control at a University setting ..............9

Influencing factors of university students' smoking status according to gender .................................................. 9

Factors affecting smoking initiation among the youth in Bangladesh - An empirical analysis .............................................. 10

POLICY AND TAXATION 1

The effectiveness of text and graphic warnings on cigarette packages on the intention to quit smoking:

Comparing punishment and reward based images in a Turkish university student sample ....................................... 10

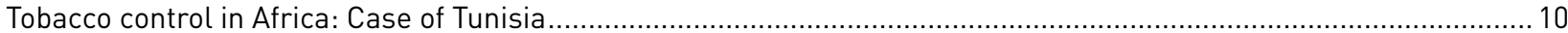

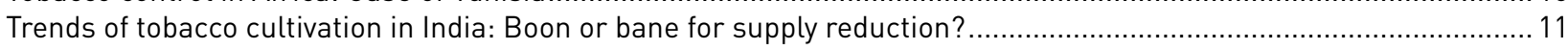

The demand for cigarettes: new evidence from South Africa..................................................................... 11

Passing FCTC compliant tobacco control legislation amid conspicuous industry interference: the case of Senegal ..... 11

IMPLEMENTING THE TOBACCO PRODUCT DIRECTIVE IN EUROPE -

THE JOINT ACTION ON TOBACCO CONTROL (JATC)

Ensuring sustainability and dissemination of TPD and JATC activities in Europe

CESSATION 1

Characteristics of smokers and outcomes of short term smoking cessation interventions according to cessation medication choice: Experience of an outpatient smoking cessation clinic .......................................................... 12

Developing message content sent via WhatsApp for improving quitting success rate ................................................ 13

"Clean Air for Babies" App: A smoking cessation mobile app based on Cognitive Behavioral Therapy combined with personal counseling to help expectant mothers quit smoking

Change in the effect of pharmacotherapy additional to behavioral counseling using inverse probability treatment weighting in Balçova Heart Study

DEUMF Pulmonary Diseases Department Smoking Cessation Clinic data

Tobacco use and rates of 4 As delivery for treating tobacco dependence among Albanian students.

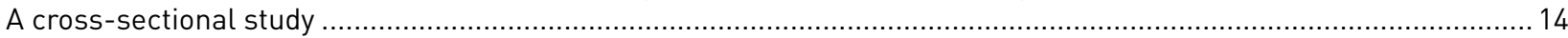

Effectiveness of Tobacco Cessation Training Program for primary health care physicians of a South Indian district .... 14

TOBACCO HEALTH EFFECTS 1

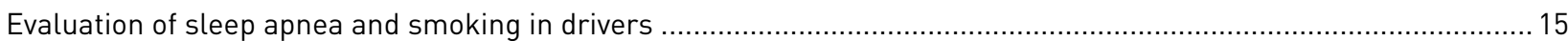

Smoking is associated with walking, fatigue, depression, and health-related quality of life in persons with multiple

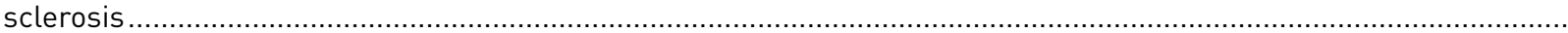

Assessment of carotid calcifications on panoramic radiographs and its relationship with periodontal condition and smoking status

The relationship between smoking history, functional exercise capacity and airway obstruction

severity in patients with chronic obstructive pulmonary disease.

Frequency of smoking in subgroups of ischemic stroke and relation between smoking and various complications of ischemic stroke.

The increased cardiovascular mortality among hypertensive smokers

\section{FRIDAY 5 OCTOBER}

Tobacco-induced suppression of the vascular response to dental plaque.

Toward full involvement of oral healthcare providers in tobacco dependence treatment in Japan ...............................17

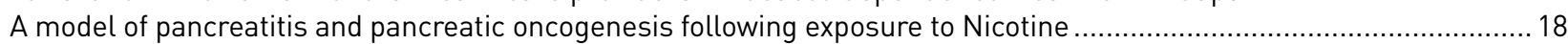

ORAL HEALTH AND TOBACCO 1

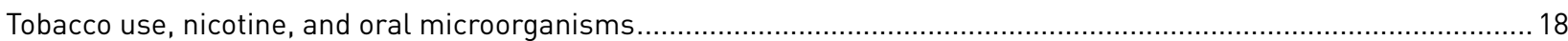

Effects of smoking on non-surgical periodontal therapy in generalized aggressive periodontitis ............................. 18

Dimensional changes of recipient site following free gingival graft around dental implants in smokers and non-

smokers: A prospective controlled clinical study......

The effect of synbiotic tablet usage on the clinical and biochemical parameters in smokers and nonsmokers with

gingivitis: a randomized placebo-controlled clinical trial

Impact of smoking on marginal bone loss in implant supported removable prosthesis

Effect of smoking on salivary free amino acid levels 
WATERPIPE AND NOVEL PRODUCTS.

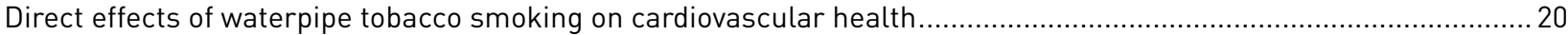

Rise of popularity of electronic cigarettes and correlates with marketing and regulations trajectory .........................2 20

Impact of water-pipe smoking on testosterone levels in Qatari males ............................................................. 21

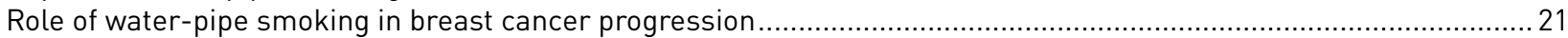

Hookah use among adolescent school students from urban slums of Mumbai, India ................................................ 22

Prevalence, harm perception, correlates of favourable harm perception and predictors of waterpipe smoking among

University of Ibadan undergraduate students....

The role of socio-demographic factors associated with water pipe smoking among male adolescents,

in western Iran: A cross-sectional study.

\section{EUREST-PLUS: TOBACCO CONTROL POLICY IMPLEMENTATION}

TO REDUCE LUNG DISEASE.

Evaluating the European Union (EU) Tobacco Products Directive: Findings from the EUREST-PLUS ITC cohort study among six EU Member States (MS).

Chemical analysis and hazard identification of the most common electronic cigarette liquids in nine European

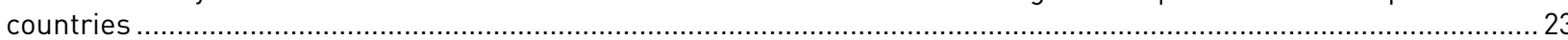

Undesirable events during electronic cigarette use prior to the implementation of Article 20 of the European Union

Tobacco Products Directive: Findings from the EUREST-PLUS ITC Europe Surveys ...............................................24

Quitting behaviors and cessation assistance used among smokers with anxiety or depression: Findings among six

countries of the EUREST-PLUS ITC Europe Surveys

SECONDHAND SMOKE EXPOSURE

Validity and reliability study of the Turkish version of beliefs about third hand smoke (BATHS) scale .........................25

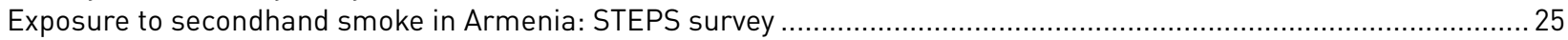

Evaluating the association between breast cancer and second hand smoking in Tekirdag ......................................26

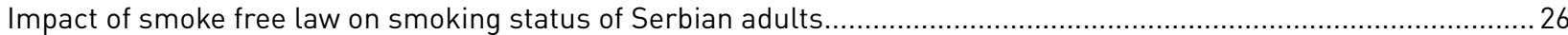

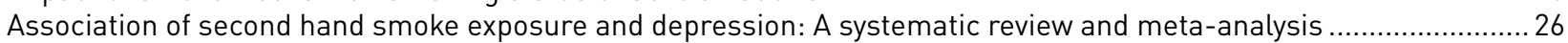

TOBACCO HEALTH EFFECTS 2

Population attributable fractions of tobacco related cancers in Turkey and seven geographical regions ..................... 27

An evaluation of the relation between atrial fibrillation and smoking in patients undergoing stroke...........................27

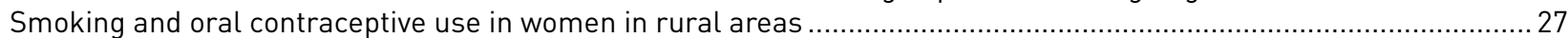

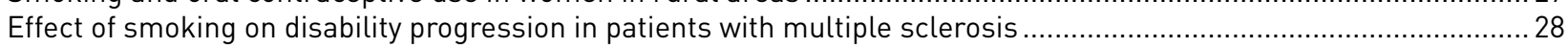

Smokers with diabetes: Twice as deadly and shortened life by 15 years ..........................................................28

Tobacco use, determinants and effects on treatment among persons living with HIV/AIDS at a Military Hospital in

Makurdi, Benue State, Nigeria

PREVALENCE STUDIES

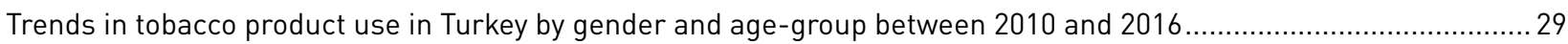

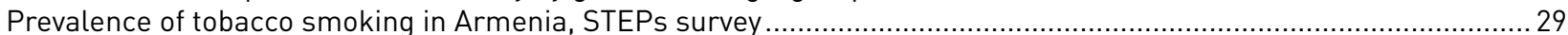

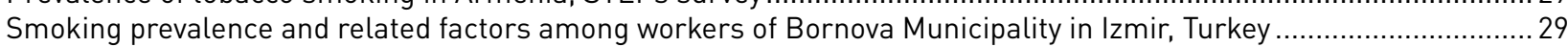

A Study on Nicotine Dependency Levels of Smoking University Students Depending On Socio-Demographic Features, and Smoking Habits.

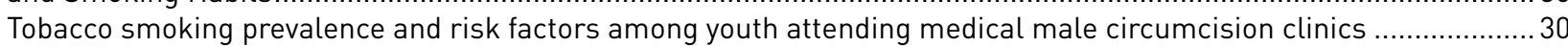

Comparison of tobacco use prevalence between Panama nationwide and the Guna Yala Indigenous Territory ............. 31

Intention and quitting pattern of smokeless tobacco in a rural community of Anambra state of Nigeria ......................3 31

\section{SATURDAY 6 OCTOBER}

CESSATION 2

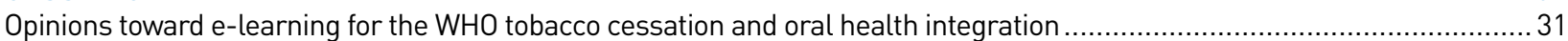

Smoking cessation services for health staff: Experiences of a university hospital in Izmir, Turkey ..............................32

The status of smoking cessation according to anxiety, depression and addiction level of patients .................................32

Do the features of smoking cessation service users change during governmental drug donation period? ...................32

Stopping smoking prior to elective hip and knee surgery: the impact of visiting a community pharmacist for tobacco

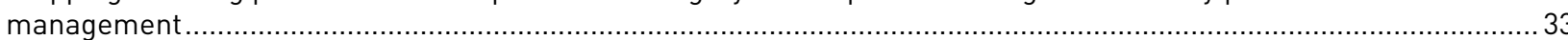

Ethiopian health care delivery system's responsiveness to smoking cessation therapy and its predictors: A mixed method study in Ethiopia.

ORAL HEALTH AND TOBACCO 2

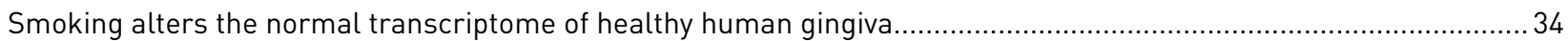

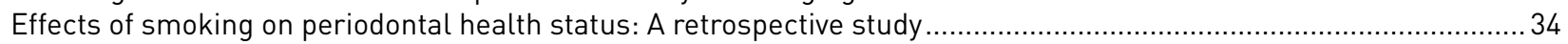

The effect of smoking on peri-implant marginal bone loss in periodontally compromised patients .............................34

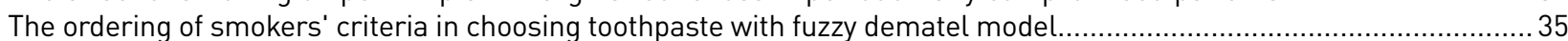

Effect of smoking on long-term stability of coronally advanced flap: 6 -year follow-up................................................... 35
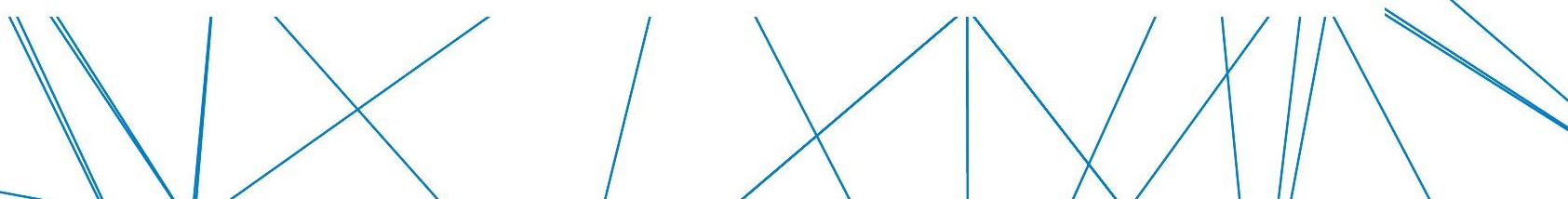
YOUTH AND TOBACCO 2 36

Smoking status of students of medical school and factors affecting their smoking .............................................. 36

Change in smoking frequency and affecting factors among the students of a medical faculty in Ankara - Turkey: 2013-2016.... 36

Smoking status of medical students at Ege University: A cross-sectional survey of 1040 students in $2018 \ldots \ldots \ldots \ldots \ldots . . . . .36$

Parent smoking behavior and children's future development: evidence from Indonesia Family Life Survey (IFLS)........ 37

Tobacco smoking imagery in Nigerian musical videos; A four year retrospective review ..........................................37

Marginal effects of determinants of smoking participation among young adults in Kenya: A by gender logistic

regression analysis

POLICY AND TAXATION 2

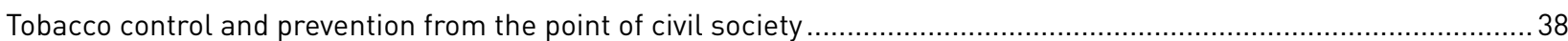

EUREST-FLAVOURS: European Regulatory Science on Tobacco to support the assessment of characterising

flavours in tobacco products.

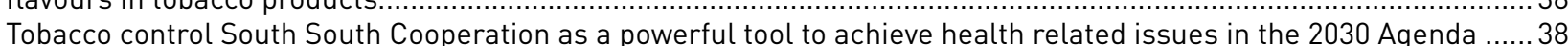

Awareness campaign on tobacco misdeeds and the anti-smoking law in schools and universities: the case of Senegal...... 39

Challenging tobacco promotions in Tamil media through community responses

POSTERS

Marlboro is the only smuggled cigarette which was used in Tehran. An experience from third cigarette pack surveys in Tehran, 2018

The factor structure and factorial invariance of short form of smoking temptation for TTM framework in Iranian smoker population: Golestan Province....

Hukah smoking and lung cancer in Kashmir.

Children and youth exposure to tobacco products in Ghana.

41

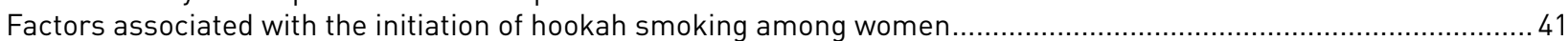

Violence and power in the absence of tobacco control in prison environments ................................................... 41

Smoking habits and effects in a pulmonary outpatient clinic in Ağrı ................................................................42

Tobacco industry interference in price and tax policies in Kenya: Analysis of tobacco industry internal communication documents

Attitude and perception towards secondhand smoke among general public in Nigeria

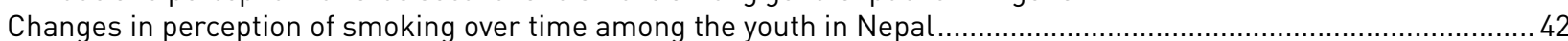

Effective use of Food Safety and Standards Act, 2006 to prevent the sale of tobacco products along with

food items in supermarkets: A case study from Punjab.....

Strengthening the effectiveness of Indian Penal Code (1860) regarding spitting of tobacco at public places - A case

study from North region of Indian subcontinent.....

Is ban on Hookah bars under Code of Criminal Procedure $(\mathrm{CrPC})$ effective in controlling the menace: $\mathrm{A}$

case study from Punjab, India

Should Ministry of Health ban manufacturing and sale of Electronic Nicotine Delivery Systems (ENDS)

popularly called E-cigarettes - result of an online poll

Tobacco use of the healthy aging individuals

What is necessary to fight against tobacco vaporizers in Japan?.....

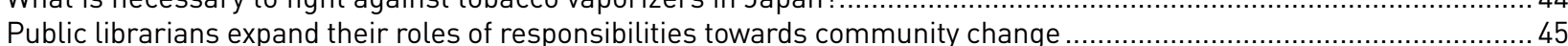

Media advocacy on alternative crops, a tool for tobacco control; Experience from Tanzania, East Africa ..................... 45

Injunctive norms and associations with smoking susceptibility in Hong Kong adolescents ........................................45

Public poll for support $100 \%$ smoke free area regulation to protect children from secondhand smoke exposure

in big city on 8 provinces in Indonesia

Correlates of quit attempts among smokers in Nigeria

Biochemical profiling of smokeless tobacco product Kiwam at different processing steps ......................................46

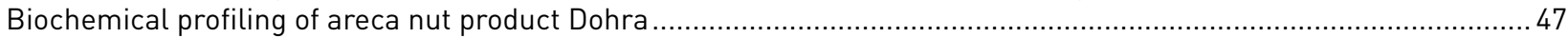

The globalized tobacco industry interference - The Brazilian tobacco additives ban case .........................................47

Sex patterns of lung cancer mortality in Russia over a 16-year period, 2000-2015 ................................................47

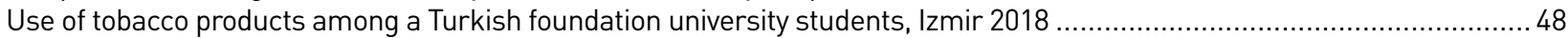

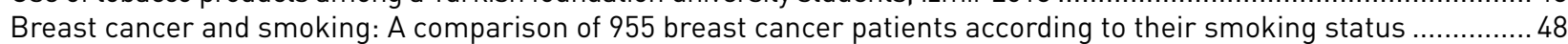

Association of tobacco industry denormalisation beliefs with smoking cessation and nicotine addiction in adolescent smokers

Outcomes of University Hospital Outpatient Smoking Cessation Clinic in İzmir

Prevalence of cigarette smoking and cessation among 15 years old and older people in Kayapınar district of

Diyarbakır.

Smoking status of oncological patients

Tobacco consumption among high school students in Kathmandu, Nepal........................................................50

Determination of cigarette drinking curriculum and investigation of some demographic effects of grade 1

students of Dicle University Faculty of Medicine

Nicotine down-regulates the proliferation of the cementoblasts (OCCM.30) ..........................................................5 50

Effect of diode laser decontamination as an adjunct to nonsurgical periodontal therapy on the clinical and

biochemical parameters in smokers and nonsmokers with chronic periodontitis......

Smokers melanosis: A case report 


\section{THURSDAY 4 OCTOBER}

\section{YOUTH AND TOBACCO 1}

What is the rate of tobacco usage among dental school students?

Nurcan Buduneli', Onder Gurlek', Pinar Meric', Ulku Baser $^{2}$, Guliz Guncu3 ${ }^{3}$, Sema Hakki ${ }^{4}$, Leyla Kuru', Muge Lutfioglu', Ebru Olgun 7 , Burcu Ozdemir ${ }^{8}$, Zekeriya Tasdemir ${ }^{9}$, Kemal Ustun ${ }^{10}$

'Department of Periodontology, School of Dentistry, Ege University, Izmir, Turkey, ${ }^{2}$ Department of Periodontology, School of Dentistry, Istanbul University, Istanbul, Turkey, ${ }^{3}$ Department of Periodontology, School of Dentistry, Hacettepe Univiversity, Ankara, Turkey, ${ }^{4}$ Department of Periodontology, School of Dentistry, Selçuk University, Konya, Turkey, ${ }^{5}$ Department of Periodontology, School of Dentistry, Marmara Univinersity, Istanbul, Turkey, ${ }^{6}$ Department of Periodontology, School of Dentistry, Ondokuz Mayis University, Samsun, Turkey, ${ }^{7}$ Department of Periodontology, School of Dentistry, Kirikkale University, Kırıkkale, Turkey, ${ }^{8}$ Department of Periodontology, School of Dentistry, Gazi University, Ankara, Turkey, 'Department of Periodontology, School of Dentistry, Erciyes University, Kayseri, Turkey, ${ }^{10}$ Department of Periodontology, School of Dentistry, Akdeniz Univesity, Antalya, Turkey

\section{Introduction}

This survey aimed to investigate the rate of students in dental schools that use various tobacco products and possible factors affecting their attitudes towards tobacco products.

\section{Methods}

The survey was conducted between May 1 and June 30 2018 and participants were from ten dental schools in Turkey. First year students and fifth year students were compared in terms of tobacco product usage and their attitudes towards tobacco. Data were tested statistically using Statistical Package for Social Sciences (SPSS) 15.0 program and chi-square test.

\section{Results}

A total of 1228 students from eleven different dental schools completed the online survey. Majority of the participants were females $(62.1 \%)$ and males were less (37.9\%). Mean age of the participants was $21.8 \pm 2.9$ years (min-max; 18 54 years). The overall rate of current smokers was $38.11 \%$, but $56.6 \%$ of the participants have inhaled tobacco smoke. More than half $(55.3 \%)$ of the current smokers stated that they wish to quit and $36.7 \%$ of these students have attempted to quit within the last six months. More than $10 \%$ of all participants defined themselves as highly addicted to cigarette smoking. The rate of waterpipe smokers were $41.2 \%$ and $83.7 \%$ of these students were not willing to stop waterpipe smoking.

\section{Conclusions}

The rate of current tobacco smokers is rather high among dental school students and this finding points out the need for more effective precautions against tobacco.

\section{Funding}

This study has been funded solely by the institutions of the authors.

\section{Tob. Induc. Dis. 2018;16(Suppl 3):A1}

DOI: 10.18332/tid/94783

Assessment of the joint approach of family, school and family physician in smoking and alcohol drinking behaviors of adolescents Burcu Bicer ${ }^{1}$ ${ }^{1}$ Faculty of Medicine, Yüksek Ihtisas University, Ankara, Turkey

\section{Introduction}

The environment has an important role in gaining healthy behaviors for adolescents. The interaction of family, school and health services constituting this environment should be demonstrated and a positive approach model should be displayed. In this study, knowledge and consistency of some behaviors such as smoking and alcohol in adolescents in family, school system and health services is examined.

\section{Methods}

The study, which was designed as a case-control type, reached 1462 students in eight schools from the middle and lower socio-economic level. Scores were calculated according to the Risk Health Behaviors Scale (RSSS) and face-to-face interviews were conducted with 78 students and 78 families with risky health behaviors (RSD), their teachers, and family physicians.

\section{Results}

There was a low consistency $(p<0,001)$ between the answers given by the adolescents about smoking and the answers given by the family members, and low consistency ( $p<0,001)$ between the answers given by the teachers. There was no consistency in response to drinking alcohol. There was no statistically significant consistency between the responses of the adolescents with RSD to attitude questions and the responses of family, teachers and family physicians ( $p>0,05)$.

\section{Conclusions}

Family, school and family physicians in the adolescent social environment are poorly aware of adolescents smoking and drinking alcohol. The family, school and health services around adolescents and adolescents must be in collaboration, to improve adolescent health.

\section{Funding}

Hacettepe University Scientific Research Projects Coordination Unit, Project no: 013D01106001.

\section{Tob. Induc. Dis. 2018;16(Suppl 3):A2 DOI: 10.18332/tid/94794}

\section{Social factors should not be underestimated} in smoking behaviour among adolescents: $A$ patriarchal experience from senior high school students in Turkey

Ersin Nazlıcan', Özgür Ersoy', Muhsin Akbaba', Hakan Demirhindi' ${ }^{1}$

'Department of Public Health, Faculty of Medicine, Çukurova University, Adana, Turkey

\section{Introduction}

Smoking threatening especially younger age groups is a multi-factorial phenomenon on which socio-demographic, environmental and behavioural factors are effective. We aimed to evaluate the prevalence of smoking among senior high school students in Kahramanmaras city centre, Turkey and to determine the effect of social contributing factors in order to provide an insight to future precautionary interventions including education strategies targeting not only the adolescent population, but also their families in a patriarchal method approach in Turkey.

\section{Methods}

This cross-sectional study included 1,537 senior students from 47 randomly selected high schools. Smokers group consisted of daily smokers and intermittent smokers except social intermittent smokers.

\section{Results}

The prevalences were found as $63.7 \%$ for trying to smoke at least once in a life time and $24.5 \%$ for smoking $121.1 \%$ for daily and $3.4 \%$ for infrequent smoking). The most
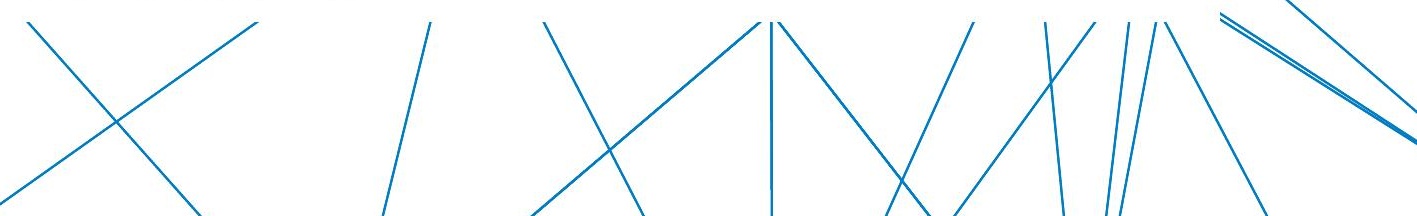
frequent reason to smoke was curiosity (41.7\%). Most of the participants $(82.9 \%)$ did not want to quit. The mean Fagerström test for nicotine dependence score of daily smokers was 2.1 \pm 1.4 . Significant odds ratios for smoking were found as being male (3.26), no talking with parents (1.85 only in males), no support from parents (2.27 only in males), self-violence (2.73 only in females), violence against others (1.87 only in males), a smoking father (1.58 in males and 2.53 in females), a smoking sibling (1.50 in males, 2.00 in females), a smoking close friend (10.69 for males and 3.78 for females). The smoking status of the mother was not found to be effective for neither the males nor the females.

\section{Conclusions}

If we intend to prevent the use of tobacco products especially prevalent among senior high school students and to construct an approach model for quitting to smoke more emphasis should be placed on social environment including the role models especially in communities with patriarchal structure.

\section{Funding}

Cukurova University Scientific Research Foundation No. TTU-2015-3448.

\section{Tob. Induc. Dis. 2018;16(Suppl 3):A3}

\section{DOl: 10.18332/tid/94796}

\section{Smoke-free Ege: An attempt for an integrative prevention strategy for tobacco control at a University setting}

Isil Ergin', Aliye Mandıracioglu', Seyfi Durmaz', Haydar Karakus', Ayhan Caliskan', Gorkem Yararbas' ${ }^{1}$ Hur Hassoy', Raika Durusoy', Alev Gurgun'1, Zeynep Ozsaran'1, Muge Gor ${ }^{1}$, Kumral Oralalp ${ }^{1}$, Ozen Basoglu', Tuncay Goksel ${ }^{1}$, Cemil Gurgun ${ }^{1}$, Necdet Budak ${ }^{1}$

'Smoke-Free Ege Working Group, Ege University, Izmir, Turkey Introduction

Ege University is a pioneering university at Ege region with its 70000 students and approximately 3000 academic staff. Tobacco control policies, parallel to the current regulations in the country, are an important issue for Ege University too, yet it bares important opportunities as well as barriers for an integrative approach for tobacco control on University Campus.

\section{Aim}

This study aims to explain the construction of Smoke-Free Ege Working Group, its formal initiation at the World No Tobacco Day (May 31st) and its subsequent action plan structured in the light of MPOWER

\section{Methods}

Since 1999, smoking cessation outpatient service delivery points have been the main units of motivation for tobacco control policies at Ege University. Although Turkey is moving well about tobacco regulations, adherence to regulations is deficient and high prevalence of smoking among university staff and students remains as a major concern throughout the years. In March 2018, the administrative bodies of Medical School, have dealt their concerns to the units serving care for cessation and have gathered them at a first meeting. The Dean and Medical Manager of Medical Faculty, with a non-smoker administrative team, mentored and facilitated these efforts. Starting at this point, with regular meetings, the representatives determined their objectives, current barriers and opportunities. The construction of Smoke-Free Ege Working Group has rooted from these consecutive meetings. In the light of MPOWER, specific objectives at University Campus were listed. The major aim of the group was recognized as "changing the norms and culture for smoking". This needed a good promotion strategy as well as collaboration with staff, students and administrative units. The efforts were collaborated with the Communications Unit of the University. A logo was created, brochures to raise awareness for the Smoke Free issue and the Working group, were prepared. The formal presentation of the Working Group was planned as a colorful activity on World No Tobacco Day, May 31st. To gather more visibility at the social media and press, representatives from three major opponent sports teams of Izmir city were invited.

\section{Results}

The Working Group was introduced to the media in the presence of the Rector, Dean, Medical managerl and all administrative units of the Medical School. Staff who succeeded to stop smoking, at the cessation service of the University, were awarded with certificates. The media showed great interest in the activity as it was put as "the famous sportsmen are supporting the efforts for a Smokefree university". Students and staff attended and shared the activity in social media as the entrance of the meeting was also colorfully designed for such promotion.

\section{Conclusions}

The Working Group has achieved to attract attention of staff, students and responsible bodies of the University and now moving forward for Smoke -Free Councils with students and staff representatives. Barriers and opportunities will be discussed, actions in the light of MPOWER, will be planned at these Councils. Smoke -Free Unit certifications and awards, designing smoking points outside of education and hospital settings and changing the "norm" are targeted.

\section{Tob. Induc. Dis. 2018;16(Suppl 3):A4 DOI: 10.18332/tid/94807}

\section{Influencing factors of university students' smoking status according to gender \\ Dilek Karadoğan ${ }^{1}$, Özgür Önal²}

'Department of Chest Diseases, Recep Tayyip Erdoğan University, Rize, Turkey, ${ }^{2}$ Department of Public Health, Süleyman Demirel University, Isparta, Turkey

\section{Background and aim}

Despite the strict anti-tobacco policies, smoking is still a major preventable public health problem in Turkey. We aimed to evaluate the smoking status of university students and the influencing factors of their smoking according to both gender.

\section{Methods}

This cross-sectional study conducted between Mach 2017 and June 2017 at an university located in the Eastern Black Sea region of Turkey. Among all students who had been reached and agreed to participate the study were included. A self-administered questionnaire was used to collect information.

\section{Results}

Totally 2505 students' data were evaluated with a mean age of $20.8 \pm 2.5$ and female dominance (58.9\%). Overall current smoking rate of the students was $27.9 \% ; 15.3 \%$ among females and $46.0 \%$ among males, additionally, the rate of ever smokers was $60.7 \% ; 51.9 \%$ among females, $73.4 \%$ among males $(p<0.05)$. The smoking rate of students who have at least one smoker family member (mother or father or sibling) was $61.4 \%, 63.3 \%$ among females and $58.6 \%$ among males $(p<0.05)$ and also $40.1 \%$ of the students were exposed to tobacco in their residence. Among current smokers (n:699), compared to males, female students had lower mean Faqerström nicotine dependence level
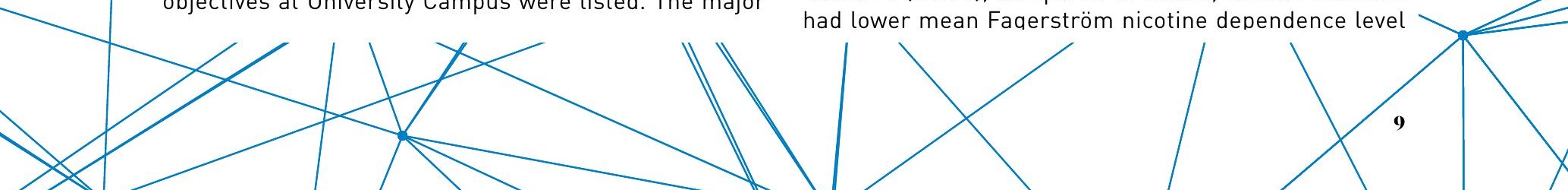
and higher mean age of beginning smoking $(p<0.05)$. Multivariate logistic regression analysis of male students and female students seperately revealed that; studying in a 2 year faculty, having at least one smoker family member having smoker close friends and presence of alcohol consumption were positively associated with current smoking for both gender.

\section{Conclusions}

This study showed that overall smoking rate of male students are higher than female students. Hovewer the influencing factors on their smoking status were similar.

Tob. Induc. Dis. 2018;16(Suppl 3):A5 DOI: 10.18332/tid/94764

Factors affecting smoking initiation among the youth in Bangladesh - An empirical analysis Biva Mallik'

'Department of Economics, East West University, Dhaka, Bangladesh

\section{Introduction}

Tobacco is the single greatest preventable cause of death in the world today. Prevalence of tobacco use among youth has always been a critical issue in tobacco control. This paper examines factors that can contribute to smoking initiation among the youth in Bangladesh.

\section{Methods}

The 2013 Bangladesh Global Youth Tobacco Survey (GYTS) is used in this study. Logistic regression models are carried out to explore various factors that affect initiation of cigarette smoking among the youth in Bangladesh.

\section{Results}

Results reveal that the youth who has more money to spend are more than twice as likely to initiate smoking, however the youth who thinks cigarettes are expensive are less likely to smoke. Results also show that the youth who witness smoking inside their homes and school premises has a higher probability to initiate smoking compared to their respective counterparts. Among the young population who initiates smoking also believes that it would be easy to quit smoking relative to the beliefs of the non-smokers. Moreover, the youth who are not taught about the dangers of smoking in classes has a higher chance to initiate smoking.

\section{Conclusions}

Results of this paper hold strong policy implications. Findings of this paper demonstrate that imposing higher taxes on cigarettes as well as smoking ban at home and schools can reduce smoking initiation rates among the young population of Bangladesh. Furthermore, in the academic curriculum it is essential to include the harmful effects of tobacco use to discourage the youth from initiation.

\section{Tob. Induc. Dis. 2018;16(Suppl 3):A6}

DOl: 10.18332/tid/94761

\section{POLICY AND TAXATION 1}

The effectiveness of text and graphic warnings on cigarette packages on the intention to quit smoking: Comparing punishment and reward based images in a Turkish university student sample

Rümeysa Biçer ${ }^{1}$, Șule Kara², Simge Șișman-Bal ${ }^{3}$ ${ }^{1}$ Independent Researcher, Hatay, Turkey, ${ }^{2}$ Toxicology and Pharmaceutical Science, Institute on Drug Abuse, Ege University Izmır, Turkey, ${ }^{3}$ Department of Psychology, Istanbul University, Istanbul, Turkey

\section{0}
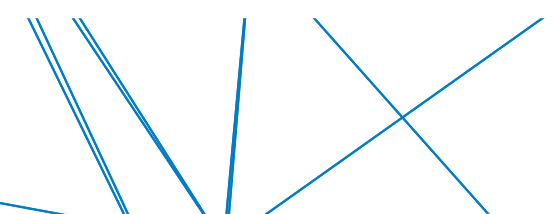

\section{Objective}

Text and graphic warnings on cigarette packs focus on the negative consequences of smoking. Although some studies have shown that warning labels on cigarette packets to be effective for smoking cessation, smoker adolescents in Turkey have generally find ineffective these messages or have changed their assessments according to the content. In this study, the impact of both punishment-based le.g. 'Smoking causes lung cancer') and reward-based (e.g. 'If you do not smoke, you will have a beautiful smile') warnings on the intention to quit smoking was examined.

\section{Methods}

The sample of the study consisted of 22 undergraduate students from Istanbul University who have been smoking for the past 6 months. Participants filled out a brief information form about their smoking habits, followed by displayed a PowerPoint presentation with 20 images (10 punishment-based/10 reward-based) which they have never seen before randomly arranged on the computer screen. After each images, students were asked to respond the question of 'Did you think that you should stop smoking?' with a 5-point scale.

\section{Results}

The mean duration of smoking was $5.1 \pm 3.3$ years and the average number of cigarettes per day was $9.6 \pm 7.8$. Participants who smoke $\leqslant 10$ cigarettes per day found punishment-based images more effective $(p=.042)$ however participants who wanted to quit smoking within 6 months rated reward-based images more effective ( $p=.017)$. In addition, $90.9 \%$ of the participants reported that current warnings on cigarette packages had no effect on thinking of stopping smoking.

\section{Conclusions}

These results showed that in addition to punishmentbased warnings some reward-based images can be used on cigarette packages in order to more motivate smokers to quit smoking.

\section{Tob. Induc. Dis. 2018;16(Suppl 3):A7 \\ DOl: 10.18332/tid/94758}

\section{Tobacco control in Africa: Case of Tunisia \\ Radhouane Fakhfakh ${ }^{1}$ \\ 'Department of Preventive Medicine, Faculty of Medicine, University of Tunis El Manar, Tunis, Tunisia}

\section{Introduction}

The aim of the study is to describe the main challenges of tobacco control in Tunisia.

\section{Results}

Tunisia has the top 10 worldwide tobacco use prevalence among men and the highest one in Africa. Furthermore, the tobacco use prevalence is more and more common among female and adolescents. In 2010, about quarter of deaths among men is caused by tobacco. More men die in Tunisia than on average in middle-income countries. The Tobacco-related Cancer Incident Cases will increase by $80 \%$ by 2030 . While Tunisia adopted anti-tobacco law on 1998 and ratified the FCTC on 2010, effective action of tobacco control was not implemented. Socio cultural factors favoring smoking initiation, lack of awareness among the public about the smoking hazards, weak support of governments and strong resistance of the tobacco industry are major reasons for the lack of effectiveness of current tobacco control measures. Effective intervention efforts are urgently required. Firm actions would be taken. These actions include accelerating the adoption of a new proposed law, enforcing actual law and the new one once adopted, developina an advocacy and arqument about 
the positive impact on state budget balance, increasing taxes, combating smuggling and illicit manufacturing and counterfeiting, increased education, increased smoking cessation support and implementing periodic surveillance.

\section{Conclusion}

Effective tobacco control should be implemented urgently in Tunisia Commitments from government are crucial for this tobacco control actions. The international support is also needed.

\section{Tob. Induc. Dis. 2018;16(Suppl 3):A8}

\section{DOl: 10.18332/tid/94527}

Trends of tobacco cultivation in India: Boon or bane for supply reduction?

Jagannath Purushothama', Preetha Shekar², Mackwin D'Mello', Priyanka Rent ${ }^{1}$

${ }^{1}$ Nitte (Deemed to be University), Karnataka, India, ${ }^{2}$ District Tobacco Control Cell, Karnataka, India

\section{Introduction}

Flue-cured Virginia Tobacco is an important commercial crop grown in India. It occupies the third position in the world with an annual production of about 800 Million Kgs and 5 th in exports. Tobacco contributes to over Rupees 340 Billion astax revenue to the national exchequer and approximately Rs.50 Billion by foreign exchange every year.

\section{Objective of the study}

To determine the trends of tobacco cultivation and tobacco revenue in India.

Data sources: Data on tobacco production, crop target, crop price etc were collected for the years 2012-2016 from Annual reports of Tobacco Board, Ministry of Trade and Commerce, India.

Study method: Secondary data-based Cross-Sectional Study

Data analysis: Data were analyzed using percentage, proportion and Pearsonn's Correlation Coefficient on SPSS version 16. Results were considered significant at 95\% level of significance.

\section{Results}

The mean Flue-cured virginia production between 2012 and 2016 was 270.35 million $\mathrm{kg} \mathrm{(} \pm 51.52)$ with a percentage reduction of $27 \%$ from the baseline year. Flue-cured virginia had a mean target of 259.5 million $\mathrm{kg}( \pm 26.55)$ during this period which showed $18 \%$ reduction in the target between base and end year. As FCV crop target increased, production also increased with a strong positive correlation $(r=0.96$; $p \leqslant 0.05$ ) which was statistically significant. Excise duty and foreign exchange in million rupees between 2012 and 2016 showed a percentage increase of $8 \%$ and $22 \%$ respectively.

\section{Conclusions}

The study depicts that FCV crop target is correlated to the production positively. Hence, reducing crop target is an effective supply reduction measure.

\section{Tob. Induc. Dis. 2018;16(Suppl 3):A9}

DOl: 10.18332/tid/94800

\section{The demand for cigarettes: new evidence from}

\section{South Africa}

Alfred Mukong ${ }^{1}$, Ernest Tingum

${ }^{1}$ Economics of Tobacco Control Project, School of Economics, University of Cape Town, Cape Town, South Africa

This paper estimates the price elasticity of demand for cigarettes in South Africa, a country that has currently experienced a transition in the cigarette market, from a near monopoly to a more competitive market structure. Based on longitudinal data drawn from the South Africa
National Income and Dynamic Study (NIDS: 2008 - 2014], we compare the results of the conditional elasticity (random and fixed effect panel estimates) and total elasticity of demand (two-part model). Like previous evidence into cigarette prices, we obtain negative price elasticity of demand for cigarettes, with the total price elasticity significantly larger than the conditional elasticity. For the total elasticity, a $10 \%$ increase in price reduces cigarette consumption by $4.3 \%$ for the economy brands and $6.9 \%$ for the mid-price brands. However, we find that over the same period, estimates from the fixed effect model are statistically insignificant. This is probably due to the limited within variation in both cigarette consumption and cigarette prices. Thus, with evidence from between variation models, increased tobacco taxes can, in the presence of the changing market structure, remain a desirable policy tool for reducing cigarette consumption.

\section{Tob. Induc. Dis. 2018;16(Suppl 3):A10}

\section{DOl: 10.18332/tid/94551}

Passing FCTC compliant tobacco control legislation amid conspicuous industry interference: the case of Senegal

Alioune Sylla'

'Programme national de Lutte contre le tabac, Senegal

\section{Background and context}

Senegal achieved significant legislative advances with the adoption of a Tobacco Control (TC) Act in 1981. However, since 1985, increasingly powerful industry lobbying resulted in important aspects of the Act being made less effective or reversed. In 2004 Senegal ratified the WHO Framework Convention on Tobacco Control (FCTC), but once again tobacco industry interference delayed preparation of a draft bill implementing the provisions of the FCTC until 2011.

\section{Aim}

To use civil society advocacy to catalyze a public health movement and reduce prevalence of tobacco use through adoption and implementation of new FCTC-compliant legislation in Senegal.

\section{Strategy / tactics}

LISTAB conducted a program of advocacy activities in parallel to the three year legislative development process, from initial drafting by Ministry of Health, through parliamentary amendment and approval, and finally promulgation by the President.

\section{Programme / Policy process}

Our activities included:

- Setting up a watchdog body called Tobacco Industry Monitoring Team

- Sensitizing and training decision makers, politicians and journalists on the FCTC, particularly Article 5.3

- Lobbying religious leaders and Members of Parliament, and identifying among them TC champions

- Running a national media campaign to gain exposure for TC issues and counter tobacco industry interference

Outcomes / What was learned

In March 2014, the TC bill was approved by the Senegalese parliament and promulgated by the President. In supporting this achievement, the work conducted by LISTAB highlights the importance of:

- Capacity building of tobacco control actors in both FCTC content and advocacy techniques to create a sustainable movement for policy change

- Engagement with MPs at all stages of policy design and implementation to create a favorable political
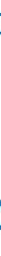
environment for adoption of the bill in Parliament and countering industry interference

- Integrating media coverage to enhance outreach and help raise the profile of education campaigns, accelerating public understanding and galvanizing support for policy change.

Tob. Induc. Dis. 2018;16(Suppl 3):A11

DOl: 10.18332/tid/94552

\section{IMPLEMENTING THE TOBACCO PRODUCT DIRECTIVE IN EUROPE - TIIE JOINT ACTION ON TOBACCO CONTROL (JATC)}

Ensuring sustainability and dissemination of TPD and JATC activities in Europe

Constantine I. Vardavas', Panagiotis Behrakis¹, Anna Tzortzi' ${ }^{1}$, Biljana Kilibarda ${ }^{2}$

${ }^{1}$ Hellenic Cancer Society, Athens, Greece, ${ }^{2}$ Institute of Public Health of Serbia, Belgrade, Serbia

The Tobacco Products Directive (TPD) is a complex binding European Union (EU) legislative document. The aim of the TPD is to preserve a high level of European public health and support the functioning of the internal market of tobacco products in the EU. The European Commission concluded that the European Union Member states need additional assistance in this daunting task. Over the 3 years period (2017-2020) the TPD will come into full swing and the wealth of information that will be available to regulators will be unprecedented.

The Joint Action for Tobacco Control (JATC) presents action oriented, evidence-based initiative that should provide support the implementation of the TPD. This collaboration between 30 partners from 23 European countries is funded through the European Commission's 3rd Health program. The aim of the JATC is to harmonize the regulation of tobacco products in all EU Member States, through the analysis of data submitted by the tobacco industry to EU regulators and development of actions needed to take place in tobacco product licensing and regulation.

Objective of the symposium is to provide information on the TPD and JATC and to foster communication and collaboration between relevant stakeholders. The symposium target audiences are EU Regulators and Policymakers, International and National Tobacco Control Stakeholders and researchers who will benefit from the findings and the project's broader policy implications as the largest current European Public Health Policy in implementation.

The nine work packages of the JATC are Coordination, Dissemination, Evaluation, Integration into National Policies and Sustainability, EU Common Entry Gate (EUCEG) data, Extraction and Handling, Tobacco Product Evaluation, E-cigarette Product Evaluation, Laboratory Verification, Collaboration and Analyses and Additives Subject to Enhanced Reporting Obligations.

Under the TPD (2014/40/EU), manufacturers and importers of tobacco products, have to submit key information to the authorities in the Member States in which they plan to market the products. This submission of information is performed through the EU Common Entry Gate (EU-CEG). While the EU-CEG IT-system is owned by the European Commission, each EU MS own their data in the EU-CEG. TPD states that EU MS should share data with other EU MS and with the Commission. Furthermore, this data is, to the extent possible, to be released to the public. Actions within this package bring significant added value as it addresses the issue of tobacco product monitoring at an EU wide level - an activity that would be impossible to be done by one, or a few, EU MS by themselves.

One of the specific aims of the JATC is dissemination of information and project's results to the public, regulators and researchers. Dissemination of information relevant to Tobacco Products Directive and tobacco control in general is essential for maximizing the impact of the JATC. Finding the most appropriate way of dissemination with protection of sensitive data is of great importance. However, despite the numerous available communication tools, dissemination of information is challenging.

\section{Funding}

JATC has received funding from the European Union's Health Programme (2014-2020).

Tob. Induc. Dis. 2018;16(Suppl 3):A12

DOl: 10.18332/tid/95251

\section{CESSATION 1}

Characteristics of smokers and outcomes of short term smoking cessation interventions according to cessation medication choice: Experience of an outpatient smoking cessation clinic

Dilek Karadoğan

'Department of Chest Diseases, Recep Tayyip Erdoğan University, Rize, Turkey

\section{Background and aim}

There are three forms of stop smoking medications (SSMs) in Turkey; bupropion SR, varenicline and nicotine replacement therapy (NRT) that are nicotine patches and nicotine gums. The aim of this study is to make a comparison between the SSM choices.

\section{Methods}

Patients applied to the local SCC in a secondary health care unit between June 2014 and June 2017 were retrospectively evaluated. Among them the ones who had records of phone visits at third month were included. Patients were grouped according to the started SSM and comparisons were made by using appropriate statistical methods.

\section{Results}

Totally 417 patients' data were evaluated with a mean age of $44.0 \pm 13.7$ and male dominance $(65.0 \%)$. Bupropion started group was consisted of $218(52.2 \%)$ smokers, that number was $134(32.1 \%)$ for varenicline started group and $65(15.5 \%)$ for NRT started group. Between groups; mean ages, education levels, jobs, comorbid disease, Fagerström test score level, mean treatment usage period, mean control visit number, presence of adverse reactions and coverage status of the treatment had significant differences $(p<0.05)$, however, difference according to gender and quit rate were not significantly different ( $p>0.05)$. Varenicline started group has the lower mean age, higher education level, higher rate of patients with actively working, lower rate of comorbid disease, higher mean medication usage duration, higher control visit number, lower rate at the paid medication period than both groups (bupropion SR and NRT), while presence of adverse reaction rate was only significantly higher than NRT $(p<0.05)$.

\section{Conclusion}

This study showed that not only the demographical characteristics but also the clinical outcomes as well as
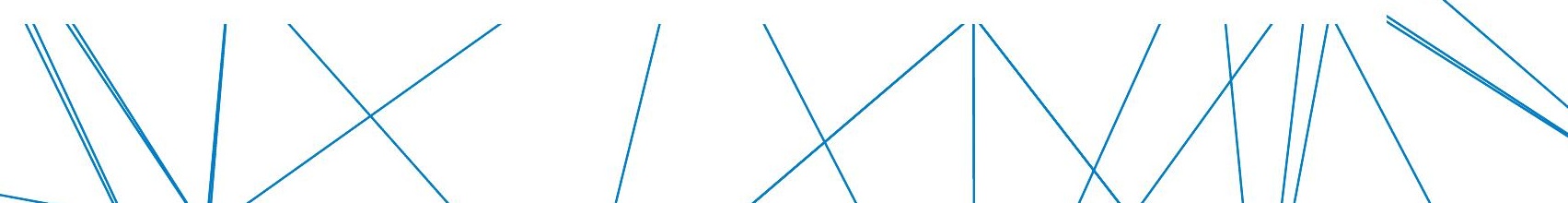
the coverage status of health insurances affect the SSM choice. Therefore at the time of evaluating the results of the smoking cessation interventions all these factors should be considered and each medication's outcomes should be evaluated seperatelly.

\section{Tob. Induc. Dis. 2018;16(Suppl 3):A13 \\ DOl: 10.18332/tid/94532}

Developing message content sent via WhatsApp for improving quitting success rate

Seyfi Durmaz¹, S. Calıșkan¹

${ }^{1}$ Ege Üniversitesi, İzmir, Türkiye

\section{Aim}

To present the content development study of support messages to be sent via WhatsApp embedded to smoking cessation healthcare service to increase the individuals' success rate.

\section{Methods}

After the literature review, 178 key messages were gathered supporting smoking cessation. Similar messages related to "preparation" and "action" phases of the Transtheoretical Model were combined and a total of 60 key messages were obtained. Messages have been transformed into graphic images and sending period has also been determined for each message. Graphic messages were sent to field experts and individuals with quitting experience via an online questionnaire. Participants were asked to rate each graphic message in terms of content and appropriateness of sending period on a Likert-type scale 11: Absolutely no - 5: Absolutely yes). Messages with 4.0 and higher average scores were decided appropriate and, others were revised. After the revision, messages were sent back to the both participant groups again and, they were asked to evaluate with the same scale.

\section{Results}

A total of 60 messages were developed (seven for prequitting and, 53 for quitting phase). All ( $n=14)$ participants (seven from expert and seven from quitters group) were responded in the first round and $10(71.4 \%)$ in the second round. The average score of the messages in the first round; $4.4 \pm 1.0$ in the expert group, $4.6 \pm 0.8$ in the quitters group and $4.5 \pm 0.9$ for all participants. The number of messages below the cutoff point were five $(8.3 \%)$ in the expert and two $(3.3 \%)$ in the quitters group. The average score of messages in the second round; $4.9 \pm 0.3$ in the expert group, $4.7 \pm 0.6$ in the quitters group and $4.8 \pm 0.4$ for all participants. In this round, all messages' average scores were found above (> 4.0) the cut-off point.

\section{Conclusions}

Study was conducted with a multidisciplinary participation. Sixty messages were created to support quitters according to stages of Transtheoretical model. A consensus developed on these graphic messages among field experts and individuals with quitting experience in terms of content and sending period.

\section{Tob. Induc. Dis. 2018;16(Suppl 3):A14 \\ DOl: $10.18332 /$ tid/94550}

“Clean Air for Babies" App: A smoking cessation mobile app based on Cognitive Behavioral Therapy combined with personal counseling to help expectant mothers quit smoking.

Ohad Ashur ${ }^{1}$, Nimrod Levine ${ }^{1}$, Benjamin Chayen ${ }^{1}$, Shosh Karni', Liora Valinsky ${ }^{1}$

${ }^{1}$ Mind Innovations, Israel

\section{Introduction}

Approximately $5 \%-10 \%$ of pregnant women smoke worldwide, placing their unborn babies under risk of complicated medical conditions.

To date, common smoking cessation treatments have shown to be less adequate for smoking expectant mothers since the safety of anti-smoking medications during pregnancy has not yet been clearly proven, and current behavioral interventions available today fail to meet the intense emotional needs of this population.

Our company, Mind Innovations, develops and integrates digital health solutions. Our aim is to reduce perinatal smoking by developing a clinical-based solution tailored specifically to the expectant mother that consists of three modules: (1) CBT-based mobile app, (2) 6-week personal counseling program, and (3) Patient Relationship Management (PRM) tool. We expect this will fill the gap where other solutions fall short by better addressing this population's unique needs.

\section{Methods}

Mind Innovations collaborated with Meuhedet Health Provider, Israel to develop, implement, and recruit patients for this program.

We created an 18-hour clinical training course designed to qualify experienced counselors for running a 6-week personal counseling program that prepares the perinatal smoker towards her quit date aided by our PRM.

We developed a CBT-based app that provides motivation, knowledge, and training for preparing patients to succeed in meeting their quit date and preventing relapses

\section{Results}

We used questionnaires to evaluate our counselor training course. Results show satisfaction was very high (Mean=9.81/10;sd=0.48), and knowledge and skills increased from 5.93 to 8.86 lon a scale of $1-10$, paired t-test ; $p<0.001)$. The intervention program's results will be published soon.

\section{Conclusions}

Counselor training has proved successful. Our mobile intervention program is undergoing research.

\section{Funding}

The project was funded by Global Bridges organization for Meuedet Health provider, Israel, and developed by Mind Innovations, a company specializing in developing digital health solutions.

\section{Tob. Induc. Dis. 2018;16(Suppl 3):A15 DOI: 10.18332/tid/94792}

\section{Change in the effect of pharmacotherapy} additional to behavioral counseling using inverse probability treatment weighting in Balçova Heart Study

Erdem Erkoyun', Murat Aysin'1, Özlem Pekel², Gül Ergör ${ }^{1}$ ${ }^{1}$ Department of Public Health, Faculty of Medicine, Dokuz Eylul University, Izmir, Turkey, ${ }^{2}$ Bayraklı Districh Health Center, Izmir, Turkey

\section{Aim and objective}

In 2007 Balcova Heart Study cohort was started to determine cardiovascular disease risk in 35 years and older people in Balcova district, Izmir, Turkey. Among participants who were willing to quit smoking were invited to smoking cessation clinic. This study aims to analyze the effect of inverse probability treatment weighting (IPTW) against no weighting to predict relapse in smoking cessation.

\section{Methods}

Smokers who were screened in Balçova Heart Study for ischemic heart disease risk factors and declared the will to quit smoking were invited to the outpatient smoking
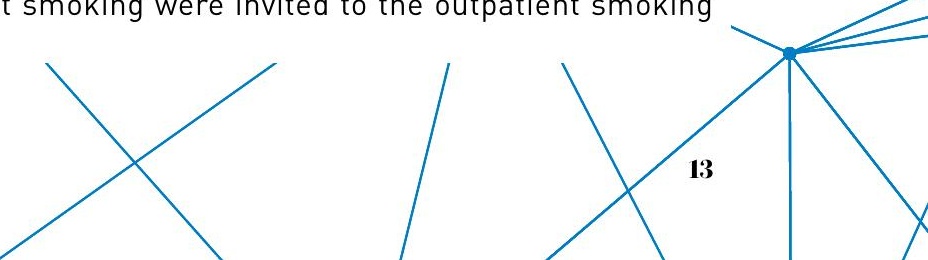
cessation clinic. All patients were given behavioural counseling and a proportion of the smokers received pharmacotherapy (varenicline or bupropion) by clinical decision. After one year all patients were called to estimate the success rate of the intervention $(n=359)$. The results of pharmacotherapy and behavioural counseling versus only behavioural counseling were compared in generalized estimating of effects model with and without IPTW weighting. The fully adjusted model included age and education category, gender, marital and working status, Fagerström Test for Nicotine Dependence category.

\section{Results}

Relapse rate was $51.3 \%(n=184)$. Additional to the behavioural counselling pharmacotherapy lowered relapse rate by $20.0 \%$ [relative risk $=0.80,95 \%$ confidence interval (CI): 0.64-0.99] relative to only behavioural counselling in crude analysis. In the fully adjusted model without IPTW beta regression coefficient of pharmacotherapy was -0.548 [odds ratio (OR) $=0.58,95 \% \mathrm{Cl}: 0.37-0.90, \mathrm{p}=0.016$ ) After IPTW weighting the coefficient was -0.545 (OR=0.58, $95 \% \mathrm{Cl}: 0.37-0.90) \mathrm{p}=0.016$ ).

\section{Conclusions}

Additional to behavioural counseling pharmacotherapy is effective to prevent relapse in smoking cessation follow-up and IPTW weighting reveals only a slight change in beta regression coefficient.

\section{Funding}

Balçova Municipality funded Balçova Heart Study.

Tob. Induc. Dis. 2018;16(Suppl 3):A16

DOl: 10.18332/tid/94877

\section{DEUMF Pulmonary Diseases Department}

\section{Smoking Cessation Clinic data}

Gökcen Ömeroğlu Simșek', Nurcan Güler ${ }^{1}$, Oğuz Kılınc 'Respiratory Diseases Department, Medical School, Dokuz Eylúl University, Izmir, Turkey

\section{Summary}

Nicotine dependence is the most prevalent disease of our society, with smoking rates of $37 \%$. Pharmacotherapy and behavioral therapy play an important role in reducing smoking. In this context, it is suggested that the daily behavioral models should be questioned and the methods of combating them by determining the factors that trigger the desire for smoking.

\section{Methods}

The data of 326 patients who were followed-up between 2016-2018 in the DEUMS Pulmonary Diseases Department Smoking Cessation clinic were screened. Demographic data, Fagerström Nicotine Dependence Test (FBNT), treatments and responses were questioned.

\section{Findings}

It's have been given to $\% 71$ patients varenicline, $\% 11$ bupropion, $\% 4$ nicotine replacement therapy. \%14 patients were followed up without pharmacotherapy. $\% 27$ of the patients have quit the smoking, $\% 22$ not, $\% 8$ have reduction at daily smoking. $\% 43$ of the patients still in the process of treatment. For this reason it was considered as an unknown group. Trigger factors for relaps; $31.4 \%$ stress, $23.3 \%$ post-meal, tea $19.8 \%$ coffee $17.4 \%$ alcohol $8 \%$. According to FBNT, $26.7 \%$ of patients had low, $25.6 \%$ had moderate and $47.7 \%$ had high level of addiction.

\section{Conclusions}

Nicotine dependence is a disease that not too easy to treat. It is observed that the rate of tobacco use in early ages is increasing and the abstinence rate is very low at all ages. The first thing to do is to prevent tobacco using and to optimize the policies, to recommend the release it to every smoking patient and to direct the patients to the relevant centers.

\section{Tob. Induc. Dis. 2018;16(Suppl 3):A17 DOl: 10.18332/tid/94878}

\section{Tobacco use and rates of 4 As delivery for} treating tobacco dependence among Albanian students. A cross-sectional study

Enkeleint A. Mechili ${ }^{1}$, Charis Girvalaki ${ }^{2}$, Ela Peto ${ }^{1}$, Roza Risilia' ${ }^{1}$, Emirjona Kicaj', Filippidis, Filippos ${ }^{3}$, Constantine I. Vardavas ${ }^{4}$

'Department of Healthcare, Faculty of Public Health, University of Vlora, Vlora, Albania, ${ }^{2} \mathrm{Clinic}$ of Social and Family Medicıne, Medical School, University of Crete, Heraklion, Greece, ${ }^{3}$ Department of Primary Care and Public Health, School of Public Health, Imperial College, London, United Kingdom, ${ }^{4}$ Institute of Public Health, American College of Greece, Athens, Greece

\section{Background:}

Tobacco dependence treatment in clinical settings is of prime public health importance, especially in the Albanian population, as more than $23 \%$ ( $41 \%$ male and $5.6 \%$ female) are daily smokers. This study sought to examine the characteristics of tobacco users among university students and document rates of tobacco treatment delivery in Vlora, Albania.

\section{Design/Methods:}

A cross-sectional study was conducted (May-July 2017) among students of University of Vlora, Albania. Students who agreed to participate in the study, completed a selfreported questionnaire, part of which was based on the Global Adult Tobacco Survey (GATS). Students from all Faculties and all semesters were randomly selected before each course. Statistical analyses were conducted with SAS 9.1.

\section{Results:}

In total 1360 students participated (73\% female) with $18 \%$ $(n=234)$ of them being daily smokers. The majority of the smoker participants $(81.0 \%)$ reported living with their family or a roommate, $45.5 \%$ of which are also smokers. Most of the smokers $(62.7 \%)$ were willing to quit smoking within the next 6 months while the $62.0 \%$ had made at least one attempt to quit smoking during the last 12 months. Doctor's advice appears to be an important motivation to quit for the majority of smokers (73.0\%), yet of those visited a doctor $(39.0 \%)$ within the same year, $70.9 \%$ were Asked about their smoking behaviour, 53.3\% were Advised to quit, 33.8\% were offered Assistance with quitting, 21.1\% were offered help to set a quit date and $22.4 \%$ Arranged a follow-up meeting with the doctor.

\section{Conclusions:}

Our study showed that although the advice of a doctor is a strong influence for young adults in quitting smoking, not all of them are asked about their smoking status or advised to quit as it is strongly recommended by all international guidelines for treating tobacco dependence. New interventions targeted on evaluating the effectiveness of well-designed training programmes in influencing tobacco treatment outcomes in healthcare settings in Albania are necessary.

\section{Tob. Induc. Dis. 2018;16(Suppl 3):A18 \\ DOl: $10.18332 /$ tid/95113}

Effectiveness of Tobacco Cessation Training Program for primary health care physicians of a South Indian district
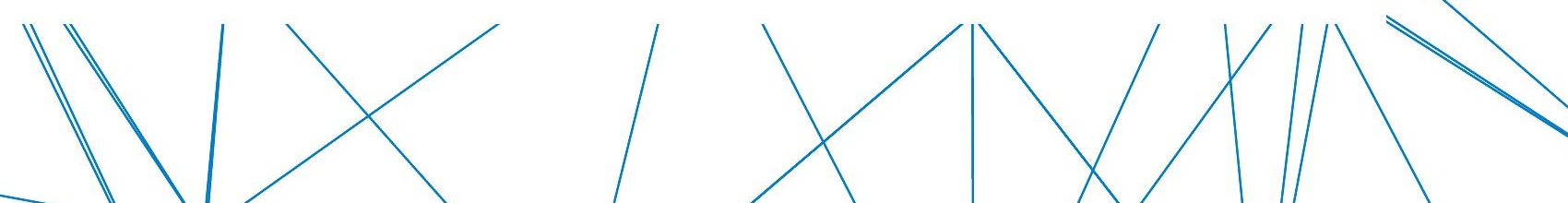
Jagannath Purushothama', Sanjeev Badiger², Priyanka Rent $^{1}$, Mackwin D'Mello ${ }^{1}$

'Department of Public Health, K. S. Hegde Medical Academy, Mangaluru, India, ${ }^{2}$ Department of Community Medicine, K. S. Hegde Medical Academy, Mangaluru, India

\section{Introduction}

Tobacco Cessation is one of the least attended components of Tobacco Control strategies worldwide. Although there is a felt need by tobacco users to quit the use and Tobacco Cessation Services can be provided in low-resource healthcare settings, lack of adequate training in tobacco cessation among health care physicians acts as a major deterrent to provide the services.

\section{Objective}

To determine the effectiveness of training medical officers in providing tobacco cessation services.

\section{Methods}

Study design: Cross Sectional Study.

Study method: Self-scored questionnaire, selfadministered pre and post one-day training on tobacco cessation.

Study area: Dakshina Kannada, Karnataka, India. Sample size: Universal sample of 55 Medical Officers. Study period: 1 month.

\section{Results}

None of the Medical Officers were earlier trained in tobacco cessation services. Among the 55 medical officers, 23 were females. Mean number of years of experience of respondents was $8.2 \pm 6.99$ years. Mean pre-test score for overall ability to provide tobacco cessation services was $46.31 \pm 9.41$ and post-test score was $54.40 \pm 8.67$ which showed a statistically significant difference $(t=-7.58$ $p<0.05)$. The overall mean of pre and post test scores for ability to counsel the respondents using 5A's were $19.73 \pm 3.47$ and $21.87 \pm 3.37$ respectively which showed a statistically significant difference $(t=-5.29 ; p<0.0005)$. A moderate positive correlation was observed between the overall pre and post test scores $(r=0.62 ; p<0.01)$.

\section{Conclusions}

The study revealed that there was a significant improvement in the perceived ability to provide tobacco cessation services after the conduct of the Workshop.

\section{Funding}

District Tobacco Control Cell, Dakshina Kannada, Karnataka, India.

\section{Tob. Induc. Dis. 2018;16(Suppl 3):A19 \\ DOI: 10.18332/tid/94767}

\section{TOВАССО HEALTH EFFECTS 1}

\section{Evaluation of sleep apnea and smoking in drivers}

Safiye Ozvurmaz ${ }^{1}$, Aliye Mandıracıoğlu²

${ }^{1}$ Halk Sağlığı Hemșireliği Anabilim Dalı, Hemșirelik Fakültesi, Adnan Menderes Üniversitesi, Aydin, Türkiye, ${ }^{2}$ Halk Sağlığ Anabilim Dali, Tıp Fakültesi, Ege Üniversitesi, İzmir, Türkiye

\section{Aim and objective}

Smoking is a potential risk factor for sleep apnea, which increases the risk of health problems and accidents in drivers. The aim of this study was to determine relationship between smoking and sleep apnea.

\section{Methods}

This cross-sectional study was performed on 196 minibus drivers in the city of Aydın. Data were collected with a questionnaire. STOP-Bang questionnaire, adapted to Turkish by Acar et al., was utilized to evaluate sleep apnea.
The questionnaire is composed of eight questions. The responders are asked to mark either yes or no. The scores 5-8, 3-4 and 0-2 for yes are considerate high, moderate and low respectively.

\section{Results}

All the drivers were male, and their mean age was $41,00 \pm 9,49$ years. Seventy-four percent of the drivers were smokers and $40.3 \%$ of the drivers were taking alcohol. The mean duration of smoking was $19.46 \pm 8.41$ years. Fortypoint three percent of the drivers were working in shifts, the mean duration of working per day was $7,02 \pm 1,47$ hours. Twenty-six-point seven percent of the drivers had a health problem. Based on the analysis of data collected with STOP-bang questionnaire, $9.8 \%$ of the drivers had a high score for sleep apnea, $46.1 \%$ of the drivers had a moderate score for sleep apnea and $44.1 \%$ of the drivers had a low score for sleep apnea. The sleep apnea score was higher in the drivers aged over 50 years, the smoking drivers and the drivers with a health problem.

\section{Conclusions}

Smoking was found to be common in the drivers and to be related to high sleep apnea scores. It can be recommended that drivers should be provided counseling to help them quit smoking and that sleep apnea should be treated. They should also be informed about the risk of accidents due to sleep apnea.

\section{Tob. Induc. Dis. 2018;16(Suppl 3):A20}

\section{DOl: $10.18332 /$ tid/94563}

Smoking is associated with walking, fatigue, depression, and health-related quality of life in persons with multiple sclerosis

Asiye Ozdogar ${ }^{1}$, Turhan Kahraman², Serkan Ozakbas ${ }^{3}$ 'School of Physical Therapy and Rehabilitation, Dokuz Eylül University, Izmir, Turkey, ${ }^{2}$ Department of Physiotherapy and Rehabilitation, Faculty of Health Sciences, Izmir Katip Celebi University, Izmir, Turkey, ${ }^{3}$ Department of Neurology, Faculty of Medicine, Dokuz Eylül University, Izmir, Turkey

\section{Aim and objective}

Recent studies have reported that smoking is associated with increased multiple sclerosis (MS) risk. Additionally, non-smokers have lower self-reported disability and smoking cessation resulted in the decreased risk of reaching disability milestones. Although some studies have reported that smoking is associated with anxiety and depression, little is known about other common symptoms in persons with MS (pwMS). Thus, the aim was to investigate the association between smoking and walking, fatigue, depression, and health-related quality of life in pwMS.

\section{Methods}

This study included 279 (199 female) pwMS. The current smoking status and pack-years of smoking were evaluated. Walking was assessed using Timed 25-Foot Walk (T25FW), Six-Minute Walk Test (6MWT), and 12-Item MS Walking Scale (MSWS-12). Fatigue, depression and health-related quality of life were assessed using Modified Fatigue Impact Scale (MFIS), Beck Depression Inventory (BDI), and MS International Quality of Life questionnaire (MusiQoL), respectively. Disability level was assessed using Expanded Disability Status Scale (EDSS).

\section{Results}

There were $95(34.1 \%)$ current smokers (mean pack-years of smoking was 9.2 (SD 7.1) years). Current smokers had significantly worse MFIS ( $\left.p=0.003, p \eta^{2}=0.031\right), B D I(p=0.044$, $\left.p \eta^{2}=0.015\right)$, and MusiQoL ( $\left.p=0.003, p \eta^{2}=0.031\right)$ scores adjusting for age, gender, EDSS and disease duration
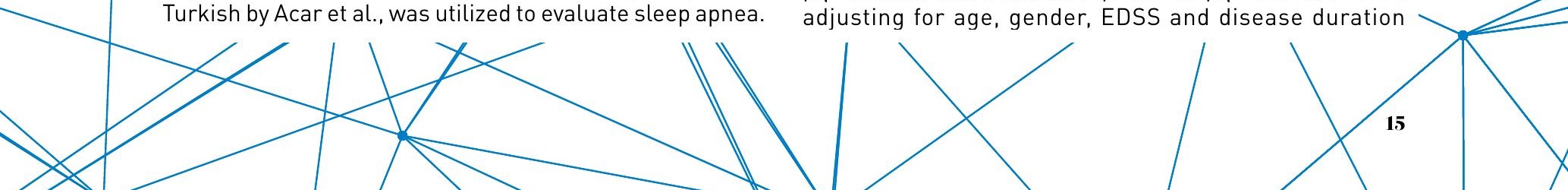
compared to non-smokers. No significant difference was observed between smokers and non-smokers in walking and physical activity measures ( $p>0.05)$. Pack-years of smoking was significantly correlated with T25FW $(r=0.574$, $p<0.001)$, 6MWT $(r=-0.461, p<0.001)$, MSWS-12 ( $r=0.684$ $p<0.001)$, MFIS $(r=0.370, p<0.001)$, MusiQoL $(r=-0.259$, $p=0.012)$, and $B D I(r=0.269, p<0.001)$ in smokers.

\section{Conclusions}

Smokers have significantly more fatigue and depression levels and less health-related quality of life compared to non-smoker pwMS. Increased pack-years of smoking is associated worse walking ability, depression, fatigue and health-related quality of life levels. Smoking cessation may reduce walking impairment as well as fatigue and depression, additionally increase health-related quality of life in pwMS.

\section{Tob. Induc. Dis. 2018;16(Suppl 3):A21 \\ DOI: 10.18332/tid/94759}

\section{Assessment of carotid calcifications on} panoramic radiographs and its relationship with periodontal condition and smoking status

Mehtap Bilgin Cetin ${ }^{1}$, Yasemin Sezgin ${ }^{1}$, Mediha Nur Nisanci

Yilmaz1, Cansu Koseoglu Secgin²

'Department of Periodontology, Faculty of Dentistry, Baskent University, Ankara, Turkey, ${ }^{2}$ Department of Dentomaxillofacial Radiology, Faculty of Dentistry, Baskent University, Ankara, Turkey

\section{Objectives}

The aim of this study is to determine retrospectively the presence of carotid artery calcifications (CACs) detected on panoramic radiographs and to correlate the finding of such calcifications with gender, smoking status, medical history and periodontal status were evaluated.

\section{Methods}

Periodontal conditions of 1100 patients were assessed. According to periodontal clinical measurements, the patient was diagnosed with gingivitis or periodontitis. Each of the subjects had one digital panoramic radiograph. CAC findings were defined as radiopaque masses adjacent to the cervical vertebrae at or below the intervertebral space between $\mathrm{C} 3$ and $\mathrm{C} 4$ on the panoramic radiograph. Panoramic radiographs were evaluated for CAC presence.

\section{Results}

Of 1100 patients, 34 patients $(3.1 \% ; 21$ female, 13 male) had one or more radiopaque mass detected on digital images. There was no statistically significant difference in smoking status, gender, sistemic health status between CAC (+) and CAC (-) gruops. As a result of multivariate logistic regression analysis, age was found to be an independent risk factor for differentiating $\mathrm{CAC}++)$ and CAC (-) groups. There were 16 and 17 patients with smoking history in $\mathrm{CACl}+$ ) and $\mathrm{CACl}-\mathrm{l}$ groups, respectively. The distributions of the patients in terms of smoking history were statistically similar. Compared to patient under 40 years of age, the risk of CACs increases 4.49 fold in patients aged $40-55$ years and 4.40 fold in patients over 55 years.

\section{Conclusions}

Digital panoramic images may have some diagnostic value for detecting CACs and this early diagnosis could potentially increase the length and quality of life for people with CACs. It was demostrated that the detection of CACs are increased with age.

Tob. Induc. Dis. 2018;16(Suppl 3):A22

DOl: 10.18332/tid/94765
The relationship between smoking history, functional exercise capacity and airway obstruction severity in patients with chronic obstructive pulmonary disease

İsmail Özsoy', Buse Kahraman², Aylin Tanrıverdi², Aylin Alpaydın ${ }^{3}$, Can Sevinç ${ }^{3}$, Sema Savcı ${ }^{2}$

'School of Physical Therapy and Rehabilitation, Ahi Evran University, Kırsehir, Turkey, ${ }^{2} \mathrm{~S} c h o o l$ of Physical Therapy and Rehabilitation, Dokuz Eylul University, Izmir, Turkey, ${ }^{3}$ Department of Chest Disease, School of Medicine, Dokuz Eylul University, Izmir, Turkey

\section{Aim and objective}

The aim of the study was to investigate the relationship between smoking history, functional exercise capacity and airway obstruction severity in patients with chronic obstructive pulmonary disease (COPD).

\section{Methods}

Thirty patients with stable COPD participated in this study. Demographic value and smoking history (pack-years) were recorded. Pulmonary function tests were performed. Functional exercise capacity was evaluated with six minute walking test (6MWT). The Pearson correlation coefficient was calculated to examine the correlation between the variables.

\section{Results}

The mean of age (years), smoking history (pack-years), forced expiratory volume in 1 second (FEV1\%), 6MWT distance $(\mathrm{m})$ were $74.60,47.30,55.03,382.70$ respectively. The smoking history had significant negative correlation with FEV1 \% ( $r=-0.374, p=0.042)$ and 6MWT distance ( $r=-$ $0.426, p=0.019$ ).

\section{Conclusions}

The study showed that smoking history had significant negative correlation with functional exercise capacity and airway obstruction severity in patients with COPD. By reducing cigarette consumption, functional exercise capacity can be increased and the severity of airway obstruction can be decreased.

\section{Tob. Induc. Dis. 2018;16(Suppl 3):A23 DOl: $10.18332 /$ tid/94786}

Frequency of smoking in subgroups of ischemic stroke and relation between smoking and various complications of ischemic stroke Murat Atmaca ${ }^{1}$, Esme Ekizoglu-Turgut ${ }^{2}$

${ }^{1}$ Clinic of Neurology, Sultan Abdulhamid Han Training and Research Hospital, Istanbul, Turkey, ${ }^{2}$ Department of Neurology, Istanbul Faculty of Medicine, Istanbul University, Istanbul, Turkey Aim

To find out the frequency of smoking in subgroups of ischemic stroke and to search for relation between smoking and asymptomatic ischemic lesions (AILs) in cranial magnetic resonance imaging (MRI), recurrence of ischemic stroke, hemorrhagic transformation, seizure, pneumonia, pulmonary embolism, myocardial infarction and deep vein thrombosis.

\section{Methods}

The stroke database of the Neurology Clinic in Istanbul Faculty of Medicine were retrospectively screened and patients with ischemic stroke admitted between 19952014 were included in this study.

\section{Results}

There were 3615 patients. The lowest frequency of smoking was found in patients with cardioembolism 1348/1160, $30 \%)(p<0,001)$. But we found significantly more patients with AILs $(p=0,022)$ and higher rate of pneumonia $(p=0,016)$ in smokers compared with non-smokers in patients with
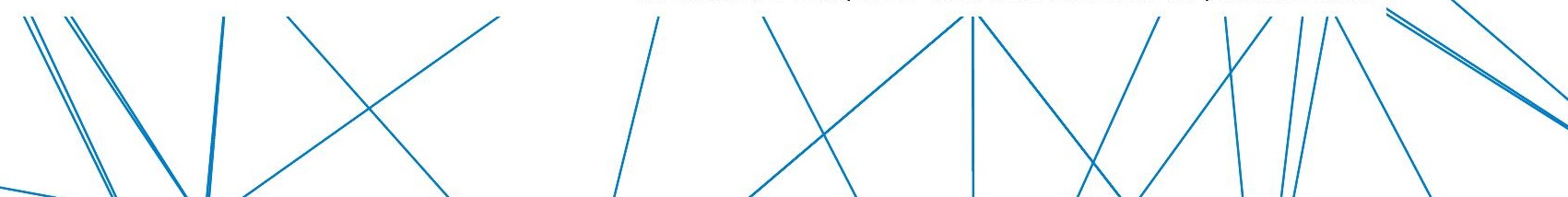
cardioembolism. We looked for relation between AILs and other potential risk factors such as hypertension, alcohol consumption, diabetes mellitus and hyperlipidemia. Only hypertension was found to be related with AILs $(p<0,001)$. Logistic regression analysis showed that both smoking ( $p=0,013,0 R: 0,61 \% 95 \mathrm{Cl}:[0,41-0,9])$ and hypertension ( $p=0,01$ OR: $0,39 \% 95 \mathrm{Cl}[0,23-0,66])$ were independent risk factors for AlLs. We also looked for relation between pneumonia and other potential risk factors such as hypertension, alcohol consumption, diabetes mellitus and higher modified Rankin Scale (mRS) score at admission. Only higher mRS score at admission was found to be related with pneumonia $(4,54$ vs. $4,37, p=0,027)$. Logistic regression analysis showed that both smoking $(p=0,012$ OR: 0,52\%95 Cl [0,32-087], and higher mRS score at admission ( $p=0,0170 R: 0,73 \% 95 \mathrm{Cl}[0,56-0,94]$ ) were independent risk factors for pneumonia.

\section{Conclusions}

The lowest frequency of smoking is found in patients with cardioembolic stroke but smoking in those patients is an independent risk factor for development of AILs and pneumonia.

\section{Tob. Induc. Dis. 2018;16(Suppl 3):A24 DOI: 10.18332/tid/94861}

The increased cardiovascular mortality among hypertensive smokers

Wayne Gao', Chi Pang Wen²

${ }^{1}$ Taipei Medical University, Taipei, Taiwan, ${ }^{2}$ National Research Institute, Taipei, Taiwan

\section{Introduction}

Nearly half of all smokers are hypertensive based on new guidelines issued in 2017. The objective of this study is to assess the excess risk and shortened life expectancy of smokers with 1) elevated blood pressure $(120-129 /<80)$, 2) stage 1 hypertension (130-139/80-89), and 3) stage 2 hypertension $(\geqslant 140 / \geqslant 90)$ compared to non-smokers with normal blood pressure $<120 / 80 \mathrm{mmHg}$.

\section{Methods}

A cohort, consisting of 422,771 adults, was recruited successively during routine health surveillance visits between 1996 and 2008 in Taiwan. Lifestyle information indicated on a questionnaire and results from fasting blood and other screening tests, including blood pressure measured while sitting, were repeatedly collected. Hazard ratios (HRs) were determined by the Cox regression method, and life expectancy was determined using the life table method.

\section{Results}

One-quarter of the cohort participants were current smokers. Nearly half of the smokers $(48 \%)$ were classified as hypertensive, with $14 \%$ having elevated blood pressure, $19 \%$ stage 1 and $16 \%$ stage 2 hypertension. The HR for cardiovascular disease (CVD) mortality was 1.41 for smokers with normal blood pressure, 1.45 for smokers with elevated blood pressure, 2.11 for smokers with stage 1 hypertension, and 4.92 for smokers with stage 2 hypertension, representing an average threefold increase compared to non-smokers with normal blood pressure. The HR for heart disease mortality was 1.43 for smokers with elevated blood pressure, 1.85 for smokers with stage 1 hypertension, and 3.56 for smokers with stage 2 hypertension. The HR for stroke mortality was 1.54 for smokers with elevated blood pressure, 2.98 for smokers with stage 1 hypertension, and 8.82 for smokers with stage 2 hypertension, representing a five-fold increase.
Smoking shortened the life span by six years, and stage 2 hypertension shortened it by four years, representing a combined loss of life of 10 years. Elevated blood pressure alone did not increase mortality, when compared with normotensive (non)smokers (normal subjects).

\section{Conclusions}

Smokers with hypertension have a three- to five-fold increase in CVD mortality, including mortality due to heart diseases and stroke. Life span shortened by five to six years for smokers and by 10 years for hypertensive smokers. Unfortunately, most smokers were unaware of their hypertension status, which could triple or quintuple their CVD mortality risks.

\section{Tob. Induc. Dis. 2018;16(Suppl 3):A25}

DOl: 10.18332/tid/94793

\section{FRIDAY 5 OCTOBER}

\section{Tobacco-induced suppression of the vascular response to dental plaque \\ David Scott ${ }^{1}$ \\ 'Department of Oral Immunology and Infectious Diseases, School of Dentistry, University of Louisville, Louisville, KY, USA}

\section{Aim and objective}

Cigarette smoking presents oral health professionals with a clinical conundrum: reduced vascular responsiveness in response to the oral biofilm loften incongruously equated to decreased gingival inflammation per sel, accompanied by increased susceptibility to destructive periodontal diseases. The aim of this review was to summarize contemporary hypotheses that help explain the suppressed bleeding response in the oral cavity of smokers.

\section{Methods}

The core of this review was informed by a PubMed search for "(smok* OR cigar* OR nicotine OR tobacco) AND (periodont* OR gingiv*) AND (blood OR vascul*)" generating $n=958$ hits on March 17, 2018 .

\section{Results and conclusions}

Smoke exposure influences angiogenesis, innate cell function, the production of inflammatory mediators including cytokines and proteases and tobacco-bacterial interactions, while concomitant smoking and specific genetic traits predispose to destructive periodontal diseases.

\section{Funding}

The tobacco-related research in D.A. Scott's lab is currently funded by the U.S. Department of Health and Human Services via the National Institute for Dental and Craniofacial Research (R01DE026963 [DAS]; R01DE017680 [DAS]; and R01DE026963 [P.I., H. Wang]); and via the National Institute for General Medical Sciences (P20GM125504 [P.I., R.J. Lamont]).

\section{Tob. Induc. Dis. 2018;16(Suppl 3):A26 DOl: 10.18332/tid/94524}

\section{Toward full involvement of oral healthcare providers in tobacco dependence treatment in Japan \\ Takashi Hanioka}

'Department of Preventive and Public Health Dentistry, Fukuoka Dental College, Fukuoka, Japan

Several numbers regarding nationally representative activity of oral healthcare professionals (OHP) indicate importance of the involvement of OHP in tobacco dependence treatment. OHP are ideally placed to promote
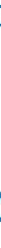
quitting. Global tobacco control should involve OHP to increase capacity for tobacco control. Then, 2011 United Nation political declaration for NCDs included oral diseases in article 19 as: Renal, oral and eye diseases pose a major health burden for many countries and that these diseases share common risk factors and can benefit from common responses to non-communicable diseases. Again, OHP are in the unique position in helping tobacco users to quit in tobacco control and for prevention and control of NCDs.

However, this opportunity has been not fully achieved even in developed countries, and in Japan, the developing country with respect to tobacco control, where no national data is currently available regarding smoking and dental care. I believe that dentistry in the US, UK, and Japan and Turkey share various information toward full involvement of OHP in tobacco dependence treatment. I will present evidence for the dental involvement in national and global tobacco control, results from trials for training of the WHO recommendation of integrating brief tobacco intervention into dental program, and dissemination of the WHO recommendation in Japan in addition to heat-not-burn tobacco epidemic in Japan.

\section{Funding}

This study was supported by Pfizer Global Medical Grant \#35621681

Tob. Induc. Dis. 2018;16(Suppl 3):A27

\section{DOl: 10.18332/tid/94913}

A model of pancreatitis and pancreatic oncogenesis following exposure to Nicotine

Parimal Chowdhury ${ }^{1}$

${ }^{1}$ Department of Physiology and Biophysics, College of Medicine, University of Arkansas for Medical Sciences, Little Rock, Arkansas (AR), United States of America

Cigarette Smoking is a known risk factor for pancreatic cancer. In smokers, increased exposure causes a marked increase in the incidence of these diseases. The mechanism of this effect is yet to be fully understood. We hypothesize that nicotine, a major component of cigarette smoking will have the greatest impact of developing these diseases in smokers. Currently an established animal model is lacking to conduct detailed studies of the etiology of these diseases in smokers. Aim and objective: The aim of our study is to establish a rodent model of pancreatic cancer and to determine the relationships between the development of pancreatitis and pancreatic cancer in response to nicotine exposure. Methods: Adult Male Rats were randomly allocated into treatment groups and acclimatized for at least two weeks with monitored body weight, food and water freely available. Rats were exposed to nicotine in the aerosol chamber designed to deliver aerosol vapor for fixed intervals. At term, rats were fasted anesthetized and sacrificed. Blood and pancreatic tissues were collected and processed for physiologic studies and for histopathological evaluation. A segment of the pancreas was used for isolation of acinar cells for determination of pancreatic function and for determination of expression and mutation of oncogenes. Alterations of cellular, subcellular and/or genetic mechanisms were studied in isolated pancreatic primary cells applying classical signal transduction pathways. Results showed that nicotine inhaled rats have decreased exocrine pancreatic function and altered pancreatic morphology. These changes are associated and correlated with isolated cell culture data. Conclusions/implications: Data from these studies appear closely related to that reported in patients with pancreatitis.
Making rodent as a plausible animal model of pancreatitis and pancreatic cancer will allow us to examine and assess the evolution of this disease process in smokers.

\section{Funding}

UAMS Research Foundation 117-1002531: AWD00050842;

Tob. Induc. Dis. 2018;16(Suppl 3):A28

DOl: 10.18332/tid/94526

\section{ORAL IEALTH AND TOBACCO 1}

Tobacco use, nicotine, and oral microorganisms Takashi Hanioka1, Miki Ojima², Hiroshi Ogawa ${ }^{3,4}$

${ }^{1}$ Department of Preventive and Public Health Dentistry, Fukuoka Dental College, Fukuoka, Japan, '2Department of Oral Health Sciences, Faculty of Nursing and Health Care, BAIKA Women's University, Osaka, Japan, ${ }^{3}$ Division of Preventive Dentistry, Department of Oral Health Science, Graduate School of Medical and Dental Sciences, Niigata University, Niigata City, Japan, ${ }^{4} \mathrm{WHO}$ Collaborating Center for Translation of Oral Health Science, Niigata University, Niigata City, Japan

Evidence to infer the causal association between tobacco use and health consequences have been investigated recently for oral diseases. The aim of present review is to clarify underlying mechanisms regarding effects of tobacco use on oral microorganisms comprehensively.

Electronic searches of relevant articles were conducted with a standardized search strategy in the last 10 years. Overall, 1099 papers were extracted. The studies that addressed the relationship between tobacco and oral microorganisms were included. After reading the titles and abstracts, 121 papers were deemed appropriate for the present review.

These studies addressed periodontal pathogens, and other microorganisms included HPV, Candida species, Streptococcus mutans, and peri-implant microorganisms. Dysbiosis of periodontal microbiome in smokers has been demonstrated by observational and intervention studies. Smoking cessation is shown to be beneficial in terms of compositional changes of subgingival and periimplant microbiomes. Studies utilizing cigarette smoke extract and indicators of virulence have suggested a benefit regarding the functional changes of subgingival microbiomes for quitters. The effects of nicotine exposure on growth and metabolism of S. mutans were observed in a dose dependent manner. The potential role of tobacco use on HPV infection requires clarification with large sample studies. Potential effects of exposure to tobacco smoking were reported on accumulation of pathogenic bacteria on oral apparatus for orthodontic treatment, denture, and titanium for oral implant.

In conclusion, further studies are warranted to examine impact of tobacco intervention for healthier mouth ecosystem on the full achievement of the interventions in dental settings.

\section{Funding}

This study was supported by Pfizer Global Medical Grant \#35621681.

\section{Tob. Induc. Dis. 2018;16(Suppl 3):A29} DOl: 10.18332/tid/94880

Effects of smoking on non-surgical periodontal therapy in generalized aggressive periodontitis Burcu Kanmaz ${ }^{1}$, David Lappin², Nurcan Buduneli ${ }^{3}$

'Department of Periodontology, Faculty of Dentistry, Izmir Democracy University, Izmir, Turkey, ${ }^{2}$ Infection and Immunity Group, Faculty of Medicine, College of Medical Veterinary and Life 
Sciences, University of Glasgow, United Kingdom, 32Department of Periodontology, Faculty of Dentistry, Ege University, Izmir, Turkey Aim

To evaluate possible effects of smoking on the clinical, biochemical and microbiological outcomes of non-surgical periodontal treatment in GAgP patients.

\section{Methods}

At baseline, whole mouth clinical periodontal measurements consisting probing depth, clinical attachment level, bleeding on probing and plaque index were recorded and these measurements were repeated 1,3 and 6 months after completion of non-surgical periodontal treatment. Saliva, gingival crevicular fluid (GCF) and blood samples were obtained at the same time points. Interleukin- (IL)-17A, IL17E, IL-1B, IL-6 and tumor necrosis factor-alpha levels were determined in all samples. Moreover, subgingival plaque samples were obtained and presence, as well as quantities of 11 different bacterial species, were determined.

\section{Results}

Fourteen smoker and 13 non-smoker GAgP patients were included in the present study. There were no significant differences in clinical parameters between the study groups except the higher plaque scores in the non-smoker group at 6 -month control $(p<0.05)$. Some differences in the biochemical parameters were found between the study groups ( $p<0.05)$. The microbiological analyses indicated more Gram-negative bacteria in the smoker group than the non-smoker group ( $p<0.05$ ). Moreover, Gram-positive bacteria were more frequent in the non-smoker group than the smoker group at baseline $(p<0.05)$. Gram-negative bacteria repopulated in the smoker group much faster than the non-smoker group ( $p<0.05)$.

\section{Conclusion}

Although clinical periodontal parameters revealed no significant differences between the smoker and nonsmoker GAgP patients after the non-surgical periodontal treatment, it can be suggested that smoking has negative effects on the biochemical and microbiological outcomes.

\section{Funding}

This study was supported by a grant from the Ege University Research Foundation (Project No: 2014 DIS 013) and funds from the University of Glasgow.

\section{Tob. Induc. Dis. 2018;16(Suppl 3):A30 DOl: 10.18332/tid/94529}

Dimensional changes of recipient site following free gingival graft around dental implants in smokers and non-smokers: A prospective controlled clinical study

Ceren Altuğ ${ }^{1}$, Oya Çakal ${ }^{1}$

'Department of Periodontology, Faculty of Dentistry, Ege University, İzmir, Turkey

\section{Aim}

The aim of the present study is to investigate the effect of smoking on healing of free gingival graft around dental implants.

\section{Methods}

Twelve non-smoker and eight smoker patients presenting inadequate keratinized mucosa around dental implants in posterior area were included in the present study. Clinical parameters including probing depth, modified sulcus bleeding index and modified plaque index were determined. Individuals stents were prepared for all patients. All patients received FGG of same dimensions (5.0 $\mathrm{mm} \times 10.0 \mathrm{~mm}$ ). Vertical dimension of keratinized mucosa (KM) was measured using individual stent. All measurements were performed at baseline, 30 and 90 and 180 days. Parametric and non-parametric statistical analyses were performed.

\section{Results}

There were no significant differences in demographics between smokers and non-smokers ( $p>0,05)$. Vertical dimension of keratinized mucosa was significantly increased in both study groups at sixth month compared to baseline $(p<0,05)$. There was no significant difference between smokers and non-smokers in vertical dimension of keratinized mucosa changes $(p>0,05)$. The total area of FGG significantly decreased at first, third and sixth months compared to baseline in both study groups $(p<0,05)$. The shrinkage of FGG significantly higher in smokers than nonsmokers at sixth months $(p<0,05)$.

\section{Conclusion}

Within the limitation of the present study, dimensional changes of recipient site following free gingival graft around dental implants seems to be affected from smoking.

\section{Funding}

Scientific Research Commission of Ege University.

\section{Tob. Induc. Dis. 2018;16(Suppl 3):A31 DOI: 10.18332/tid/94533}

\section{The effect of synbiotic tablet usage on the} clinical and biochemical parameters in smokers and nonsmokers with gingivitis: a randomized placebo-controlled clinical trial

Nuray Ercan', Ebru Olgun', Ücler Kisa², Mehmet Yalim³ ${ }^{1}$ Periodontology Department, Faculty of Dentistry, Kirikkale University, Kirikkale, Turkey, ${ }^{2}$ Biochemistry Department, Faculty of Medicine, Kirikkale University, Kirikkale, Turkey, ${ }^{3}$ Periodontology Department, Faculty of Dentistry, Gazi University, Ankara, Turkey

\section{Introduction}

The aim of this study is to evaluate the efficacy of oral administration of synbiotic tablets on the clinical parameters and the levels of selected inflammatory mediators in gingival crevicular fluid (GCF) in smokers and non-smokers with gingivitis.

\section{Methods}

Eighty patients with gingivitis (40 smoker (+), 40 nonsmoker (-)), randomly assigned to test (T) or control (C) groups. Each subject was instructed to chew one tablet per day, during 30 days. Clinical parameters including plaque and gingival indices and GCF samples obtained from all subjects on baseline, 1st month, and 2nd month. The GCF levels of interleukin (IL)-6, IL-8 and IL-10 were determined.

\section{Results}

All clinical and biochemical parameters for all groups were significantly reduced compared to baseline $(p<0.05)$. GCF volume didn't show a significant intergroup difference at any time whereas Plaque Index (PI) was significantly higher in both smoker groups compared with the T(-) group in the 2 nd month follow-up ( $p<0.05)$. GCF levels of IL-8 in $\mathrm{Cl}-$ ) group, IL-6 in both control groups were significantly higher compared to $\mathrm{T}(+)$ group and IL-10 in both control groups were significantly higher compared to $\mathrm{T}(-)$ group at the 2 nd month follow up $(p<0.05)$.

\section{Conclusions}

Adjunctive synbiotic tablets enhance subclinic therapeutic outcomes regardless of smoking compared with placebo according to the levels of IL-6, IL-8 and IL10 variables.

\section{Tob. Induc. Dis. 2018;16(Suppl 3):A32}

DOl: 10.18332/tid/94756
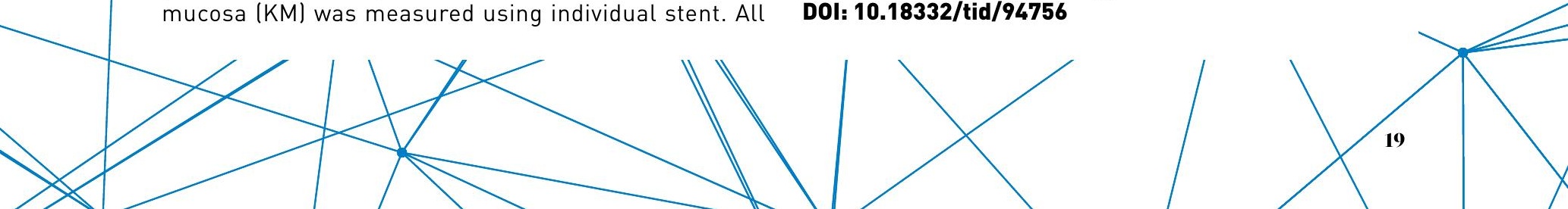
Impact of smoking on marginal bone loss in implant supported removable prosthesis

Emre Mumcu', Arzu Beklen²

'Department of Prosthodontics, Eskisehir Osmangazi University, Eskisehir, Turkey, ${ }^{2}$ Department of Periodontology, Eskisehir Osmangazi University, Eskisehir, Turkey

\section{Aim and objective}

For permanently replacing missing teeth, dental implant placement is a common treatment procedure in dentistry. The success rates of implants depend on the presence of healthy surrounding tissue and finally amount of marginal bone levels. In this study we aimed to compare marginal bone loss around implants in implant supported removable prosthesis in smokers and non smokers.

\section{Methods}

Records of 64 non-smoker, and 19 smoker pateients were collected from 166 implants in routine recall sessions 6,12 , and 24 months after loading. The collected data consisted of gender, age, implant diameter, implant length and periodontal parameters (plaque index, gingival index and pocket probing depth). Marginal bone measurements was analized using digitized periapical dental images. Statistical analysis was performed using the SPSS 22.0 version. The results were assessed at $95 \%$ confidence interval, at a significance level of 0.05 .

\section{Results}

Marginal bone loss was affected by the smoking and severity of loss was increased signficantly from 6 to 24 months ( $p<0.05)$ in smokers. Age was also significantly related to marginal bone loss, while, there was no significant relationship between marginal bone loss and gender or implant length or diameter ( $p>0.05)$. Plaque index and probing depth was higher in smokers, while gingival index was higher in non-smokers.

\section{Conclusions}

Implants used for removable prosthesis in the elderly smokers may be at higher risk to present marginal bone loss leading to loss of implants.

\section{Tob. Induc. Dis. 2018;16(Suppl 3):A33}

\section{Dol: 10.18332/tid/94781}

\section{Effect of smoking on salivary free amino acid levels}

Duygu Taș ${ }^{1}$, Canan Önder ${ }^{1}$, Șivge Kurgan¹, Cavid Mammadov ${ }^{1}$, Muhittin Serdar ${ }^{2}$

'Department of Periodontology, Faculty of Dentistry, Ankara University, Ankara, Turkey, ${ }^{2}$ Department of Medical Biochemistry, School of Medicine, Acıbadem University, Ankara, Turkey

\section{Objective}

The aim of this study was to identify probable intermediate biomarkers of disturbed pathways and their link between smoking.

\section{Methods}

Un-stimulated whole saliva and serum samples were collected from a total of 30 systemically healthy participants with periodontally healthy smokers (S) $(n=15)$ and nonsmokers $(n=15)$. Periodontal indices (plaque index, gingival index, probing depth, bleeding on probing, clinical attachment level) were recorded to confirm periodontal health. Saliva was purified, and a total of 28 amino acids and metabolites were analyzed by liquid chromatographymass spectrometry (LC-MS/MS). Smoking status was validated measuring serum cotinine levels. Intergroup comparisons were assessed using the Mann Whitney $U$ test.

\section{Results}

When 28 amino acids were evaluated, smokers had statistically significantly higher cystathionine levels than non-smokers ( $p<0.05$ ).

\section{Conclusions}

Saliva cystathionine is associated with smoking in periodontally healthy individuals, and is possibly related to altered sulfuration pathway.

Tob. Induc. Dis. 2018;16(Suppl 3):A34

DOI: 10.18332/tid/94833

\section{WATERPIPE AND NOVEL PRODUCTS}

\section{Direct effects of waterpipe tobacco smoking on cardiovascular health \\ Kawkab Shishani ${ }^{1}$ \\ ${ }^{1}$ College of Nursing, Washington State University, Pullman, United States}

\section{Introduction}

Waterpipe smoking is characterized by long sessions of smoking, deep inhalation of tobacco smoke, and longer puffs compared to cigarette smoking. Clearly, waterpipe smokers are exposed to high levels of tobacco smoke. Waterpipe smoke contains carcinogens and toxicants, such as tobacco-specific nitrosamines, benzene, nitric oxide and heavy metals. Nicotine impact on hemodynamic responses is evident by increase in heart rate, constriction in blood vessels, and increase in myocardial contraction which contribute to acute cardiovascular events.

\section{Methods}

This secondary analysis was completed using data from a randomized clinical trial to investigate the direct effects of nicotine (published elsewhere). Twenty-four young adults smoked waterpipe tobacco for 45 minutes in a controlled environment once a week for 4 weeks. Carbon Monoxide was measured pre and post smoking. Heart rate was measured continuously during smoking. The two nicotine conditions were placebo and nicotine tobacco.

\section{Results}

Heart rate increased significantly over time while smoking nicotine containing waterpipe tobacco. The mean heart rate increased from $78 \pm 12$ lat baseline) to $86 \pm 13$ (post smokingl in the nicotine condition and from $72 \pm 11$ (baseline) to $77 \pm 9$ (post smoking) in the non-nicotine condition. $\mathrm{CO}$ levels increased significantly from pre smoking (1.18 \pm 1.05$)$ to post smoking (16.83 \pm 12.45$)$ in the nicotine condition and the increase was significant l $\mathrm{t}=$ $6.18, p<.00)$. Also, CO levels increased from pre smoking $(1.27 \pm .93)$ to post smoking $(19.62 \pm 12.64)$ in the nonnicotine condition and the increase was significant $(\mathrm{t}=$ $6.89, \mathrm{p}<.00$ ).

\section{Funding}

Washington State University Alcohol and Drug Abuse Research Program.

\section{Tob. Induc. Dis. 2018;16(Suppl 3):A35 DOI: 10.18332/tid/94534}

\section{Rise of popularity of electronic cigarettes and correlates with marketing and regulations trajectory \\ Radhouane Fakhfakh ${ }^{1}$, Rafla Dellagi ${ }^{2}$}

${ }^{1}$ National Institute of Health, Tunisia, ${ }^{2}$ Ministry of Health, Tunisia Introduction

Electronic nicotine delivery systems (ENDS) were introduced and advertised since five years in Tunisia (The developing African Country), but Public interest in this product is undocumented.
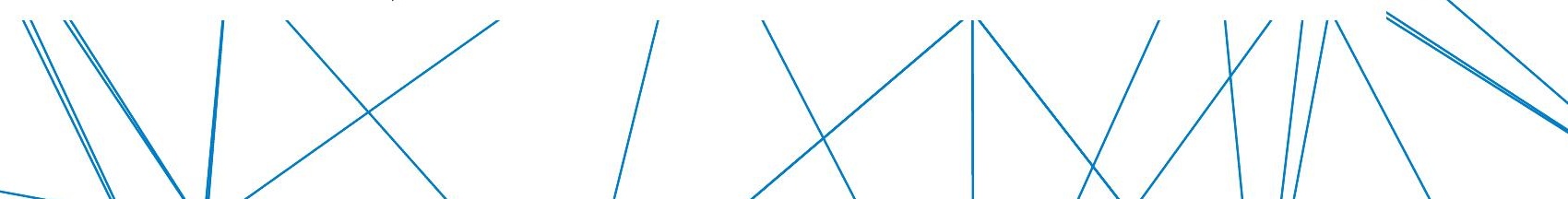
Hookah use among adolescent school students from urban slums of Mumbai, India

Himanshu Gupte ${ }^{1}$, Gauri Mandal ${ }^{2}$, Leni Chaudhuri ${ }^{1}$

${ }^{1}$ Narotam Sekhsaria Foundation, Mumbai, India, ${ }^{2}$ Salaam Bombay Foundation, Mumbai, India

\section{Introduction}

"Hookah" or waterpipe smoking is becoming popular among youth. It is addictive and associated with multiple, long-term, adverse health outcomes. Availability of flavored hookah, increasing social acceptability, influence of tobacco industry and misconceptions about hookah have contributed to its increasing use among youth. Many adolescents from urban slums of Mumbai do not know that hookah contains tobacco. The aim of the study was to assess the prevalence of hookah and factors associated with its cessation among adolescents from slums of Mumbai.

\section{Methods}

LifeFirst is a tobacco/areca-nut dependence treatment program implemented in 40 schools in slum areas of Mumbai in 2017-18. 4302 students of 7th-9th grades attended orientation sessions about tobacco products including hookah and their harmful effects. Students were informed about the availability of a cessation service and encouraged to register voluntarily for six theme-based group sessions conducted over six months. At the end of the six sessions, cessation outcomes were recorded.

\section{Results}

Of the 1441 students registered for tobacco/areca-nut cessation, $6 \%$ were current hookah users $13 \%$ of boys and $7 \%$ of girls). $65 \%$ of them initiated hookah use because of curiosity and $25 \%$ due to peer influence. Of the current hookah users, $8 \%$ smoked hookah daily. At the end of six sessions, $54 \%$ of the hookah users reported stopping smoking hookah while the abstinence was $72 \%$ among the rest of the students.

\section{Conclusions}

Hookah smoking is prevalent among school-going adolescents from slums of Mumbai and school-based cessation programs are required to increase awareness and support them to quit.

Tob. Induc. Dis. 2018;16(Suppl 3):A39 DOI: 10.18332/tid/94864

Prevalence, harm perception, correlates of favourable harm perception and predictors of waterpipe smoking among University of Ibadan undergraduate students

Ayobamigbe Faloye ${ }^{1,2}$, Oluwaseun Akinyemi ${ }^{1}$, Folashayo Adeniji ${ }^{1}$, Hassana Shuaib ${ }^{2,3}$

'Department of Health Policy and Management, University of Ibadan, Ibadan, Nigeria, ${ }^{2}$ Young Professional and Student Assembly-Society for Public Health Professionals of Nigeria, Ile-Ife, Nigeria, ${ }^{3}$ Department of Community Medicine, University of Ibadan, Ibadan, Nigeria

Tobacco kills half of its users, and despite the achievement of public health policies in plummeting cigarette smoking worldwide, waterpipe smoking (WPS) is emerging to sustain tobacco consumption. Hence, this study sought to determine the prevalence, harm perception, correlates of favourable harm perception and predictors of WPS among undergraduate students in University of Ibadan.

A cross sectional descriptive study was conducted among 390 undergraduate students residing in the halls at the University of Ibadan. Data were obtained using a semistructured questionnaire and analysed with SPSS 21. A Likert scale was used to determine the harm perception of WPS by current smokers. A Bi-variate analysis was used to test for associations and correlates of favourable harm perception while logistic regression was carried out to determine predictors of WPS.

The study revealed that mean age of initiation of WPS was $18.5 \pm 2.7$ years, $3.9 \%$ were current users. $33 \%$ of current WP users had favourable harm perception. Health warnings on shisha smoking packages and considering shisha use as smoking were significant correlates of favourable harm perception. Ever cigarette smoking $[p=0.013 ; 95 \% \mathrm{Cl} ; 1.7-84.4]$, smoking of other products aside cigarette $[p=0.012 ; 95 \% \mathrm{Cl} ; 1.7-94.0]$, having all close friends as smokers $[\mathrm{p}=0.016 ; 95 \% \mathrm{Cl} ; 3.3-129.4]$, having divorced parents $[\mathrm{p}=0.002 ; 95 \% \mathrm{Cl} ; 3.5-216.0]$ and shisha smoking among siblings $[p=0.001 ; 95 \% \mathrm{Cl} ; 2.0-124.1]$ were predictors of current WPS.

There is less awareness on WPS health consequences among the University's undergraduate students. Hence, advocacy strategies on the harms of WPS and specific laws regulating WPS should be established.

\section{Funding}

This study was self financed.

\section{Tob. Induc. Dis. 2018;16(Suppl 3):A40 DOl: 10.18332/tid/94876}

\section{The role of socio-demographic factors} associated with water pipe smoking among male adolescents, in western Iran: A crosssectional study

Saeed Bashirian', Majid Barati', Hamid Abasi ${ }^{2}$, Manoj Sharma ${ }^{3}$, Manoochehr Karami ${ }^{4}$

${ }^{1}$ Social Determinants of Health Research Center, Hamadan University of Medical Sciences, Hamadan, Iran, ${ }^{2}$ Department of Public Health, School of Health, Hamadan University of Medical Sciences, Hamadan, Iran, ${ }^{3}$ Behavioral \& Environmental Health School of Public Health, Jackson State University (Challenging Minds, Changing Lives), Jackson, United States, ${ }^{4}$ Research Center for Health Sciences, Hamadan University of Medical Sciences, Hamadan, Iran

\section{Aim and objective}

Water pipe (WP) smoking is a significant leisure activity among young people in Iran that is on the rise. The purpose of this study was to identify the role of sociodemographic factors associated with WP smoking among male adolescents in Iran.

\section{Methods}

The study used a cross-sectional design. It included 730 high school male students (grades 10-12)recruited through multi-stage random sampling conducted in 2017 in the Hamadan city of western Iran. The selfadministered questionnaires included information on demographic variables and behavioral risk factors related to WP smoking. Statistical analyses were executed using SPSS version 22 summarizing descriptive statistics and conducting inferential statistics through multi nominal logistic regression modeling.

\section{Results}

The mean (SD) ages of the students and at WP smoking initiation were $16.41(0.84)$ and 13.31 (2.43), respectively. The distribution of never, ever and current WP smoking were $37.3 \%, 35.3 \%$ and $27.4 \%$, respectively. We found that ever cigarette smoking $(\mathrm{OR}=5.34 ; 95 \% \mathrm{Cl}[2.66,10.73])$ and WP smoking family $(\mathrm{OR}=2.41 ; 95 \% \mathrm{Cl}[1.32,4.40])$ were significantly associated with ever WP smoking. WP smoking friends $(\mathrm{OR}=0.50 ; 95 \% \mathrm{Cl}[0.35,0.72])$ had protective role on ever WP smoking. Also, the variables 18 years of age, studying in technical fields, ever and current smoking of cigarettes and family usage of WP smoking were significantly
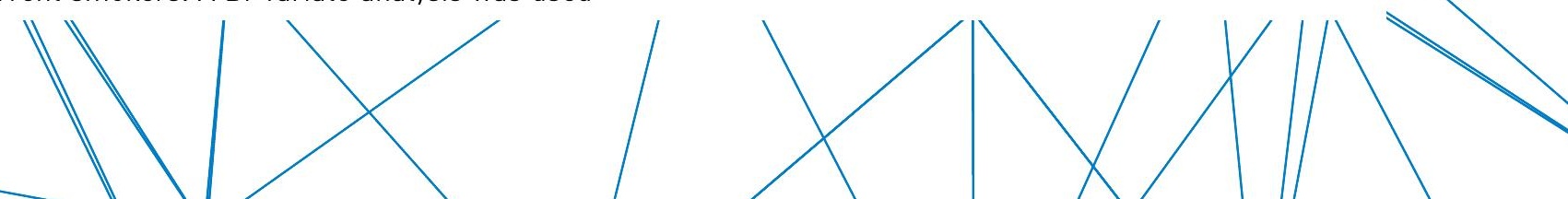
associated with the current usage of WP smoking.

\section{Conclusion}

The results indicated that the prevalence of ever and current WP smoking were high in Hamadan city. Thus, designing and implementing interventions for increasing students', friends' and family's awareness regarding the harms of WP smoking and cigarette smoking facilitating behavior change in this direction is necessary.

\section{Funding}

This study was supported by Hamadan University of Medical Sciences, Hamadan, Iran.

\section{Tob. Induc. Dis. 2018;16(Suppl 3):A41}

DOl: 10.18332/tid/94548

\section{EUREST-PLUS: TOBACCO CONTROL POLICY IMPLEMENTATION TO REDUCE LUNG DISEASE}

\section{Evaluating the European Union (EU) Tobacco} Products Directive: Findings from the EURESTPLUS ITC cohort study among six EU Member States (MS)

Constantine I. Vardavas ${ }^{1,2}$, Nicolas Bécuwe ${ }^{3}$, Tibor Demjén ${ }^{4}$ Esteve Fernández ${ }^{5,6}$, Ann McNeill7, Ute Mons ${ }^{8}$, Yannis Tountas ${ }^{9}$, Antigona Trofor ${ }^{10,11}$, Aristidis Tsatsakis ${ }^{2}$, Gernot Rohde $^{12}$, Marc Willemsen ${ }^{13}$, Krzysztof Przewoźniak ${ }^{14,15}$ Witold A. Zatoński 14,16, Geoffrey T. Fong ${ }^{17,18}$, on behalf of the EUREST-PLUS Consortium

'European Network on Smoking and Tobacco Prevention (ENSP), Brussels, Belgium, ${ }^{2}$ University of Crete (UoC), Heraklion, Greece, ${ }^{3}$ Kantar Public (TNS), Brussels, Belgium, 4 Smoking or Health Hungarian Foundation (SHHF), Budapest, Hungary, ${ }^{5}$ nstitut Català d'Oncologia (ICO) and Bellvitge Biomedical Research Institute (IDIBELL), Catalonia, Spain, ${ }^{6}$ School of Medicine and Health Sciences, Universitat de Barcelona, Catalonia, Spain, ${ }^{7}$ King's College London (KCL), London, United Kingdom, ${ }^{8}$ Cancer Prevention Unit and WHO Collaborating Centre for Tobacco Control, German Cancer Research Center (DKFZ), Heidelberg, Germany, 'University of Athens (UoA), Athens, Greece, 'OUniversity of Medicine and Pharmacy 'Grigore T. Popa', lasi, Romania, "Aer Pur Romania, Bucharest, Romania, ${ }^{12}$ European Respiratory Society (ERS), Lausanne, Switzerland, ${ }^{13} \mathrm{CAPHR}$, University of Maastricht (UniMaas), Maastricht, The Netherlands, ${ }^{14} \mathrm{Health}$ Promotion Foundation (HPF), Warsaw, Poland, ${ }^{15}$ Maria Sklodowska - Curie Institute - Oncology Center Warsaw, Poland, ${ }^{16}$ European Observatory of Health Inequalities, President Stanistaw Wojciechowski State University of Applied Sciences, Kalisz, Poland, ${ }^{17}$ University of Waterloo (UW), Waterloo, Canada, ${ }^{18}$ Ontario Institute for Cancer Research, Toronto, Canada Efforts to mitigate the devastation of tobacco-attributable morbidity and mortality in the European Union (EU) consist of its newly adopted Tobacco Products Directive (TPD) along with the first-ever health treaty, the WHO Framework Convention on Tobacco Control (FCTC). The aim of this Horizon 2020 project entitled European Regulatory Science on Tobacco: Policy Implementation to Reduce Lung Disease (EUREST-PLUS) is to monitor and evaluate the impact of the implementation of the TPD across the EU, within the context of WHO FCTC ratification. The EUREST-PLUS ITC cohort study of adult smokers in six EU MS (Germany, Greece, Hungary, Poland, Romania, Spain), uses a pre-vs. post-TPD implementation study design, evaluating the impact of several tobacco control policy provisions, including but not limited to health warning labels, smoke free areas and electronic cigarettes. The study is designed to generate strong inferences about the effectiveness of tobacco control policies, as well as to elucidate the mechanisms and factors by which policy implementation translates to population impact. Findings from EUREST-PLUS have potential global implications for implementation of innovative tobacco control policies and its impact on the prevention of lung diseases.

\section{Funding}

The EUREST-PLUS Project takes place with the financial support of the European Commission, Horizon $2020 \mathrm{HCO}$ 6-2015 program (EUREST-PLUS: 681109; C. I. Vardavas) and the University of Waterloo (GT. Fong). Additional support was provided to the University of Waterloo by the Canadian Institutes of Health Research (FDN-148477). GT. Fong was supported by a Senior Investigator Grant from the Ontario Institute for Cancer Research. E. Fernández is partly supported by Ministry of Universities and Research, Government of Catalonia (2017SGR139) and by the Instituto Carlos III and co-funded by the European Regional Development Fund (FEDER) (INT16/00211 and INT17/00103), Government of Spain.

\section{Tob. Induc. Dis. 2018;16(Suppl 3):A42}

\section{DOl: 10.18332/tid/95140}

Chemical analysis and hazard identification of the most common electronic cigarette liquids in nine European countries

Charis Girvalaki ${ }^{1}$ Manolis Tzatzarakis ${ }^{1}$, Christina N. Kyriakos1, 2, Alexander I. Vardavas', Polychronis D. Stivaktakis', Matthaios Kavvalakis ${ }^{1}$, Aristidis Tsatsakis ${ }^{1}$, Constantine I. Vardavas ${ }^{1,2}$, on behalf of the EUREST-PLUS consortium

${ }^{1}$ Laboratory of Toxicology, Medical School, University of Crete, Heraklion, Greece, ${ }^{2}$ European Network on Smoking and Tobacco Prevention (ENSP), Brussels, Belgium

\section{Background}

We aimed to detect the composition and reported chemical health hazards of the most common electronic cigarette liquids (e-liquids) in nine European Union (EU) Member States (MS) prior to adoption of the Tobacco Product Directive (TPD).

\section{Materials and methods}

Within the Horizon2020, EUREST-PLUS study, 122 of the most commonly used e-liquids were purchased from 9 EU MS. Chromatography - mass spectrometry and liquid chromatography - mass spectrometry methods were used to analyze the samples. Among the most frequently detected compounds (detected $\geqslant 4$ times), Danger Globally Harmonized System of Classification and Labelling of Chemicals (GHS) and Warning GHS codes were identified.

\section{Results}

During the samples analysis, several discrepancies in nicotine concentration were detected among the samples from the 9 EU MS. French samples contained an average of $21.9 \%$ more nicotine than labelled, while Romanian samples contained an average of $22.5 \%$ less nicotine than labelled. In addition, in the $9.8 \%$ of the samples, the nicotine concentration exceeded the limit of $20 \mathrm{mg} / \mathrm{ml}$. With regards to the samples' composition, 171 different compounds were identified and detected 750 times in total while we did not identify samples positive for PAHs or nitrosamines. Finally from the 171 substances, only $5(10.4 \%)$, (Oxime-, methoxy-phenyl, +/-.-.alpha.Methylbenzyl acetate, 1,3-Dioxolane, 2-butyl-4-methyl-, Melonal and (-Menthyl acetate) were not associated with a Danger GHS and Warning GHS codes.

\section{Conclusions}

As large number of potential harmful compounds was
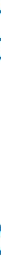
identified, the systematic monitoring and chemical evaluation of e-liquids is necessary in order to protect the consumers' health.

\section{Funding}

The EUREST-PLUS Project takes place with the financial support of the European Commission, Horizon $2020 \mathrm{HCO}$ 6-2015 program (EUREST-PLUS: 681109; C. I. Vardavas) and the University of Waterloo (GT. Fong). Additional support was provided to the University of Waterloo by the Canadian Institutes of Health Research (FDN-148477). GT. Fong was supported by a Senior Investigator Grant from the Ontario Institute for Cancer Research. E. Fernández is partly supported by Ministry of Universities and Research, Government of Catalonia (2017SGR139) and by the Instituto Carlos III and co-funded by the European Regional Development Fund (FEDER) (INT16/00211 and INT17/00103), Government of Spain.

\section{Tob. Induc. Dis. 2018;16(Suppl 3):A43 \\ DOl: 10.18332/tid/95141}

Undesirable events during electronic cigarette use prior to the implementation of Article 20 of the European Union Tobacco Products Directive: Findings from the EUREST-PLUS ITC Europe Surveys

Christina N. Kyriakos ${ }^{1,2}$, Filippos T. Filippidis ${ }^{3}$, Sara Hitchman ${ }^{4}$. Charis Girvalaki ${ }^{2}$. Chara Tzavara ${ }^{3}$, Tibor Demjén ${ }^{5}$, Esteve Fernández ${ }^{6,7}$, Ute Mons $^{8}$, Antigona Trofor $^{9,10}$, Yannis Tountas ${ }^{3}$, Mateusz Zatoński ${ }^{11,12}$, Witold A. Zatoński ${ }^{11,13}$, Geoffrey T. Fong ${ }^{14,15}$, Constantine I. Vardavas ${ }^{1,2}$, on behalf of the EUREST-PLUS consortium

${ }^{1}$ European Network on Smoking and Tobacco Prevention (ENSP), Brussels, Belgium, ${ }^{2}$ University of Crete (UoC), Heraklion, Greece, ${ }^{3}$ National and Kapodistrian University of Athens (UoA), Athens, Greece, 'King's College London (KCL), London, United Kingdom, ${ }^{5}$ Smoking or Health Hungarian Foundation (SHHF), Budapest, Hungary, 'Institut Català d'Oncologia (ICO) and Bellvitge Biomedical Research Institute (IDIBELL), Catalonia, Spain, ${ }^{7}$ School of Medicine and Health Sciences, Universitat de Barcelona, Catalonia, Spain, ${ }^{8}$ Cancer Prevention Unit and WHO Collaborating Centre for Tobacco Control, German Cancer Research Center (DKFZ), Heidelberg, Germany, 'University of Medicine and Pharmacy 'Grigore T. Popa', Iasi, Romania, ${ }^{10} \mathrm{Aer}$ Pur Romania, Bucharest, Romania, ${ }^{11} \mathrm{Health}$ Promotion Foundation (HPF), Warsaw, Poland, ${ }^{12}$ London School of Hygiene and Tropical Medicine, London, United Kingdom, ${ }^{13}$ European Observatory of Health Inequalities, President Stanistaw Wojciechowski State University of Applied Sciences, Kalisz, Poland, ${ }^{14}$ University of Waterloo (UW), Waterloo, Canada, ${ }^{15} \mathrm{Ontario}$ Institute for Cancer Research, Toronto, Canada

\section{Introduction}

Article 20 of the European Union (EU) Tobacco Products Directive (TPD) sets forth provisions on electronic cigarette (e-cigarette) product regulation, such as child-proof packaging and protection against e-liquid refilling without leakage. The aim of the current study was to examine frequencies and correlates of experiencing undesirable events during e-cigarette use related to e-cigarette product design parameters prior to the implementation of the EU TPD.

\section{Methods}

The EUREST-PLUS ITC Europe Wave 1 survey was conducted with adult cigarette smokers from June to September 2016 across Germany, Greece, Hungary, Poland, Romania, Spain.

\section{Results}

Among our sample of adult cigarette smokers, one in five reported having ever used e-cigarettes. Prevalence of current e-cigarette use (daily or weekly) was very low (1.5\%). Major undesirable events, such as battery exploding or catching fire $(1.9 \%)$ or overheating $(11 \%)$ were uncommon. Among those reporting at least monthly use and whose usual/ current brand has a tank that you fill with liquids, $18.8 \%$ experienced spilling during refill and $18.5 \%$ experienced e-liquid leaking during use. Nearly one-quarter reported that the e-liquid cap was easy for a child to open.

\section{Conclusions}

In light of the EU TPD establishing standards around e-cigarette design parameters to mitigate undesirable events and risks during e-cigarette use, these findings further support the need for its implementation, as well as for monitoring undesirable events experienced during e-cigarette use once Article 20 is fully implemented.

\section{Funding}

The EUREST-PLUS Project takes place with the financial support of the European Commission, Horizon $2020 \mathrm{HCO}-$ 6-2015 program (EUREST-PLUS: 681109; C. I. Vardavas) and the University of Waterloo (GT. Fong). Additional support was provided to the University of Waterloo by the Canadian Institutes of Health Research (FDN-148477). GT. Fong was supported by a Senior Investigator Grant from the Ontario Institute for Cancer Research. E. Fernández is partly supported by Ministry of Universities and Research, Government of Catalonia (2017SGR139) and by the Instituto Carlos III and co-funded by the European Regional Development Fund (FEDER) (INT16/00211 and INT17/00103), Government of Spain.

\section{Tob. Induc. Dis. 2018;16(Suppl 3):A44 DOI: 10.18332/tid/95144}

\section{Quitting behaviors and cessation assistance} used among smokers with anxiety or

depression: Findings among six countries of the EUREST-PLUS ITC Europe Surveys

Ioanna Petroulia', Christina N. Kyriakos ${ }^{2,3}$, Sophia Papadakis $^{3,4}$, Chara Tzavara', Filippos T. Filippidis ${ }^{1,5}$, Charis Girvalaki ${ }^{3}$, Theodosia Peleki', Paraskevi Katsaounou', Ann McNeill ${ }^{6}$, Ute Mons ${ }^{7}$, Esteve Fernández ${ }^{8}$, , Tibor Demjén $^{10}$, Antigona Trofor ${ }^{11,12}$, Aleksandra Herbec ${ }^{13}$, Witold Zatoński ${ }^{13,14}$, Yannis Tountas ${ }^{1}$, Geoffrey T. Fong ${ }^{15,16}$, Constantine I. Vardavas ${ }^{2,3}$, on behalf of the EUREST-PLUS Consortium

'National and Kapodistrian University of Athens (UoA), Athens, Greece, ${ }^{2}$ European Network on Smoking and Tobacco Prevention (ENSP), Brussels, Belgium, ${ }^{3}$ University of Crete (UoC), Heraklion, Greece, ${ }^{4}$ Division of Prevention and Rehabilitation, University of Ottawa Heart Institute, Ottawa, Canada, ${ }^{5}$ Department of Primary Care and Public Health, School of Public Health, Imperial College London, London, United Kingdom, ${ }^{6}$ King's College London (KCL), London, United Kingdom, ${ }^{7}$ Cancer Prevention Unit and WHO Collaborating Centre for Tobacco Control, German Cancer Research Center (DKFZ), Heidelberg, Germany, ${ }^{8}$ Institut Català d'Oncologia (ICO) and Bellvitge Biomedical Research Institute (IDIBELL), Catalonia, Spain, ${ }^{9} \mathrm{School}$ of Medicine and Health Sciences, Universitat de Barcelona, Catalonia, Spain, '0Smoking or Health Hungarian Foundation (SHHF), Budapest, Hungary, ${ }^{11}$ University of Medicine and Pharmacy 'Grigore T. Popa', Iasi, Romania, ${ }^{12}$ Aer Pur Romania, Bucharest, Romania, ${ }^{13} \mathrm{Health}$ Promotion Foundation (HPF), Warsaw, Poland, ${ }^{14}$ European Observatory of Health Inequalities, President Stanistaw Wojciechowski State University of Applied Sciences, Kalisz, Poland, ${ }^{15}$ University of Waterloo (UW), Waterloo, Canada, ${ }^{16}$ Ontario Institute for Cancer Research, Toronto, Canada

\section{Introduction}

The current study explores quitting behaviours and use of cessation assistance among adult tobacco users with
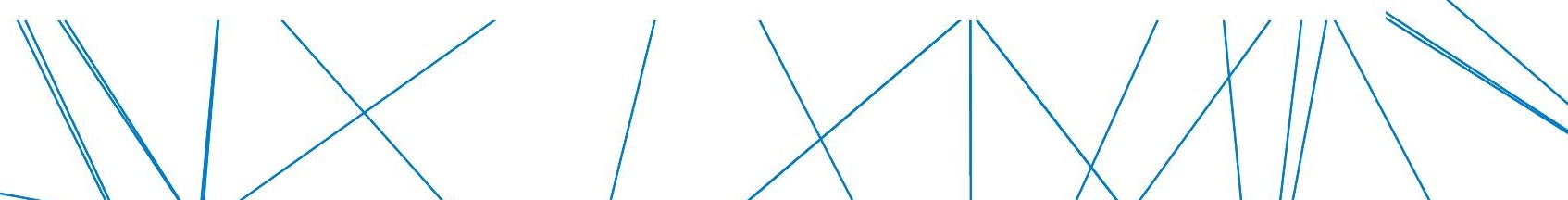


\section{Conclusions}

STEPS aims also at understanding the prevalence of exposure to secondhand smoke; assessing the levels of awareness of the dangers of secondhand smoke, as well as drafting a new regulation on tobacco prevention based on best practices and approaches from worldwide. The survey results may also serve as the basis for coordination of measures to prevent exposure to secondary smoke and to reduce the consumption of tobacco products and their substitutes.

Tob. Induc. Dis. 2018;16(Suppl 3):A47 DOl: 10.18332/tid/94871

\section{Evaluating the association between breast} cancer and second hand smoking in Tekirdag Petek Taneri ${ }^{1}$, Hülya Becerir², Gamze Saraçoğlu³ ${ }^{1}$ Tekirdağ Çorlu Toplum Sağ ığı Merkezi, Çorlu, Turkey, ${ }^{2}$ Tekirdağ Il Sağlık Müdürlüğü, Tekirdağ, Turkey, ${ }^{3} \mathrm{H}$ alk Sağlığı Anabilim Dalı,Tıp Fakültesi, Namık Kemal Üniversitesi, Tekirdağ, Turkey

\section{Aim and objective}

The aim of the study was to determine if there any possible relationship between breast cancer and second hand smoking, with considering other potential factors.

\section{Methods}

Thirty cancer patients and sixty controls were selected among the women in the database of Cancer Early Diagnosis and Education Centers at Corlu and Suleymanpasa, Tekirdag. Controls were matched by age and location. After their verbal approval, they were questioned on the phone with a questionnaire. Crude odds ratios and adjusted odds ratios were calculated via SPSS.

\section{Results}

With 29 cancer patients $(96.7 \%$ ) and 52 controls $(86.7 \%)$, in total there were 81 women enrolled. Smoking regularly at a point in lifetime rates were $40.4 \%$ for controls and $41.4 \%$ for cases. For controls and cases; their parents' smoking rates at childhood were $67.3 \%$ and $65.5 \%$ respectively, and their partner's smoking rates were $57.7 \%$ and $68.9 \%$. Exposure to smoking at home rates were $73.1 \%$ and $62.1 \%$ in childhood and $59.6 \%$ and $75.8 \%$ in adult life, respectively. In analysis there were no significant association between breast cancer and smoking or second hand smoking. Breast cancer rates were high in those who had family history of breast cancer, not had any chronic disease, not had any abortus (induced or spontaneous), used oral contraceptives and hormone replacement therapy.

\section{Conclusions}

Possibly because of the high smoking and second hand smoking rates of both groups, we were not able to determine any significant relationship. This and our other results need to be further researched among Turkish women.

\section{Tob. Induc. Dis. 2018;16(Suppl 3):A48}

DOl: 10.18332/tid/94873

Impact of smoke free law on smoking status of Serbian adults

Biljana Kilibarda ${ }^{1}$, Nadezda Nikolic ${ }^{1}$, Milena Vasic ${ }^{1}$, Cornel Radu Loghin²

${ }^{1}$ Institute of Public Health of Serbia, Belgrade, Serbia, ${ }^{2}$ European Network for Smoking Prevention, Brussels, Belgium

\section{Aim and objective}

Smoke free law came into effect in Serbia on December 2010. Law bans smoking in enclosed public places with exemption to hospitality sector. The aim of the study is to present changes in smoking status after the adoption of the smoking ban.

\section{Methods}

We used data of nine survevs which are conducted since the adoption of the law. First survey was conducted at the time of adoption, followed by surveys three and nine months after adoption of the law and afterwards on annual basis. These surveys were conducted on representative samples of the ca 1000 of Serbian adults.

\section{Results}

Three months after adoption of the law $22.9 \%$ smokers stated that smoke free law had influence on their smoking status in the way they stoped smoking or reduced number of smoked cigarettes. Percentage of smokers that reduced or stopped smoking reached $29.2 \%$ in the fourth year after adoption of the law (2014), followed by the decrease. In 2017, less smokers stopped or reduced number of cigarettes $(21.6 \%)$ compared to the first year. The changes in smoking status by years were statistically significant $(\mathrm{p}=0.000)$.

One of the factors contributing to the reversed trend might be lower compliance with the Law. Same surveys showed that also that in the fourth year after adoption of the law, percentage of people estimating compliance with the current smoke free law as not good, started to increase and reached $22,8 \%$ in 2017.

\section{Conclusions}

The smoke free law contributed to changes in smoking status and patterns of smoking in Serbia. However, the influence of the smoke free law started to weaken in the forth year after the implementation. Contributing factor might be lower compliance with the law.

\section{Tob. Induc. Dis. 2018;16(Suppl 3):A49} DOl: 10.18332/tid/94909

\section{Association of second hand smoke exposure} and depression: A systematic review and metaanalysis

Siva Pentapati ${ }^{1}$, Harshal Salve ${ }^{1}$

${ }^{1}$ Centre for Community Medicine, All India Institute of Medical Sciences, New Delhi, India

\section{Aim \& Objective}

Impact of exposure of smoking on mental health conditions is well studied, but not of second hand smoke exposure. This is an attempt to find the association between second hand smoke exposure and depression.

\section{Methods}

A systematic search was conducted for published studies in English till June 2017. Independent two electronic searches were carried out in Medline, IndMED using key words "second hand smoking", "passive smoking", "environmental tobacco smoke" \& "depression". We have included articles reporting adjusted relative risk (RR) or odds ratio. References of the selected articles were also traced. Meta-analysis was performed to calculate pooled estimate using random effects model.

\section{Results}

We have got 165 records from searched databases. Of which, 20 records were included for full text review after screening abstract and removing duplicates. Finally, fifteen articles were included for meta-analysis. Second hand smoke exposure exposure was found to be associated with depression ( $R R=1.37,95 \mathrm{Cl}: 1.26,1.48$ ) with heterogeneity, I2: $83 \%$.

\section{Conclusions}

We have found modest strength of association for second hand smoke exposure and depression. Unknown confounders might have reduced the pooled estimate in the longitudinal studies.

Tob. Induc. Dis. 2018;16(Suppl 3):A50

DOI: $10.18332 /$ tid/94862 


\section{TOBАССО НЕАLTI EFFECTS 2}

Population attributable fractions of tobacco related cancers in Turkey and seven geographical regions

Sultan Eser ${ }^{1}$, Su Özgür ${ }^{2}$

${ }^{1}$ Department of Public Health, Faculty of Medicine, Balıkesir University, Balıkesir, Turkey, ${ }^{2}$ Faculty of Medicine, Biostatistics and Medical Informatics, Ege University, Izmir, Turkey

\section{Introduction}

Anti-tobacco interventions have been effective in many developed countries where lung and other tobacco-related cancers are declining. In Turkey, the first tobacco legislation put into practice in 1996 and strengthened in 2008. Aim of this work was to quantify the size of the problem in each of the seven geographical regions and in the whole of Turkey.

\section{Methods}

We followed the methods proposed by Peto et al.(Lancet $339,1992)$ and Parkin et al.(Int. J Cancer 59, 1994). Incidence rates of lung and other tobacco-related cancers were obtained from $\mathrm{CI} 5 \mathrm{C}$ vol.XI for 8 provinces and projected to the regions. Estimates of the incidence of lung cancer in non-smokers and relative risks for the other cancer sites were obtained from the large CPS II cohort of the American Cancer Society. By combining these parameters in the usual formula due to Cole\&MacMahon we obtained estimates of the fraction of tobacco-related cancer attributable to smoking (PAF).

\section{Results}

For Turkey, in total, $59.4 \%$ of the 351591 TRC cases can be attributed to tobacco smoking; $74.5 \%$ in males, $6.8 \%$ in females. PAFs by cancer sites are as follow: $89.6 \%$, $38.4 \%$ of lung; $86.4 \%, 5.1 \%$ of laryngeal; $70.3 \%, 4.3 \%$ of oesophagial; $70.5 \%, 3.1 \%$ of oral-cavity\&pharyngeal; $54.4 \%, 0.4 \%$ of kidney; $53.2 \%, 1.7 \%$ of bladder; $38.4 \%$, $1.1 \%$ of stomach, $39.1 \%, 1.1 \%$ of liver, $41.3 \%, 1.5 \%$ of the pancreas cancers and $30.4 \%, 0.5 \%$ of myeloid leukemias in men and women respectively; $1.03 \%$ of cervical cancers in women. The highest PAF for all TRCs is in Marmara (81.9\%) where the lowest in Eastern and Southeastern Anatolia region (58.0\%) in men, and in Mediterranean $(10.4 \%)$, in Western Black Sea region (0.0\%) respectively in women.

\section{Conclusions}

More than half of all TRCs in Turkey is due to tobacco smoking. Implemented tobacco control programs should be strengthened.

\section{Tob. Induc. Dis. 2018;16(Suppl 3):A51}

DOl: 10.18332/tid/94797

\section{An evaluation of the relation between atrial} fibrillation and smoking in patients undergoing stroke

Bilge Cinar ${ }^{1}$, Halil Gulluoglu², Refik Kunt ${ }^{3}$

${ }^{1}$ Neurology Department, School of Medicine, Bulent Ecevit University, Zonguldak, Turkey, ${ }^{2}$ Neurology Department, Medicalpark Izmir Hospital, Izmir, Turkey, ${ }^{3}$ Neurology Department, Aydin State Hospital, Aydin, Turkey

\section{Aim and objective}

Atrial fibrillation (AF) occupies an important place among the etiological agents in ischemic cerebrovascular disease. Smoking is thought to be a predisposing factor for AF. The probable relation between smoking and AF can be explained in terms of oxidant mechanisms and inflammation. This study investigated the probable link between smoking and AF against a background of stroke.

\section{Methods}

Three centers were included in the study. Cases diagnosed with stroke and transient ischemic attack (TIA) arriving at these centers were evaluated in terms of demographic, clinical, and radiological characteristics. The Modified Rankin Score (MRS) and National Institutes of Health Stroke Scale (NIHSS) scores were used to assess severity of stroke.

\section{Results}

Three hundred forty-one patients with a mean age of $73.73 \pm 11.40$ were enrolled; 282 were evaluated as ischemic stroke, 50 as hemorrhagic stroke, and 9 as TIA. Mean MRS was $2.92 \pm 1.63$, and mean NIHSS was $10.12 \pm 8.01$. Of the study group, $65.7 \%$ had never smoked, $23.2 \%$ were active smokers, and $11 \%$ had quit. The relation between etiological factors and smoking was investigated based on the TOAST classification in the ischemic subgroup. Stroke associated with large or small vessel disease and the AFrelated stroke group were compared in terms of smoking status, and smoking status was significantly higher in the AF group $(p=0,04)$. A significant difference was observed in mean EF values at echocardiography performed on patients in the ischemic subgroup between the smoking and non-smoking groups $(57.71 \pm 14.37$, and $60.83 \pm 8.92$, respectively, $p=0,002$ ).

\section{Conclusions}

Our study determined no relation between smoking and stroke subtypes, severity, or other risk factors, while smoking emerged as a risk factor in AF-related stroke. This once again shows that smoking, in other words nicotine, lays the foundation for AF through inflammation, catecholamine-mediated effects, and oxidative stress, constitutes a risk factor for stroke, together with advanced age.

\section{Tob. Induc. Dis. 2018;16(Supp( 3):A52 DOI: 10.18332/tid/94849}

\section{Smoking and oral contraceptive use in women in rural areas}

Safiye Ozvurmaz', Aliye Mandıracıoğlu²

${ }^{1}$ Halk Sağlığı Hemșireliği Anabilim Dalı, Hemșirelik Fakültesi, Adnan Menderes Üniversitesi, Aydin, Türkiye, ${ }^{2}$ Halk Sağlığı Anabilim Dali, Tıp Fakültesi, Ege Üniversitesi, İzmir, Türkiye

\section{Aims and Objectives}

At present, women are the target clients of tobacco companies. Female smokers using combined oral contraceptives are at higher risk of coronary heart disease and peripheral vascular disease than non-smokers. The aim of this study was to determine smoking status and oral contraceptive use in women in a rural area of the province of Aydın.

\section{Methods}

This descriptive study was performed in a rural area of Aydın. It was performed in 120 women aged 20-60 years, living in a village and accepting to participate. Data were gathered with a questionnaire prepared by the researchers and composed of questions about socio-demographic features including age, gender, education, marital status and income and presence of a health problem, height, weight, smoking status and use of contraceptives.

\section{Results}

The mean age of the women was $34.83 \pm 11.65$ years. Of all the women, $30,8 \%$ were primary school graduates, $64,8 \%$ were married, $29,2 \%$ had a child, $66,4 \%$ had a sufficient income, $65,6 \%$ did not have a check-up, $30,3 \%$ had a chronic disease and $33,6 \%$ were smokers. Twenty-eightpoint two percent of the women had a hiah bodv mass
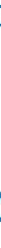
index; i.e. overweight. Eleven-point five percent and 11.5\% of the women were using an IUD and oral contraceptives respectively. Sixty-nine percent of the women were not using any contraceptives. Of all the women using oral contraceptives, $57,1 \%$ were smokers, $7,1 \%$ were obese, $7.1 \%$ were aged over 35 years and $21.4 \%$ had a chronic disease (hypertension and diabetes).

\section{Conclusions}

About one third of the women in the rural area where the study was performed were smokers and the incidence of smoking was higher among the women using oral contraceptives. It is important that women in rural areas should be offered counseling so that they can stop smoking. Individual characteristics should be taken into account in counseling for contraceptives.

Tob. Induc. Dis. 2018;16(Suppl 3):A53 DOl: $10.18332 /$ tid/94720

\section{Effect of smoking on disability progression in} patients with multiple sclerosis

Tuncay Gündüz', Murat Kürtüncü

'Department of Neurology, İstanbul Faculty of Medicine, İstanbul University, İstanbul, Turkey

\section{Aim and objective}

In general, cigarette smoking is linked to increased risk of occurrence of MS and rate of progression. Extended disability status scale (EDSS) is used for measuring disability status of MS patients. Higher EDSS score indicates a worse neurological dysfunction In our study, we aimed to reveal the effect of smoking on disability progression in Turkish patients with MS.

\section{Methods}

Patients were divided into two groups according to smoking status (smokers and non-smokers). Demographic characteristics and clinical parameters of disease progression including time to reach EDSS 3 and EDSS 6 were compared between both groups using chi-square, student's t-test, log-rank test, and ANOVA.

\section{Results}

Overall, 280 smokers (108 males, 172 females) and 685 non-smokers (171 males, 514 females) were included in the study. There was no difference between the two groups in terms of gender, age at onset, the duration between first two relapses, and MS subtypes $(p>0,05)$. As expected, women smoked less than men ( $p<0.001)$. Interestingly, as education level increased, there was a tendency to smoking ( $p=0.001)$. We found no difference in the time to reach EDSS 3 and EDSS 6 for smokers and non-smokers (log-rank test; $p=0.48$ and $p=0.93$ ).

\section{Conclusions}

Our study suggests that, unlike general notion, cigarette smoking does not affect the rate of progression in MS patients negatively. The lack of effect of smoking in Turkish patients with MS suggests that the relationship between smoking and MS may be affected by complex genetic factors.

\section{Tob. Induc. Dis. 2018;16(Suppl 3):A54}

DOI: 10.18332/tid/94763

Smokers with diabetes: Twice as deadly and shortened life by 15 years

Wayne Gao ${ }^{1}$, Enkhzaya Chuluunbaatar ${ }^{1}$, Chi Wen ${ }^{2}$ ${ }^{1}$ Taipei Medical University, Taipei, Taiwan, ${ }^{2}$ National Health Research Institute, Taipei, Taiwan

\section{Introduction}

Both smoking and diabetes are known to have health risks, but the extent of the risks when both co-existed are little known.

\section{Methods}

A cohort, consisting of 422,771 adults, was recruited successively during health surveillance between 1996 and 2008. Data from questionnaire, and results from fasting blood and other screening tests were collected. Hazard ratios (HR) came from Cox model and life expectancy from life table method.

\section{Results}

One quarter of the cohort were current smokers (23.2\%), but only $7 \%$ had pre-diabetes and $6 \%$ diabetes. HR for all-cause mortality for smoking, 1.51, for diabetes, 2.02 , but when co-existed, 3.38. Life span shortened 6 years for smokers, 9 years for diabetes, but 15 years for combined. $\mathrm{HR}$ for all cancer increased from 1.77 (smoking) or 1.42 (diabetes) to 2.87 (combined), for heart disease, from 1.43 (smoking) or 2.24 (diabetes) to 4.05 (combined), and for stroke, from 1.54 (smoking) or 1.82 (diabetes) to 2.69 (combined).

\section{Conclusions}

Smokers with diabetes became doubly deadly for all cause (1.51 to 3.38), all cancer (1.77 to 2.87) and heart disease (1.43 to 4.09) and shortened life expectancy by 15 years, from 6 years of smoking and 9 years of diabetes. Overwhelming majority of smokers were not aware of such a large risk. The large life expectancy risk could be leveraged to motivate smokers into smoking cessation.

\section{Tob. Induc. Dis. 2018;16(Suppl 3):A55}

\section{DOI: 10.18332/tid/94795}

Tobacco use, determinants and effects on treatment among persons living with HIV/AIDS at a Military Hospital in Makurdi, Benue State, Nigeria

Elias Aniwada', Godian Ezema', Chika Onwasigwe 'Department of Community Medicine, College of Medicine, Enugu, Nigeria

\section{Aim and objective}

To assess the prevalence, determinants and effects on treatment among persons living with HIV/AIDS at a Military Hospital in Makurdi, Benue State, Nigeria.

\section{Methods}

Study was at a military Hospital, in Benue State. The centre cares for both military and civilian population, with over $98 \%$ being civilian clients. Analytical cross-sectional design was used. Patients $\geqslant 18$ years on care for $\geqslant 12$ months were studied excluding those with frank psychosis, poor record of CD4 count or viral load, chronic health condition known to interfere with CD4count. Patient's folder records, Questionnaire and DAST-10 tool were tools used. Ethical clearance and written informed consent were obtained.

\section{Results}

Majority of the patients were aged $31-60$ years $61(8.3 \%)$ and females $441(63.0 \%)$. Prevalence of Tobacco use were $138(19.7 \%)$ for ever used and $66(9.4 \%)$ for use in past 3 months. Also $114(16.3 \%)$ used Tobacco and other substances; $90(12.9 \%)$ Alcohol, 73(10.4\%) Kola nut, 8(1.1\%) Cannabis and $5(0.7 \%)$ Cocaine with Tobacco. No statistical significant associations between ever used, use in past 3 months or degree of Tobacco use with Viral load CD4 count. Predictors of use includes; males sex (AOR 0.23; $95 \% \mathrm{Cl} 0.15-0.35$ ) and earning $<18,000$ (AOR 2.23; $95 \% \mathrm{Cl}$ 1.05-4.70).

\section{Conclusions}

Use of Tobacco was high as well as use with other 
substances. Tobacco use had no effect on CD4 count and viral load. Sex and Family income predicts use of substance. There is serious and urgent need for improved tobacco prevention and control interventions in the country especially among PLWHA.

\section{Tob. Induc. Dis. 2018;16(Suppl 3):A56}

DOI: 10.18332/tid/94555

\section{PREVALENCE STUDIES}

Trends in tobacco product use in Turkey by gender and age-group between 2010 and 2016 Erdem Erkoyun ${ }^{1}$, Belgin Unal ${ }^{1}$

'Department of Public Health, Faculty of Medicine, Dokuz Eylul University, Izmir, Turkey

\section{Aim and objective}

Turkey has a tobacco control law since 1996 and the law was amended to cover Framework Convention on Tobacco Control in 2008. We aimed to present trends in selfreported smoking in Turkey between 2010 and 2016 by gender and age-groups.

\section{Methods}

Turkey Health Survey is based on a multi-stage, stratified sample of the general population and includes data on self-reported health conditions including tobacco product use behaviour since 2010. Tobacco use was defined as daily or occasional use of tobacco product. Age group and gender-specific prevalence of tobacco use was presented.

\section{Results}

In 2010 tobacco product use in men was $31.7 \%$ and in women was $11.9 \%$ while in $201644.1 \%$ and $17.4 \%$ in both gender, respectively. Tobacco use prevalence was highest in 2014 in both genders (men: $47.6 \%$, women: 18.1\%) and lowest in 2010. In men except 2016 highest tobacco product use prevalence was in 25-34 age-group and was always over fifty percent. In 2016 highest prevalence was in 35-44 age-group and was $55.7 \%$. In women highest tobacco use prevalence was among 35-44 age-group in all years and was about $25 \%$. Age-group 75 and over has the lowest tobacco product use prevalence while in women between 2012 and 2014 prevalence of tobacco product was almost doubled (from $1.9 \%$ to $3.4 \%$ ) and stayed nearly stable in 2016 (3.0\%).

\section{Conclusions}

Tobacco product use prevalence is high in Turkey despite comprehensive tobacco control law. There are minor shifts in the smoking behaviour of different age-groups by survey year.

\section{Funding}

Erdem Erkoyun applied to Turkish Statistical Institute to do the analysis based on the institution's regulations. By law, public institutions can obtain relevant data without additional charges.

Tob. Induc. Dis. 2018;16(Suppl 3):A57

DOI: 10.18332/tid/94775

\section{Prevalence of tobacco smoking in Armenia,} STEPs survey

D. Andreasyan', Al. Bazarchyan, A. Torosyan', Sh. Sargsyan ${ }^{1}$

${ }^{1}$ National Institute of Health, Ministry of Health, Yerevan, Armenia Introduction

To assess the prevalence of tobacco use in 18-69 population of Armenia the survey participants were asked about their current smoking status, previous smoking experience, types of tobacco products used, and their exposure to second-hand smoke at home, workplace and public places.

\section{Methods}

The sample was based on a multi-stage cluster sampling method using demographic data on adult population of Armenia. A sample size of 2380 households was selected and one questionnaire for adults was filled out per household. The survey was conducted with financial and technical assistance of the World Health Organization.

\section{Results}

Every 4 th $(27,9 \%)$ respondent in the $18-69$ age group and every second men (51.5\%) were considered smokers. Smoking tobacco in men is one of the most prevalent risk factors of NCD development. Tobacco use was more prevalent in residents of Yerevan (30.2\%), than in other cities $(21.3 \%)$ and villages $(23.3 \%)$. Nine out of ten smokers were daily smokers. The mean age of starting to smoke was 18.1 . Three $(32.7 \%)$ out of ten smokers smoked 25 and more cigarettes per day, thus putting them at risk of malignancies and cardiovascular diseases. Every five (56.4\%) out of ten respondents were found to be exposed to secondhand smoke at home and every fourth $(26.6 \%)$ in the workplace.

\section{Conclusions}

STEPS survey will enable implementing the tobacco strategy introduced in 2017. The main objective and goal of the strategy and of the RA Government is to implement measures and activities aimed at reducing the prevalence and consumption rates, maintaining the health of the population and also reducing the incidence of NCD by cutting the use of tobacco products and other tobacco substitutes.

\section{Tob. Induc. Dis. 2018;16(Suppl 3):A58 DOI: 10.18332/tid/94872}

Smoking prevalence and related factors among workers of Bornova Municipality in Izmir,

Turkey

Ilker Adıgüzel'1, Raika Durusoy², Nurcan Çakır, Aliye Mandıracıoğlu², Zeliha Öcek²

${ }^{1}$ Non Communicable Diseases Department, Izmir Provincial Health Directorate, Izmir, Turkey, ${ }^{2}$ Department of Public Health, Medical School, Ege University, Izmir, Turkey, ${ }^{3}$ Health Affairs, Bornova Municipality, Izmir, Turkey

\section{Aim and objective}

The aim of this study was to determine the prevalence of smoking and factors related to smokingamong the workers of a district municipality in Izmir.

\section{Methods}

The study consists of a secondary analysis of data collected during a cross-sectional survey on physical activity among municipal workers. Ethical approval and permission from Bornova Municipality were obtained. The data were collected during August-November 2016. Among a total of 2137 municipal workers, the sample size was determined as 352 workers according to $33 \%$ prevalence of physical activity (Turkey Nutrition and Health Survey 2010), $5 \%$ error, 95\% confidence interval, 20\% non-response 352. The response rate of the survey was $81.53 \%$.

\section{Results}

The mean age of the participants was $38,91 \pm 8,49$. Among the study participants, $36.2 \%$ were female and $68.3 \%$ were married. Among them, $24.0 \%$ were graduated from secondary school or lower, $32.1 \%$ from high school and $43.9 \%$ from university. The mean income per capita of workers was $1676.43 \pm 1078.16 \mathrm{TL}$. Their mean duration of emplovment at the municipality was $9.55 \pm 7.30$ vears
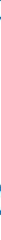
and they worked $171.71 \pm 10,91$ hours per months, $80.5 \%$ were physically active, $36.2 \%$ had a disease diagnosed by a doctor and $27.5 \%$ were on medication.

The prevalence of smoking was $48.8 \%$ among these municipal workers. There was no significant difference between the ages $(p=0.138)$ and gender of smokers and non-smokers.Among women, $49.0 \%$ were smoking and $48.6 \%$ among men ( $p=0.947)$. There was a significant difference of smoking prevalence according to education ( $p=0.006)$, with $58.0 \%$ among secondary school or lower, $56.5 \%$ among high school and $38.1 \%$ among university graduates ( $42.9 \%$ among women and $32.1 \%$ among men). There was no significant difference in the marital status $(p=0.242)$, duration of employment at the municipality ( $p=0.477$ ), physically active work ( $p=0.297)$, monthly working hours ( $p=0.754)$, presence of a chronic disease $(p=0.755)$, medication $(p=0.887)$, presence of hobby $(p=0.898)$, body mass index $(p=0.123)$, income per capita $(p=0.395)$ and physical activity level ( $p=0.695$ ) among smokers and nonsmokers.

\section{Conclusions}

The prevalence of smoking is much higher among municipal workers compared to national adult survey data $(27 \%$ overall, $41.4 \%$ among men and $13.1 \%$ among women), with a much higher prevalence among women. The reasons underlying this high prevalence, especially some possible local or workplace-related dynamics, should be investigated. The lower prevalence among university graduates is consistent with the literature. Educational interventions could be offered.

\section{Tob. Induc. Dis. 2018;16(Suppl 3):A59}

\section{DOl: 10.18332/tid/94907}

\section{A Study on Nicotine Dependency Levels of Smoking University Students Depending On Socio-Demographic Features, and Smoking Habits}

Canan Yoruk ${ }^{1}$, Görkem Yararbas ${ }^{2}$

${ }^{1}$ Ușak Üniversitesi, Ușak, Turkey, ${ }^{2}$ Ege Üniversitesi, Izmir, Turkey Smoking is a common addictive behavior found among young people particularly university students. In the case of smoking addiction the substance nicotine has the most important influence. Therefore, in the fight against smoking addiction it is considered to be important to know the smoking habits of university students and the factors that might affect these students' nicotine addiction. In this regard, in this study it is aimed to investigate the nicotine addiction levels of smoking university students depending on their socio-demographic features and smoking habits. 460 smoking students enrolled in a public university in Turkey in the academic year of 2015-2016 participated in this study. The data were collected via personal information forms and Fagerstron Nicotine Addiction Scale. T-test for independent groups and one-way variance analysis were used in the analysis of the data. The results of the analysis revealed that nicotine addiction scores of cigar smoking university students did not differentiate significantly depending on the gender, faculty, grade level, place of residency, income, parents' level of education, smoking state of mother, father, sibling, friend and the reason of beginning to smoke. Moreover, it was found that students older than 24 had higher scores of nicotine addiction compared to students aging around 18-20 and 21-23 respectively. Additionally, students beginning to smoke at the age range of 10-13 have had higher scores of nicotine addiction compared to students beginning to smoke at the age ranges of 14-17 and 18-21. Also, students smoking for 1-3 years have had lower scores of nicotine addiction compared to students smoking at the ranges of 4-6 years, $7-9$ years, and more than 10 years of consuming. Besides, students smoking between the range of 1-10 cigars per day have had lower scores of nicotine addiction compared to student groups using 11-20, 21-30, and more than 31 respectively. The results of this study may provide insights for academicians and shed light to the studies discussing preventive works on addiction.

\section{Tob. Induc. Dis. 2018;16(Suppl 3):A60 DOI: 10.18332/tid/94832}

\section{Tobacco smoking prevalence and risk} factors among youth attending medical male circumcision clinics

Khuthadzo Hlongwane ${ }^{1}$, Minja Milovanovic ${ }^{1}$, Kennedy Otwombe1, Alpheus Pule1, Limakatso Lebina1, Neil Martinson ${ }^{1,2,3}$

${ }^{1}$ Perinatal HIV Research Unit, Faculty of Health Sciences, University of the Witwatersrand, Johannesburg, South Africa, ${ }^{2}$ Center for Tuberculosis Research, Department of Medicine, Johns Hopkins University School of Medicine, Baltimore, United States, ${ }^{3}$ MRC Soweto Matlosana Collaborating Centre for HIV/ AIDS and TB (SoMCHAT), Faculty of Health Sciences, University of the Witwatersrand, Johannesburg, South Africa

\section{Objectives}

The use of tobacco by youth constitutes a major public health problem globally as well as in South Africa. Early onset of smoking increases the risk of contracting a wide range of potentially fatal diseases. Therefore, the aim was to assess the prevalence and risk factors of tobacco smoking in youth.

\section{Methods}

Cross-sectional study across five medical male circumcision (MMC) sites in three provinces in South Africa among young healthy men aged 10-18 years. Data were collected on demographics, tobacco (positive urine cotinine test) and dagga smoking, risky behaviour, and alcohol consumption. A CO breathalyser test was done to categorise smokers as either mild, moderate or severe. Multivariable logistic regression was used to determine risk factors of tobacco smoking.

\section{Results}

Of the 1109 participants, $68.9 \%$ were aged $10-14$ years, $93.3 \%$ were in school/studying, $17.7 \%$ and $41.0 \%$ had mothers and fathers who smoke, 10\% (105/1088) of participants were tobacco smokers with $51.7 \%$ being severe smokers. Participants aged $15-18$ years were more likely to have anyone smoking indoors in the past 30 days $(32.0 \%$ vs. $19.8 \%, \mathrm{p}<0.0001)$, to smoke tobacco $(86.7 \%$ vs. $13.3 \%, p<0.0001)$ and to have smoked marijuana $(25.6 \%$ vs. $0.4 \%, p<0.0001)$. In the multivariate analysis, the odds for tobacco smoking were higher for age (OR: $1.360 ; \mathrm{Cl}$ : 1.186-1.558), those not in school (OR: 2.408; Cl: 1.117 5.192), often have anyone smoking inside their home (OR: 2.047; $\mathrm{Cl}$ : 1.103-3.798), have smoked marijuana (OR: 8.789; $\mathrm{Cl}$ : 4.551-16.97) and drink alcohol (OR: 4.368; $\mathrm{Cl}$ : 2.261-8.439).

\section{Conclusions}

The prevalence of tobacco smoking increased with age. Participants who were not in school, have smoked marijuana and drink alcohol had higher odds of smoking tobacco. Therefore, it is vital to develop interventions that will help prevent initiation of smoking among youth. This will be helpful in decreasing future tobacco associated mortality rates.
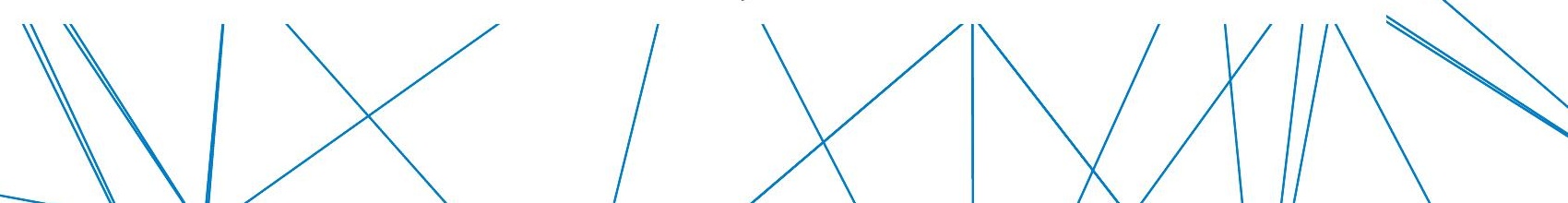
After the pilot training, we conducted 1-day workshops for oral health professionals for full modules including a module of addressing non-smokers' exposure to secondhand smoke in Tokyo, Japan. In total, 104 dentists and dental hygienists participated. A questionnaire regarding nine learning objectives was provided after training. Participants then were asked to mark the level of perceived competence on a straight line $10 \%-100 \%$ scale) regarding five counseling skills. Finally, they were asked about opinions toward development of e-learning for the WHO tobacco cessation and oral health integration: improvement, emphasis, specific recommendation in Japan, and others.

Perceived achievement of the training objectives and confidence in intervention skill were favorable overall. Various opinions regarding four items were obtained from most participants $(68 \%, 77 \%, 63 \%$, and $40 \%$, respectively). In conclusion, improvement of the training workshop is necessary for dissemination of the program by careful consideration of opinions of the participants of workshops.

\section{Funding}

This study was supported by Pfizer Global Medical Grant \#35621681.

\section{Tob. Induc. Dis. 2018;16(Suppl 3):A64}

\section{DOI: 10.18332/tid/94904}

Smoking cessation services for health staff:

Experiences of a university hospital in Izmir, Turkey

Raika Durusoy', Seyfi Durmaz', Hür Hassoy', Ișıl Ergin', Yeșim Korkmaz ${ }^{2}$

'Department of Public Health, Medical School, Ege University, Izmir, Turkey, ${ }^{2} \mathrm{Health}$ and Safety of Health Care Workers Unit, Ege University Hospital, Izmir, Turkey

\section{Aim and objective}

Our aim was to explore possible changes in the ratio of a university hospital's health professionals among patients applying to the smoking cessation clinic situated inside the same hospital and to compare the characteristics and procedure of these applicants with other cessation service users.

\section{Methods}

The smoking cessation clinic of the department of public health is situated among the outpatient clinics of Ege University Hospital and it is in operation since January 2016. In July 2017, the health and safety of health care workers unit of the hospital, which is another unit of the same department, has moved to the same location in the hospital. In August 2017, a public health specialist started working at the health and safety of health care workers unit and started to motivate health staff coming for periodic examinations to quit. Data on whether the applicants to the smoking cessation clinic were hospital staff has been recorded systematically from May 2017 on. The ratio of hospital staff among smoking cessation service users was compared in three-month intervals with the Chi square for trend analysis. The characteristics of hospital staff and other service users were compared with Chi square and Student $\mathrm{t}$ tests.

\section{Results}

Between May 2017 and June 2018, a total of 398 cessation service users' data were evaluated, among whom 76 (19.1\%) were the hospital's own staff. Only $5.8 \%$ of service users were hospital staff in May-June 2017 compared to $20.5 \%$ in July $2017-J u n e 2018$ ( $p=0.011)$, which gradually increased as $13.5 \%, 14.9 \%, 25.6 \%$ and finally reaching
$28.4 \%$ in April-June 2018 in three-month intervals, with a significantly increasing trend $(p<0.001)$.

The ratio of women was $59.5 \%$ among hospital staff using cessation services, as compared to $38.0 \%$ among others ( $\mathrm{p}=0.001)$. The mean age of the hospital staff using cessation services was $39.8 \pm 8.5$ and $40.1 \pm 13.9$ for others ( $p=0.837$ ).

The mean duration of the first appointment was $43.2 \pm 9.2$ minutes for hospital staff and $45.4 \pm 12.6$ minutes for other applicants ( $p=0.186)$. Among the hospital staff, the mean duration of the first cessation interview was $44.3 \pm 9.8$ minutes for health staff and $41.4 \pm 8.4$ minutes for other staff $(p=0.241)$.

\section{Conclusions}

Offering help to quit during periodic examinations and spatial vicinity to quit services seem to have significantly increased smoking cessation service use among health staff.

\section{Tob. Induc. Dis. 2018;16(Suppl 3):A65 DOI: 10.18332/tid/94911}

The status of smoking cessation according to anxiety, depression and addiction level of patients

Vildan Mevsim, Leyla Doğan, Aylin Demirci, Çiğdem Alkan, Ceren Akkol

\section{Introduction}

Smoking addiction is an important and preventable health problem. 16 million people are smokers in Turkey and 100,000 people die annually due to smoking-related health problems. In smoking cessation programs, assessment of addiction, motivational therapy, pharmacological, nonpharmacologic therapies and regular follow-up are recommended.

The aim of this study was to investigate the anxiety, depression and addiction level of patients who applied to the smoking cessation polyclinic of our university family medicine department.

\section{Methods}

Socio-demographic information, cigarette use cases, abstinence experience, depression, anxiety and addiction level were evaluated by 128 cigarette patients aged 18 years or older who applied to the Smoking Cessation Policlinic of the Medical Faculty of Dokuz Eylul University Medical Faculty between 1 March 2014 and 1 March 2015.

\section{Conclusions}

Nicotine dependence level was very low in $7.8 \%$, low in $18.0 \%$, moderate in $14.1 \%$, high in $26.6 \%$ and very high in $32.8 \%$ of the participants. Depression was detected in $33.6 \%$ of the participants and anxiety was present in $36.7 \%$. The proportion of non-smokers was $21.9 \%$ a year after the participants started treatment. When depression, anxiety and addiction levels were compared with smoking cessation status; there was no statistically significant difference between depression, anxiety and addiction level and smoking cessation rate.

\section{Tob. Induc. Dis. 2018;16(Suppl 3):A66 DOI: 10.18332/tid/94912}

Do the features of smoking cessation service users change during governmental drug donation period?

Seyfi Durmaz', Raika Durusoy¹, Hür Hassoy'1, Ișıl Ergin'1, Aliye Mandıracıoğlu'

${ }^{1}$ Department of Public Health, Ege University Medical School, Izmir, Turkey
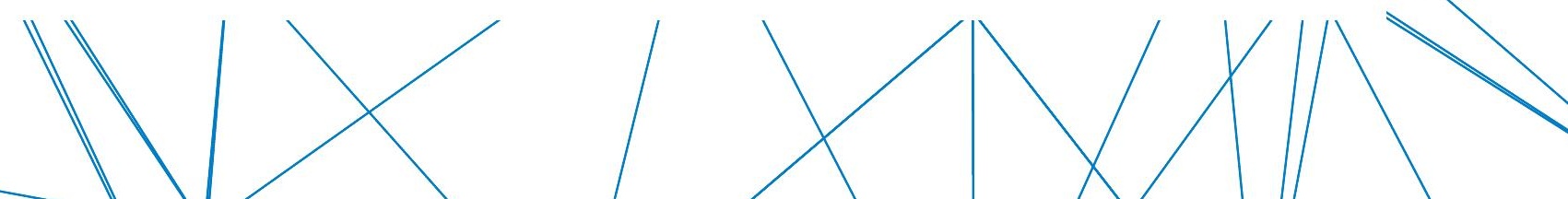


\section{Aim and objective}

The Ministry of Health of Turkey have led different smoking cessation drug delivery programs throughout different years. The last donation program provides Varenicline and nicotine patch. The aim of this study was to compare the features of service users attending to Ege University Public Health Department's smoking cessation outpatient clinic during the Ministry of Health's drug donation period and the period without donation.

\section{Methods}

All attendees ( $n=353$ ) to Ege University Public Health Department's smoking cessation outpatient clinic during January-June 2017 (period of no donation) and JanuaryJune 2018 (the latest period with governmental drug donation) were included in this cross-sectional study. The socio-demographic characteristics lage, gender, marital status, education, social class), smoking parameters (daily consumption, pack-years, nicotine-dependency level, previous quitting experience and number), health status (depression score, a physician's advice, presence of a chronic disease) and their treatment (drug choice, counselling duration) were compared in these two different periods. The chi-square and independent samples Student $t$ tests were used for analyses.

\section{Results}

Among all attendees, 140 (39.7\%) were women and their mean age was $39.6( \pm 12.6)$, with $76.2 \%$ graduated from high school.

Among participants, 167 (47.3\%) had applied during the period without donation, versus $186(52.7 \%)$ during the donation period. During the donation period, $83.5 \%$ of attendees had high school and over educational attainment versus $72.2 \%$ in the period with no donation ( $p=0.011)$. Among women, regarding social class, white collar patients have admitted more during the drug donation period $(p=0.026)$. The prescription of varenicline had significantly increase during the donation period $121.0 \%$ versus $61.8 \%, p<0.001$.

There was no significant difference for other sociodemographic variables (age, gender, marital status), smoking parameters (daily consumption, pack-years, nicotine-dependency level, previous quitting experience and number), health status (depression score, a physician's advice, presence of a chronic diseasel and duration of counselling ( $p>0.05)$.

\section{Conclusions}

Free-of-charge delivery of smoking cessation drugs through the ministry has successfully reached the moreeducated and better social class smokers with a tendency to quit. More efforts should be made to reach disadvantaged groups in the community.

\section{Tob. Induc. Dis. 2018;16(Suppl 3):A67 \\ DOI: 10.18332/tid/94779}

Stopping smoking prior to elective hip and knee surgery: the impact of visiting a community pharmacist for tobacco management

Barry Finegan 1 , Fadi Hammal' 1 , Lauren Beaupre ${ }^{2}$ 'Department of Anesthesiology and Pain Medicine, University of Alberta, Edmonton, Canada, ${ }^{2}$ Department of Physical Therapy, University of Alberta, Edmonton, Canada

\section{Aim}

To have patients quit smoking prior to elective total joint arthroplasty surgery.

\section{Objective}

Smokers have twice the rate of deep surgical site infections and three times the rate of readmission to hospital after arthroplasty than non-smokers. We assessed the impact of patients obtaining counselling and medical management for their nicotine addiction by visiting a pharmacist in their community on short and long term quit rates.

\section{Methods}

After ethics approval and written informed consent patients attending a pre-surgical assessment clinic were recruited to participate in a pharmacy delivered smoking cessation program. Patients watched a surgery specific video education about the program and smoking status was validated by exhaled $\mathrm{CO}$ determination at 30 days after program participation and by self-reported smoking status at 6 months obtained by telephone follow up.

\section{Results}

103 out of $286(36 \%)$ patients approached agreed to participate in the community pharmacist program. $52 \%$ were female with a mean age (SD) of 59 (8.4) years. Mean (SD) Fagerstrom score was 4.0 (2.2) and years smoked 36.9 (11.3). $79 \%$ had tried to quit previously. Despite all participants agreeing to see a pharmacist only $58 \%$ attended for a visit. The validated 30-day and 6-month continuous abstinence rate was $16 \%$ and $18 \%$, respectively for those who saw a pharmacist vs. $2 \%$ for non-participants.

\section{Conclusion}

Participation in this study and the pharmacy visit was voluntary. The participation rate was low but for those motivated to participate and to visit the pharmacist and receive treatment and counselling the short and long terms outcomes were significant. Mandating at least a single visit to a pharmacy-driven smoking cessation program for all patients undergoing joint arthroplasty seems worth exploring to enhance smoking cessation prior to surgery.

\section{Funding}

Global Research Award for Tobacco Dependence - (GRAND) - Pfizer.

\section{Tob. Induc. Dis. 2018;16(Suppl 3):A68 DOI: 10.18332/tid/94559}

\section{Ethiopian health care delivery system's responsiveness to smoking cessation therapy and its predictors: A mixed method study in Ethiopia \\ Temesgen Tamirat \\ 'Wachemo University, Hossana, Ethiopia \\ Introduction}

Tobacco is one of the leading public health burdens, killing six million people globally each year. The health system and health care providers can play a major role in tobacco cessation interventions to their patients. But Ethiopian health systems responsiveness level and care providers knowledge, attitude and practice level were not well understood.

\section{Objective}

To assess health care delivery system's responsiveness to smoking cessation services and its associated factors in Ethiopia.

\section{Methods}

A cross sectional study was employed both quantitative and qualitative methods. The quantitative study was used to determine knowledge, attitude, and practice of health workers with a sample of 323 . SPSS software was used for analysis. Qualitative data that was collected from key informants and transcribed translated and thematized.

\section{Results}

Majority of the health care providers had poor knowledge
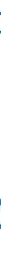
and negative attitude and below average level of practice towards providing cessation intervention.

In the multivariate analysis; being female, receiving training, having good knowledge score, and having positive attitude were associated with the above average practice. Data from the key informants indicated that no wellorganized and established system in Ethiopia.

\section{Conclusions}

Ethiopian health care providers were with poor knowledge, negative attitude and below average level of practice and medications are not in the essential drug lists of the country. Therefore, ministry of health should introduce tobacco dependence treatments in the health care system and strengthen existing weak behavioral counseling intervention.

\section{Funding}

Funding source was center for Tobacco Control in Africa and International Development Research Centre.

\section{Tob. Induc. Dis. 2018;16(Suppl 3):A69 DOI: 10.18332/tid/94774}

\section{ORAL IEALTI AND TOBACCO 2}

\section{Smoking alters the normal transcriptome of healthy human gingiva \\ Yun Wang ${ }^{1}$, Dimitris Tatakis \\ 'Division of Periodontology, College of Dentistry, The Ohio State University, Columbus, USA}

\section{Aim}

Smoking is a major risk factor for periodontitis and has been shown to impact the oral microbiome, as well as the host. However, studies on the effect of smoking on the transcriptome of healthy normal gingiva are lacking. The purpose of this study was to analyze the effects of smoking on the normal healthy human gingiva transcriptome.

\section{Methods}

Palatal biopsies, in the form of a harvested connective tissue graft, were obtained from periodontally healthy smokers and non-smokers in a prospective, experimental study. Smoking status was determined by self-reporting $1 \geqslant 10$ cigarettes/day for $\geqslant 5$ years; never smoker) and verified biochemically (exhaled air $\mathrm{CO}$ and serum cotinine levels). Tissue samples were stored frozen until processed for RNA isolation. Following RNA preparation, gene expression was analyzed by next generation sequencing (RNASeq) and real-time PCR. Gene set enrichment/pathway analysis was also performed.

\section{Results}

Tissue specimens were obtained from 24 consented participants. Two smokers were found to have consistently low biochemical values ( $\mathrm{C} O$ and cotinine) and their samples were excluded. Therefore, transcriptome data were based on samples from 10 smokers and 12 non-smokers. 830 significantly $(p<0.05)$ differentially expressed genes were identified. Of those genes with $>2$ fold-change (FC) in expression, 98 genes were up-regulated and 151 were down-regulated. CYP1A1 was the most highly up-regulated gene (17.8 FC) and IL36A, DEFB4A, DEFB4B, and SPRR2F were the most highly down-regulated ( $\geqslant 8 \mathrm{FC}$ ) genes. Several among the significantly down-regulated genes (e.g., DEFB4A, DEFB4B, CCL20, s100A7A) are reportedly involved in innate immune responses and/or antimicrobial activity.

\section{Conclusions}

Smoking has a significant effect on the gingival transcriptome of normal human gingiva and it seems to negatively impact the ability of the tissues to defend against bacteria; this could partly explain the reported changes in the gingival microbiome of periodontally healthy patients.

\section{Funding}

This study was supported by the authors' institution.

Tob. Induc. Dis. 2018;16(Suppl 3):A70

DOI: 10.18332/tid/94762

Effects of smoking on periodontal health status: A retrospective study

Melike Demirayak', Bașak Kusakç Seker ${ }^{1}$

${ }^{1}$ Periodontology Department, Faculty of Dentistry, Eskișehir Osmangazi University, Eskișehir, Turkey

\section{Introduction}

Smoking, damages directly the periodontal tissues by the harmful substances it contains and indirectly by changing the host response against them. Although it is not yet a separate disease in the classification, smoking-related periodontal health statu has its own clinical character. Our aim in this study was to investigate the relationship between smoking intensity and periodontal tissues by clinical measurements.

\section{Methods}

In this retrospective study, 300 patients were selected randomly. These patients were divided into 3 groups according to smoking status: non- smokers $n=150$, light smokers $n=75$, high smokers $n=75$. Smoking status, bleeding on probing (BOP), plaque index (PI), calculus index (CI), probing depth, gender, age, education and oral hygiene habit had determined for each individual at their first application to our clinic. ANOVA analysis of variance ( $p<0.002$ ) and chi-square test were used in the statistical evaluations.

\section{Results}

The relationship between high smoking status and increased probing depth was statistically significant in our results ( $p<0.002)$. The relationship between smoking and plaque index is also statistically significant. However, the relationship between smoking and BOP, smoking and calculus index was not statistically significant.

\section{Conclusions}

Smoking has been shown to be a major risk for periodontal disease. The fact that smoking in not associated with BOP is evidence of reduction of tobacco in the gingival vascular inflammatory reaction. The effects of smoking on periodontal tissues depend on the number of cigarettes smoked daily. Lack of relationship between smoking and $\mathrm{Cl}$ may be relevant age and oral hygiene habit of individuals.

\section{Tob. Induc. Dis. 2018;16(Suppl 3):A71 \\ DOl: 10.18332/tid/94787}

The effect of smoking on peri-implant marginal bone loss in periodontally compromised patients

Pınar Meriç ${ }^{1}$, Önder Gürlek', Burcu Kanmaz², Nurcan Buduneli

'Department of Periodontology, School of Dentistry, Ege University, İzmir, Turkey, ${ }^{2}$ Department of Periodontology, School of Dentistry, Izmir Democracy University, Izmir, Turkey

\section{Aim and objective}

Using dental implants has become an established and widely used treatment option for fully and partially edentulous patients. Success in implant dentistry relies on the initial osseointegration and long-term implant stability. Smoking is one of the essential factors that may
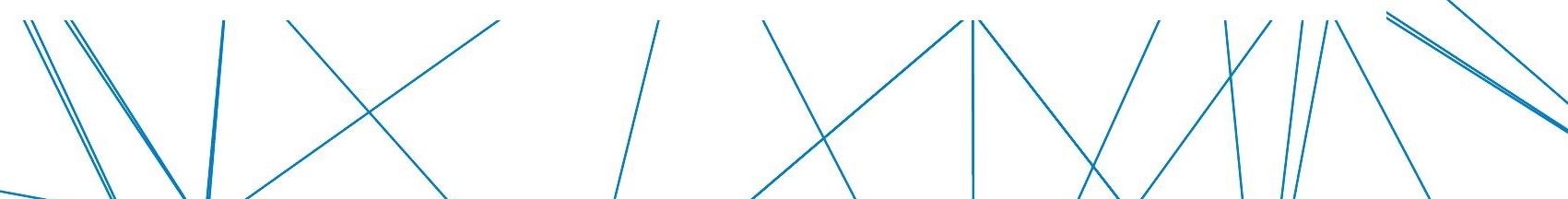
affect the success of implant stability. The aim of our study is to evaluate the effects of smoking on the success of dental implants in generalized aggressive periodontitis patients.

\section{Methods}

Totally, 32 implants were inserted in 13 generalized aggressive periodontitis patients, 7 were smoker and 6 were non-smoker. Demographic data was collected. Periimplant plaque index (PI), bleeding on probing (BOP), and probing depth (PD) were recorded. Marginal bone loss (MBL) was measured using standardized digital radiographs at baseline, 1 and 6 -months. Data were tested statistically using Kruskal-Wallis and Mann-Whitney $U$ tests.

\section{Results}

In initial osseointegation period, totally 2 implants were failed in the smoker group. 17 implants in non-smoker and the 13 implants in smoker group were evaluated. MBL was higher in the smoker group than nonsmoker both follow up periods, but the differences were not statistically significant at 1 and 6 - months $(p=0.784$ and $p=0.996$, respectivelyl.

\section{Conclusions}

Our short term findings emphasize that there is a relation in smoking and peri-implant marginal bone loss in periodontally compromised patients. Smoking is not a contraindication for dental implant therapy, however dentists should provide detailed information on the addiction-related risk of implant failure. Especially, patients should be informed that implant success is very much related to their compliance about smoking habits and a strict recall protocol.

\section{Funding}

This study was supported by Oral Reconstruction Foundation.

\section{Tob. Induc. Dis. 2018;16(Suppl 3):A72 DOl: 10.18332/tid/94863}

The ordering of smokers' criteria in choosing toothpaste with fuzzy dematel model

Ergün Tarım¹, Vildan Mevsim², Emel Kandemir ${ }^{3}$

'Department of Bioengineering, Izmir Institute of Technology, Izmir, Turkey, ${ }^{2}$ Family Medicine Department, Dokuz Eylül University, Izmir, Turkey, ${ }^{3}$ Computer Science Department, Dokuz Eylül University, Izmir, Turkey

\section{Aim}

Smokers give more harm to tooth and mouth flora than non-smokers. These conditions can affect the decision of smokers when buying toothpaste. Unlike non-smokers, expectations of toothpaste can vary. Regarding these, the aim of this study is to show which criteria are important to smokers in choosing toothpaste for dental health or related problems. These criteria are sorted according to their importance with the model to be applied.

\section{Methods}

The model applied in this study is Fuzzy DEMATEL (Fuzzy Decision-Making Trial and Evaluation Laboratoryl model. The model was used to determine the importance values of the criteria for toothpaste selection. The data were obtained from patients who smoked and who applied to outpatient clinic of Dokuz Eylül University Family Medicine Department.

\section{Results}

To put the toothpaste criteria in order of importance, the criterion selection results of smokers were taken from individual patients. With the data, the criteria in choosing
toothpaste were sorted from the most to the least important toothpaste were sorted from the most to the least important

with the Fuzzy DEMATEL model.

\section{Conclusions}

Today's personal care products directly affect the health of the individual. When providing these products, users consider not only the criteria for being healthy but also many other criteria. This effect is also observed in toothpaste, which is a specific product. The most important criterion in choosing toothpaste is that people have important data about dental care. Finding people's most important criteria in choosing toothpaste, important data about people's dental care are obtained.

\section{Tob. Induc. Dis. 2018;16(Suppl 3):A73} DOl: 10.18332/tid/94773

\section{Effect of smoking on long-term stability of} coronally advanced flap: 6-year follow-up Burcu Kanmaz', Mehmet Kanmaz², Bașak Kaval ${ }^{3}$, Nurcan Buduneli4

'Department of Periodontology, Faculty of Dentistry, Izmir Democracy University, Izmir, Turkey, ${ }^{2}$ Private CTG Oral and Dental Health Center, Izmir, Turkey, ${ }^{3}$ Karșiyaka Oral and Dental Health Center, Izmir, Turkey, “Department of Periodontology, Faculty of Dentistry, Ege University, Izmir, Turkey

\section{Aim}

Smoking is the strongest modifiable risk factor for periodontal diseases that also deteriorates the response to periodontal treatment. Mucogingival operations may also provide less successful outcomes in smokers. The aim of this study was to evaluate possible effects of smoking on long-term stability of root coverage using coronally advanced flap procedures in localized gingival recessions.

\section{Methods}

Six recession defects in each of the smoker and nonsmoker groups were evaluated in this study. Coronally advanced flap was performed with microsurgery technique. Probing depth, clinical attachment level, keratinized gingival width, plaque index, papilla bleeding index, recession depth, recession width, and root surface area were evaluated at baseline, and then postoperative 6-month, and 6-year follow-up sessions. Percentage of root coverage and complete root coverage were also calculated at postoperative controls. Data were analysed with appropriate statistical tests.

\section{Results}

All patients included in this study provided efficient plaque control and good oral hygiene level was maintained throughout the study protocol. Baseline clinical attachment level measurements revealed significantly higher values in the smoker group $(p<0.05)$. All other clinical measurements were similar in the smoker and non-smoker groups at baseline and also at 6-month and 6 -year control evaluations ( $p>0.05$ ).

\section{Conclusions}

This 6-year follow-up study suggests that smoking does not have a significant adverse effect on the long-term stability of root coverage as long as the patients maintained efficient plaque control.

\section{Funding}

This study was supported by a grant from the Ege University Research Foundation (Project No: 2010 DIS 004).

\section{Tob. Induc. Dis. 2018;16(Suppl 3):A74}

DOl: 10.18332/tid/94549 


\section{YOUTH AND TOBACCO 2}

Smoking status of students of medical school and factors affecting their smoking

Ulken Babaoglu'

'Department of Public Health, Faculty of Medicine, Ahi Evran University, Kırșehir, Turkey

\section{Aim and objective}

Tobacco epidemic among young people is defined as an important public health problem in developed and underdeveloping countries. Besides, the health problems brought by the cigarettes are not perceived enough by the adolescents and young people and they are ignored. The purpose of the study is to examine the smoking situation and the factors influencing students in a medical faculty.

\section{Methods}

This descriptive study covers a total of 126 students studying at a medical school between April and May 2018. $92.86 \%$ of the universe was reached. The data was collected by a questionnaire. Descriptive data are presented with percent, number, median. For further analysis, chi-square analysis was used.

\section{Results}

It was determined that those who participated in the study had a median age of 19.00 (min: 18.00, max: 24.00). 12.0\% of the participants stated that they used cigarettes, $31.6 \%$ said they tried but did not use it for a long time. 17.0\% stated that they use hookahs. It was found that $22.3 \%$ of smokers started smoking cigarettes at the median age of 17.00 (min: 9, max: 19), 31.3\% of them started stress and $21.9 \%$ of them started out of curiosity they said. Most of the smokers had fathers who smoked cigarettes. This was statistically significant ( $p=0.048)$.

\section{Conclusions}

Smoking rate increases in medical faculty students. It is suggested that medical students who will be role models as a medical doctor should be followed up in order to reduce the consumption of tobacco and get solved the reasons people start smoking.

\section{Tob. Induc. Dis. 2018;16(Suppl 3):A75 \\ DOI: 10.18332/tid/94908}

\section{Change in smoking frequency and affecting} factors among the students of a medical faculty in Ankara - Turkey: 2013-2016

Nihal Aykut ${ }^{1}$, Gülser Doğan', Elif Durukan', Ayșe Akın'1 ${ }^{1}$ Bașkent University School of Medicine, Department of Public Health, Ankara, Turkey

\section{Aims}

Tobacco use of healthcare professionals is a major problem in combating tobacco in Turkey. As being the physicians of the future, smoking behaviors of medical students are also important. The aim of this study is to determine the smoking prevalence and affecting factors of medical students as well as the change occurring during the study period at medical school.

\section{Methods}

This cross-sectional study was conducted among medical students at the XXX University, Ankara, Turkey in March 2013 and a similar study was repeated in March 2016. An anonymous, self-administered questionnaire was developed and used for data collection. In addition, Fagerström Test for Nicotine Dependence was applied to the current smokers. In 2013106 students, in 2016125 students participated to the study with enrollment rates of $84.8 \%$ and $100 \%$ respectively.

\section{Results}

In $2016,59.2 \%$ of the students attempted to smoke at least one puff, $34.4 \%$ had been regular smokers, $31.2 \%$ were current smokers. There was no statistically significant change in the smoking behavior of students during the period of 2013-2016. When all risk factors were evaluated together, it was determined that being a regular smoker was only affected by permission to smoke in the place of residence and the risk of being a current smoker is influenced by male sex and by permission to smoke in the place of residence.

\section{Conclusions}

More than half of medical students started smoking in their university lives. A need for effective preventive and ameliorative interventions during the medical school years is clear.

\section{Funding}

The study was supported by Bașkent University Research Fund.

\section{Tob. Induc. Dis. 2018;16(Suppl 3):A76} DOI: $10.18332 /$ tid/94778

\section{Smoking status of medical students at Ege University: A cross-sectional survey of 1040 students in 2018}

Emine Karakaș ${ }^{1}$, Aysun Zümbül ${ }^{1}$, Tuğrul Balatacı' ${ }^{1}$, Raika Durusoy', Görkem Yararbaș², Özen Bașoğlu ${ }^{3}$, Cemil Gürgün ${ }^{4}$

${ }^{1}$ Department of Public Health, Faculty of Medicine, Ege University, Izmir, Turkey, ${ }^{2}$ Institute on Drug Abuse, Toxicology and Pharmaceutical Science, Ege University, Izmir, Turkey, ${ }^{3}$ Department of Chest Diseases, Faculty of Medicine, Ege University, Izmir, Turkey, ${ }^{4}$ Department of Cardiology, Faculty of Medicine, Ege University, Izmir, Turkey

\section{Introduction}

We aimed to determine the smoking prevalence and related factors among 1,2,3 and 6th grade students at Ege University Faculty of Medicine.

\section{Methods}

This cross-sectional survey was a part of a multi-centre study throughout Turkey and the data were collected in May-June 2018. The target group of this study was 1537 medical students studying in the first, second, third and sixth grades. Questionnaires were applied to 1040 students $(67.7 \%)$ who agreed to participate in the study. The coverage was $94.5 \%, 78.6 \%, 57.4 \%, 36.7 \%$ for the first, second, third and sixth grades, respectively.

\section{Results}

The overall prevalence of smoking was $18.4 \%$, with $18.1 \%$, $18.6 \%, 17.0 \%$ and $22.1 \%$ in the first, second, third and sixth grades, respectively. The mean age at starting to smoke was $16.5 \pm 2.3$ yrs (min.8, max.23). Current smoking was more prevalent in males compared to females $124.3 \%$ vs. $11.7 \%, p<0.001$ l. Among current smokers, $27.4 \%$ had started smoking during medical school. The most common reasons for starting to smoke were the effects of close friends $(37.1 \%)$ and stress $(19.2 \%)$. Current smokers spend 201 \pm 139 Turkish Liras (min.0, max.800) monthly for cigarettes. Among smokers, $60.4 \%$ have tried to quit smoking at least once, and $78 \%$ of them thought of smoking cessation. Among e-cigarette users, 93.6\% were ever-smokers.

According to univariate analyses; male students, students whose parents, partners or best friends were eversmokers, students living alone and the ones who have smoked hookah at least once have significantly higher prevalence of being ever-smokers compared to their
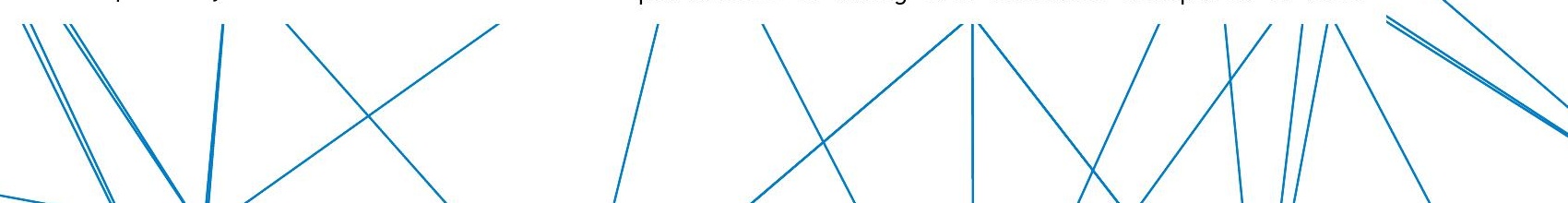
counter-parts. In multivariate analyses; having the hookah use (OR:12.4), living alone at home (OR:3.4), partner (OR:2.3) or best friend (OR:1.9) smoking, and were found to be independent risk factors related to being an eversmoker.

\section{Conclusions}

The present study shows that the prevalence of smoking in especially male medical students was high $(24.3 \%)$ in Turkey, and nearly one third of the students started smoking during medical faculty. Therefore, there is a need to include intensive education programs regarding smoking-related health problems and smoking cessation at an early stage in the medical curriculum.

\section{Tob. Induc. Dis. 2018;16(Suppl 3):A77 \\ DOl: $10.18332 /$ tid/94780}

Parent smoking behavior and children's future development: evidence from Indonesia Family Life Survey (IFLS)

Teguh Dartanto ${ }^{1}$, Faizal Moeis ${ }^{1}$, Renny Nurhasana ${ }^{2}$, Aryana Satrya ${ }^{2}$, Hasbullah Thabrany ${ }^{3}$

${ }^{1}$ Department of Economics, Faculty of Economics and Business, Universitas Indonesia, Depok, Indonesia, ${ }^{2}$ Center for Social Security Studies, Universitas Indonesia, Depok, Indonesia, ${ }^{3}$ Faculty of Public Health, Universitas Indonesia, Depok, Indonesia Indonesia is the real champions of smoking with nearly $32 \%$ of the adult populations are smokers. The prevalence of youth smoking has jumped more than fourfold during last two decades. This calls for serious effort on tobacco controlling. A high prevalence of tobacco consumption may have an adverse consequence for the future socioeconomic condition of household especially for children development. Since tobacco is addictive consumption, household often reduce other consumption to fulfil the elderly's consumption of tobacco. As many cases that children are likely powerless in the household decision making, elderly who over controlled consumption's decision might prioritize their tobacco consumption instead of investing on children development such as education, health, quantity and quality of food. This study utilize a longitudinal dataset of Indonesia Family Life Survey (IFLS) aims at evaluating the impacts of parent smoking behavior on stunting indicated by children's weight and height growth. An increase in tobacco consumption around two percentage point (19972014) has been compensated by a decrease in expenditure share of rice, protein and fat sources of food and education. These kinds of expenditure will significantly influence the children's future development in terms of weight, height and cognitive ability. Based on our observation of children ( $<=5$ years old) of IFLS 2007 \& 2014, we found that children living in household with chronic smoker as well as with transient smoker tend to have slower growth in weight and height compared to those living in household without smoker. Our study statistically confirmed that children living with non-smoking parent will grow $1.5 \mathrm{~kg}$ heavier than those living with chronic smoker parent. Active/chronic smoker tends to have a high probability of stunted kids. This finding provides valuable evidence that controlling tobacco consumption will not only reduce the prevalence of smoking but also will make a better future of Indonesia.

\section{Funding}

Campaign Tobacco-Free Kids

Tob. Induc. Dis. 2018;16(Suppl 3):A78

DOI: 10.18332/tid/94561
Tobacco smoking imagery in Nigerian musical videos; A four year retrospective review

Abayomi Adeosun', Olurogba Badewo', Adebisi Adenipekun', Moyosore Taiwo', Joshua Awogbemi² ${ }^{1}$ Lighthouse Global Health Initiative, Osogbo, Nigeria, ${ }^{2}$ Obafemi Awolowo University, Ife, Nigeria

Aim

Tobacco advertisement has been banned in mainstream media, however, contents endorsing smoking are still accessible to people, mostly adolescents, through uncensored online media platforms. This research aimed at evaluating tobacco content in Nigerian musical videos.

\section{Methods}

Top 50 videos of each year from 2014 to 2017 were reviewed independently by two researchers who checked for parameters including: antismoking message, imagery of male, female or group smoking, and imagery of soft core sexual content associated with cigarette smoking. A total of 200 videos were reviewed. The videos were sourced from Youtube according to ratings by AfricaCharts. AfricaCharts rates videos based on TV and radio airplay, record sales, streaming platforms, social media, song and video downloads from top African entertainment sites, as well as YouTube and Dailymotion views.

\section{Results}

About $22(11 \%)$ and 7 (3.5\%) videos, with 322 million combined views had imagery of male and female smoking respectively. Videos containing male smoking imagery increased by $150 \%$ between 2014 and 2017 . Three (1.5\%) videos had imagery of smoking associated with sex appeal while $5(2.5 \%)$ videos contained people smoking in groups. Only 1 video $(0.5 \%)$ with about 5.6 million views contained antitobacco smoking message. A female artiste featured smoking imagery the most.

\section{Conclusions}

Smoking imagery is contained in few Nigerian musical videos; however, its appearance is on the increase. Given the wide acceptance of Nigerian music among African youths, it may be necessary to regulate smoking imagery content of the musical videos to contain its influence on the youths.

\section{Funding}

The study was funded by the authors.

\section{Tob. Induc. Dis. 2018;16(Suppl 3):A79 DOI: 10.18332/tid/94874}

\section{Marginal effects of determinants of smoking} participation among young adults in Kenya: A by gender logistic regression analysis

Peter Kipkorir, Vincent Ngeno' ${ }^{1}$, Jared Mose ${ }^{2}$, Patrick Saisi ${ }^{3}$ ${ }^{1}$ Agricultural Economics and Resource Management, Moi University, Eldoret, Kenya, ${ }^{2}$ Agricultural Economics and Resource Management, ${ }^{3}$ Economics, Moi University, Eldoret, Kenya

Smoking causes a huge health and economic burden to society; this effect is even more pronounced for a developing country like Kenya. Despite the fact that tobacco use is preventable, the number of tobacco related deaths in Kenya is still a health challenge. Every year, more than 6,000 Kenyans die of tobacco induced diseases, while approximately 220,000 children and almost 2.7 million adults continue to smoke each day. Objectively, this study focused on the analysis of marginal effects of determinants of smoking participation among young adults in Kenya. It employed data from Kenya GATS 2014. Specifically, Logistic regression analysis was done on both young male and female adults smoking participation.

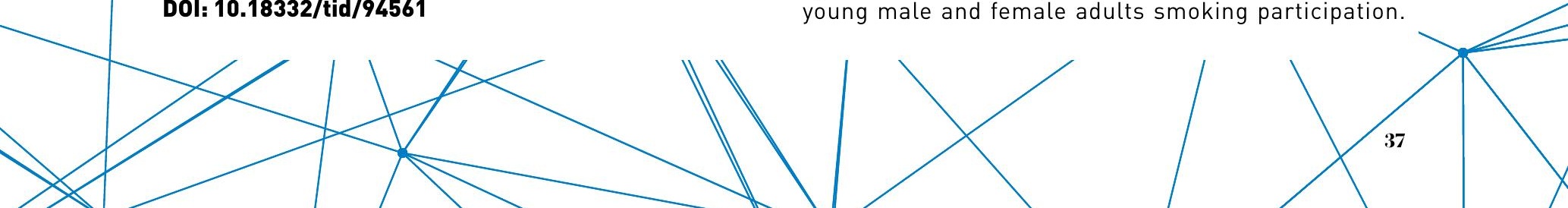


The study revealed cigarette prices had a marginally and reducing significant effect on the likelihood of young male $(B=-0.00383, \rho<0.001)$ and female $(B=-0.00003, \rho<0.050)$ adults participation in smoking while tax on cigarette, evidently, had a significant $(\rho<0.001)$ and reducing marginal $(B=-0.1198$ ) effect on the young male decision to smoke as compared to young female decision to smoke. Education also had a significant and decreasing marginal influence on the tendency of young male $(B=-0.03986, \rho<0.001)$ and female $(B=-0.00003, \rho<0.050)$ adults decision to smoke. Employed young adults showed to have a declining and significant $(\rho<0.000)$ marginal effect on their smoking participation. Therefore, price and tax on cigarette are very effective measures in reducing smoking participation among young male and female adults in Kenya.

\section{Funding}

This research was funded by the Center for Tobacco Control In Africa in collaboration with International Development and Research Center as Tobacco Control Project Grant.

Tob. Induc. Dis. 2018;16(Suppl 3):A80

DOl: $10.18332 /$ tid/94860

\section{POLICY AND TAXATION 2}

Tobacco control and prevention from the point of civil society

Osman Altay ${ }^{1}$

'Turkish Green Crescent Society, Istanbul, Turkey

\section{Introduction}

This study assessed the correlation between tobacco control media campaigns and tobacco control violations reporting by people.

\section{Methods}

Study data derived from the user and violation reporting numbers gathered from Green Detector Mobile Application which is has been designed in such a way that enables the users to report a violation without having to use his/her name. Weakly changes in these figures are compared with media campaigns aiming at rising awareness on tobacco control.

\section{Results}

Change in the number of downloads and users is in positive correlation with the broadcasting of the public ads on the tobacco control.

\section{Conclusions}

Tobacco control legislation in Turkey is aligned with international standards. However, rights of non-smokers are violated at public places such as restaurants and cafes. The ban on smoking indoors is stretched by such businesses in practice. Therefore, the non-smokers are still subjected to second-hand smoke at those places. In that regard, public awareness must be improved on and non-smokers must be reminded of the harms of secondhand smoke.

\section{Funding}

Turkish Green Crescent Society.

\section{Tob. Induc. Dis. 2018;16(Suppl 3):A81}

DOI: 10.18332/tid/94867

\section{EUREST-FLAVOURS: European Regulatory}

Science on Tobacco to support the assessment of characterising flavours in tobacco products

Constantine I. Vardavas ${ }^{1}$, Christina Kyriakos², Aristidis Tsatsakis ${ }^{3}$, Alexander I. Vardavas ${ }^{1}$, Manolis Tzatzarakis ${ }^{4}$ ${ }^{1}$ University of Crete, Heraklion, Greece, ${ }^{2}$ School of Medicine,
University of Crete, Heraklion, Greece, ${ }^{3}$ Department of Toxicology \& Forensic Sciences, Faculty of Medicine, University of Crete, Heraklion, Greece, ${ }^{4}$ Laboratory of Toxicology, School of Medicine University of Crete, Heraklion, Greece

\section{Aim and objective}

The European Union (EU) Tobacco Product Directive (TPD) concerning the manufacture, presentation and sale of tobacco and related products states in Article 7.1 that Member States (MS) shall prohibit the placing on the market of tobacco products with characterising flavours. The objective of the EUREST-FLAVOURS project is provide services to the European Commission (EC) to support the assessment of characterising flavours in tobacco products. Methods

Using a comprehensive approach for tobacco product testing, the proposed methodology will be based on a comparison of the smelling properties of the test products with those of reference products, complemented, as appropriate, by a chemical assessment of the product composition through chemical analyses.

\section{Results}

The results of the EUREST-FLAVOURS project will culminate in a clear science-based decision criteria to support the EC in the development of uniform rules for the procedures to determine whether a tobacco product imparts a characterising flavour.

\section{Conclusions}

The EUREST-FLAVOURS project, through the specification of the methodology for sensory analyses and setting up a sensory 'Technical group', which will assist an 'Independent advisory panel', will ultimately support the EC and MS in the implementation of legislation and policies in the area of tobacco and related products, in particular in relation to the provisions regarding the prohibition of products with characterising flavours foreseen in Article 7 of the TPD.

\section{Funding}

The EUREST-FLAVOURS Project takes place with the financial support of the European Commission Single framework Contract Chafea/2016/Health/36. The content represents the views of the EUREST-FLAVOURS Consortium and is its sole responsibility; it can in no way be taken to reflect the views of the European Commission and/or Chafea or any other body of the European Union.

\section{Tob. Induc. Dis. 2018;16(Suppl 3):A82}

DOl: 10.18332/tid/94776

Tobacco control South South Cooperation as a powerful tool to achieve health related issues in the 2030 Agenda

Diogo Alves

${ }^{1}$ World Health Organization, Brazilian Country Office, Brazil

\section{Introduction}

Tobacco use is one the four main behavioral risk factors for Non Communicable diseases (NCDs). Addressing other risk factors requires many of the same approaches, as does addressing tobacco control. NCDs and tobacco share persistent lack of development assistance and financing shortages. Thus, SSTC on tobacco control could be applied to help countries prevent and control NCDs.

\section{Intervention}

Highlight results from SSTC for tobacco control and position it as a high-value means of implementation for the Sustainable Development Goals (SDG). Raise awareness and strengthened support and partnerships for SSTC work on tobacco control and NCDs, and better understand of how best to leverage SSTC for other global health challenges. Methodology: Examine the potential to scale up initial
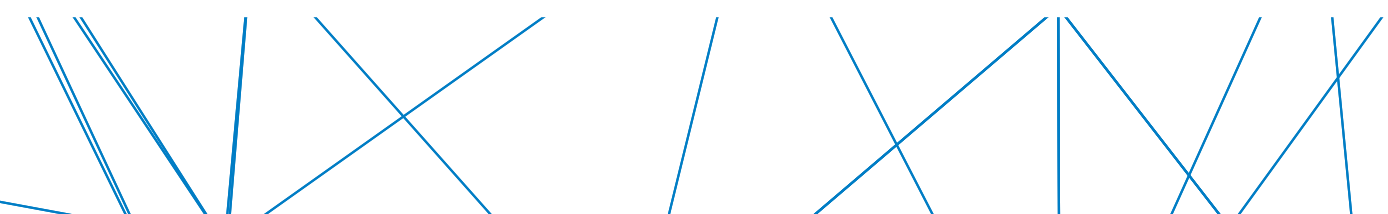
smuggling in the Eastern Mediterranean Region. Tow cigarette pack survey in Tehran, were done in 2009 and 2015 which were showed that illicit cigarettes used rate were $20.9 \%$ and $15.4 \%$ respectively. We designed this study to update trends in the illicit cigarette trade in Tehran.

\section{Methods}

A cross-sectional study of 2331 smokers aged 15 years and over was conducted in Tehran in January 2018. The sampling method was the same as previous studies. Smokers were asked to show the interviewers their current pack of cigarettes, which was categorised as either: (1) legal cigarettes: displaying governmental pictorial warning and hologram or (2) illegal cigarettes: with no governmental labeling. The packs were also categorised as either domestic (a Persian brand name) or foreign (a foreign brand name).

\section{Results}

The sample included 1827 males $(78.3 \%)$ and had a mean age of $40.3 \pm 12.1$ years. In total, 1427 smokers (61.2\%) had foreign and 904 (38.8\%) had domestic cigarettes; 2072 $(88.9 \%)$ had legal cigarettes and $259(11.1 \%)$ had smuggled cigarettes. There was a statistically significant difference in the use of smuggled cigarettes and foreign cigarette by younger smokers $(36.8 \pm 3.1 v s \quad 42.9 \pm 5.3$ years) ( $p<0.001$ ) Marlboro was the only smuggled cigarette brand (259 packs; $100 \%$ ).

\section{Discussion}

The lower prevalence of illicit cigarettes in Tehran in 2018 compared to previous studies may be due to the control and monitoring on legal cigarettes distribution. All other foreign cigarette brands except Marlboro were imported legally or had legal joint production.

\section{Tob. Induc. Dis. 2018;16(Suppl 3):A86 DOI: $10.18332 /$ tid/94528}

The factor structure and factorial invariance of short form of smoking temptation for TTM framework in Iranian smoker population:

\section{Golestan Province}

Abdurrahman Charkazi', Bagher Pahlavanzadeh², Rahman Ozouni- Davaji ${ }^{3}$, Gholamreza Sharifirad ${ }^{4}$, Alireza Abadi ${ }^{5}$ ${ }^{1}$ Environmental Health Research Center, Golestan University of Medical Sciences, Gorgan, Iran, ${ }^{2}$ Department of Biostatistics, Shahid Beheshti University of Medical Sciences, Tehran, Iran, ${ }^{3}$ Health Management and Social Development Research Center, Golestan University of Medical Sciences, Gorgan, Iran, ${ }^{4}$ School of Health, University of Medical Sciences, Qom, Iran, ${ }^{5}$ Social Determinants of Health Research Center, Department of Community Medicine, Shahid Beheshti University of Medical Sciences, Tehran, Iran

\section{Purpose}

TTM pattern has widely been used in smoking cessation interventions. This study was aimed to investigate the compatibility of a hierarchical factor structure of short form questionnaire developed by Velicer et al regarding situational temptation construct among smokers in Golestan province.

\section{Methods}

A cross-sectional study was conducted on 387 smokers that were included using inconvenient sampling method. At first, internal validity and reliability of the short-form questionnaire were examined. At second, invariance of hierarchical structure was tested in sub-groups of ethnicity, residence, education, stage of quit, starting age, and income. Measurement invariance lincluding five invariances) and structural invariance (including three invariances) were explored in each sub-group.

\section{Results}

Chi-square test for confirmatory factor analysis of hierarchical factor structure was statistically significant for all samples $\left[x^{\wedge} 2(24)=66.3, p<0.001\right]$; while, other indicators reveled the good compatibility of factor structure (CFI=0.944, TLI=0.915, RMSEA $=0.067((0.048,0.087))$ and SRMR $=0.042$ ). Values of the first order of factor loading were between 0.5 and 0.84 . There was strong correlation between first order factors and second order factor such that it was 0.9 for positive and habitual social situations factors and 0.82 for negative effects factor. Cronbach's alpha coefficient for the whole model was also 0.803 .

\section{Conclusions}

Given the findings, hierarchical factor structure of shortform inventory about temptation to cigarette smoking was confirmed by three factors that were in line with Velicer et al model. The fitting indices of the model presented that construct validity was observed in all samples and sub-groups, and can be likely used in smoking cessation programs.

\section{Funding}

Golestan University of Medical Sciences, Gorgan, Iran

Tob. Induc. Dis. 2018;16(Suppl 3):A87

DOI: 10.18332/tid/94530

\section{Hukah smoking and lung cancer in Kashmir}

Mohd Altaf Dar ${ }^{1,2}$

${ }^{1}$ Department of Health Services, Kashmir, India, ${ }^{2}$ Voluntary Health Association of India, New Delhi, India

\section{Background}

The literature about the causal relationship between lung cancer and tobacco smoking mostly concerns cigarettes. Hookah smoking is popular in the Kashmir valley, and is generally believed to be innocuous because of the passage of the smoke through water before inhalation. Hookah smoking is widely practiced in Kashmir and was found to be the commonest form of smoking amongst the patients with lung cancer. An earlier study from Kashmir also reported hookah smoking as the dominant form of smoking in a small cohort of 25 lung cancer patients.

\section{Methods}

The study was conducted in the Sheri Kashmir Institute of Medical Sciences, Kashmir (India), a 650 bedded tertiary care university hospital that serves as the main referral center for the Pulmonary and Oncology cases of the Kashmir valley of the Indian subcontinent. Predesigned questionnaire in locally understandable language was tested and validated in a cohort of 10 cases of lung cancer and 20 controls and subsequently administered to the study cases and controls.

\section{Results}

Study provides evidence that hookah smoking is associated with an increased risk of lung cancer in ethnic Kashmiri population with the risk being 6 times more as compared to non smokers. The study reaffirms the previous report by Nafae et al in the sixties who found hookah smoking as the commonest form of smoking in a cohort of 25 patients of lung cancer, seen in 20 of the 25, being exclusive in 17 . Hookah smoking has since the olden times been the major form of smoking in Kashmir and is nearly the exclusive form of smoking in women lall of our female smokers had a history of hookah smokingl.

\section{Conclusions}

Hookah smoking in Kashmir is associated with increased risk of lung cancer and the commonly held belief that passage through water renders the smoke harmless seems ill founded and potentially danqerous. Further
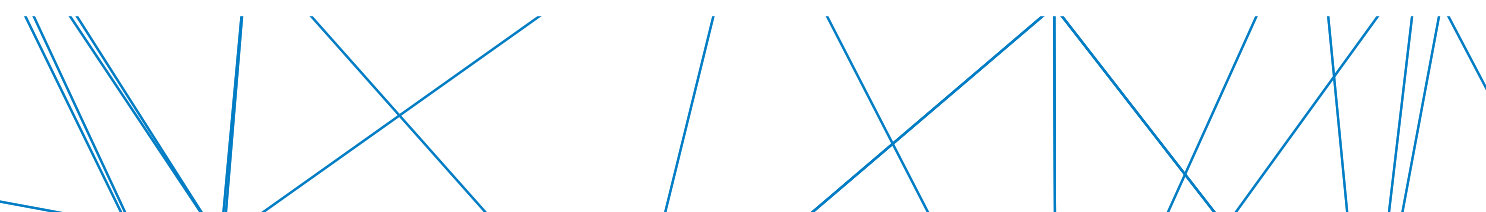
studies in this regard are warranted so as to fully analyze the various variables associated with the habit of hookah smoking and associated development of lung cancer.

\section{Tob. Induc. Dis. 2018;16(Suppl 3):A88}

DOl: 10.18332/tid/94535

\section{Children and youth exposure to tobacco products in Ghana \\ Hajara Musah}

'Vision for Alternative Development (VALD), Accra, Ghana

\section{Background and Challenges to Implementation}

Ghana Global Tobacco Youth Survey (2009) showed that $8.9 \%$ of students had ever smoked cigarettes and $12.5 \%$ currently use any tobacco product. Public Health Act 2012 bans tobacco advertisement close to school and children playing ground and sales to and by minors. The law has been violated. Cigarettes are sold closed to schools, children play ground and children buy and sell. Retailers are not aware of the laws. SDGs will not be achieved if children are not protected.

The project sought to draw attention to the violations of the law and to ensure that children are protected from tobacco.

\section{Intervention/response}

Data were collected in some selected communities in Greater Accra targeting aged 15-18 years to ascertain the level of compliance to cigarette sales to and by minor and sales close to schools as enshrined in the law. Retailers and community members were interviewed. The findings of this exercise was shared with stakeholders.

\section{Results/Outcomes}

Out of 10 retail shops, 7 indicated were not aware of the laws banning sales to and by minors and 3 knew about the law. 5 out of the 10 shops sells to children but enquires who sent them, 3 sell to children without enquiring and 2 do not sell to children. 7 out of the 10 shops sell close to schools and 3 do not. 6 out of 10 displays cigarette on the counter visible to children.

\section{Conclusion/Recommendation}

Community members were not aware of the law on tobacco control. School going children are exposed to tobacco. Retailers and community member have been sensitized on the tobacco law.

Effort must be made to intensifyawareness on the provisions of the law. Set-up taskforce to monitor compliance of the law. Conduct further research and findings on the children exposure to tobacco.

\section{Tob. Induc. Dis. 2018;16(Suppl 3):A89 \\ DOl: $10.18332 /$ tid/94536}

\section{Factors associated with the initiation of hookah} smoking among women

Shirin Sighaldeh¹, Abdurrahman Charkazi², Mahnaz Amani $^{3}$, Tayyebeh Ostovan ${ }^{3}$, Elmira Manglizadeh ${ }^{3}$

${ }^{1}$ Reproductive Health Department, School of Nursing and Midwifery, Tehran University of Medical Sciences, Tehran, Iran, ${ }^{2}$ Environmental Health Research Center, Golestan University of Medical Sciences, Gorgan, Iran, ${ }^{3}$ School of Health, Golestan University of Medical Sciences, Gorgan, Iran

\section{Introduction}

Currently, smoking hookah is the most common method of tobacco smoking among Iranian women and its rate has significantly increased over the past few decades. Many factors influence the start of hookah smoking among women. Therefore, this study aimed to determine the factors associated with the start of hookah smoking among women in the city of Gorgan, Iran.

\section{Methods}

This cross sectional study was conducted from March to June 2016 in the city of Gorgan. The participants consisted of 206 hookah smoking women who were selected by convenience and snowball sampling methods. The tool used in this study was the Bahiraei et al (2014) questionnaire to determine the factors that facilitate the start of hookah consumption among women.

\section{Results}

Positive attitudes towards hookah and its availability accounted for the most frequency $(9 / 87 \%)$. Curiosity to experience hookah (80.1\%), and hookah smoking among family members and relatives $(78.5 \%)$ were among important cause of hookah smoking among women. Among different factors, the highest amount was related to "the availability of hookah" and the lowest amount was related to "attracting other's attention and cooperation".

\section{Conclusions}

Positive attitude, availability, curiosity and hookah smoking among family members and relatives were the most important factors that facilitated the start of hookah smoking among women. Initiating intervention to change the attitude of women towards hookah and reducing the access to hookah in family and friend gatherings are recommended to prevent the initiation of hookah smoking among women.

\section{Funding}

Golestan University of Medical Sciences, Gorgan, Iran.

\section{Tob. Induc. Dis. 2018;16(Suppl 3):A90}

DOl: 10.18332/tid/94538

Violence and power in the absence of tobacco control in prison environments

Alex Kornalewski ${ }^{1}$

'Fundação Oswaldo Cruz, Rio de Janeiro, Brazil

It discusses the policy of controlling smoking in prisons, specifically regarding the legal gap that implies in the absence of public policies aimed at controlling tobacco and other drugs in these environments, on the grounds that these spaces are already under the norms of the Law No. 7,210, which establishes the Criminal Enforcement Act (LEP). Aims to reflect on the absence of tobacco control policies in prison institutions, specifically, those who are under the authority of the State. The methodological procedure is applied from a conceptual review of the effects of violence and power that allow the construction of this absence of smoking control in prisons, in addition to analyzing interviews of prisoners and security inspectors offered through projects already completed and news made available in the Observatory on the strategies of the Brazilian tobacco industry. In addition, we will use the process of analysis in which cases are seen as representation of the social, that is, the cases that will be discussed represent all the reports of the subjects that are in this intramural environment. The present communication offers some data: there is a consonance on the part of the individuals who inhabit the prison institutions regarding the problem of secondhand smoke, the consumption of cigarettes and other drugs proliferates or is potentialized within the prison and the disciplinary focus prevails, disregarding the issues in prisons.

\section{Funding}

The Union.

Tob. Induc. Dis. 2018;16(Suppl 3):A91

DOl: 10.18332/tid/94540 
Smoking habits and effects in a pulmonary outpatient clinic in Ağrı

Nejdiye Mazıcan ${ }^{1}$, Esra Yarar $^{2}$

'Division of Work Health and Occupational Medicine, Department of Public Health, School of Medicine, Ege University, İzmir, Turkey, ${ }^{2}$ Necip Fazıl City Hospital, Kahramanmaraș, Turkey

\section{Aim and objective}

The aim of this study was to determine the prevelance of cigarette smoking and its relation with diseases in patients from outpatient clinics of chest diseases in Ağrı.

\section{Methods}

In our study, 741 patients included from outpatient clinics of chest diseases coming for any reason. Data collected from digital patients' file retrospectivelyincluding demographics, pulmonary function tests (PFT), comorbidities, primary diagnosis, smoking habits and body mass index (BMI). Statistical analysis done with MedCalc Statistical Software version 12.7.7 (MedCalc Software bvba, Ostend, Belgium; http://www.medcalc.org; 2013).

\section{Results}

There was a significant difference between gender and smoking status ( $p<0.001)$, smoking was significantly higher in male sex than in female. There was a significant difference between accompanying diseases and smoking ( $p<0.001)$, and the rate of smoking was higher in those with internal non-respiratory problems (Graph 1). According to BMI, $23.2 \%$ of smokers were obese, $33.7 \%$ were overweight; $35.7 \%$ of the non-smokers were obese and $32.9 \%$ were overweight $(\mathrm{p}<0.05)$. However, BMI levels are also higher in smokers than normal. As a result, smoking does not mean that individuals will have normal weight.

\section{Conclusions}

Cigarette smoking is a serious problem that threatens the health of the community for Ağrı and it is important for physicians to develop anti-smoking awareness.

\section{Tob. Induc. Dis. 2018;16(Suppl 3):A92}

\section{DOl: 10.18332/tid/94541}

Tobacco industry interference in price and tax policies in Kenya: Analysis of tobacco industry internal communication documents

Anne Kendagor ${ }^{1}$

${ }^{1} T o b a c c o$ Control Unit, Ministry of Health, Nairobi, Kenya Tobacco use is the leading preventable cause of death, disease and disability resulting in 7 million deaths yearly with approximately 890,000 deaths occurring as result of exposure to second hand tobacco smoke. The six leading tobacco companies are experiencing tremendous growth, with a combined gross profit of USD 44.1 Billion. Driven by their main objective of profit maximization, the Tobacco Industry (TI), has sought to manipulate government agents to safeguard or at times expand market for their products. The overall goal of this study was to provide insight into their activities in undermining Tobacco control policies in Kenya. The objectives of the study were to document the history of tobacco industry interference in Kenya, create awareness on tobacco industry tactics to policy makers, decision makers and the public and to stimulate action against tobacco industry interference in public health policies. A database compiled by the University of California in San Francisco since 2002, served as the primary source of information for the study and supplemented with information from key searches in online and offline media, newspaper articles, journal articles, websites and Key Informant Interviews. The study established that the Tobacco Industry over time interfered with policy therefore the findings will guide policymakers now and in the future, to counteract Tobacco industry tactics and strategies in Tobacco control policy making.

\section{Funding}

The study was co funded by Centre for Tobacco Control (CTCA) in Africa and Makerere University School of Public Health.

\section{Tob. Induc. Dis. 2018;16(Suppl 3):A93 DOl: 10.18332/tid/94542}

\section{Attitude and perception towards secondhand smoke among general public in Nigeria \\ Abubakar Mercy ${ }^{1}$ \\ ${ }^{1}$ Educate Trust, Ibadan, Nigeria \\ Background}

Secondhand smoke is no longer a personal problem but a community problem as there is a perpetual increase in the rate of public smoking in prohibited places, even in places that are meant for children such as parks.Secondhand smoke has not been taken with much seriousness by nonsmokers as most of them do not know it consequences on their health, thus they believe they are save as long as they do not smoke.

\section{Aims and Objectives}

This research sought to know the level of awareness as well as the attitude and knowledge displayed towards secondhand smoke in public place's by nonsmoker's, the perception of nonsmokers towards secondhand smoke as well as the copping strategies they adopt when exposed to tobacco smoke.

\section{Method}

A cross sectional survey was used in selecting houses, campuses, hospitality venues as well as offices. Structured questionnaire were administered to 300 respondent in these places in measuring their knowledge, attitude and perception towards secondhand smoke as well as their copping strategies. This was however voluntary.

\section{Result}

A total number of 300 respondents participated in the research, $31.5 \%$ were smokers and $20.3 \%$ of them smoke in public places. About $19.4 \%$ of them knows the harmful effect of secondhand smoke to the health, 38complex.5\% are not aware of the effect associated to secondhand smoke, $21.2 \%$ were less concerned about the effect of secondhand smoke as they do not smoke, hence they are not affected.

\section{Conclusion}

Our study demonstrated a low level in the awareness and knowledge of the effect of secondhand smoke to the health as most resold nets who are nonsmoker's do not see secondhand smoke as a threat to their health. More awareness has to be done in enlightening the general public on the effect of secondhand smoke to the body as well the need to protect oneself from the harmful smokers.

\section{Tob. Induc. Dis. 2018;16(Suppl 3):A94 \\ DOI: 10.18332/tid/94543}

\section{Changes in perception of smoking over time among the youth in Nepal \\ Iftekharul Huq ${ }^{1}$, Biva Mallik \\ 'Department of Economics, East West University, Dhaka, Bangladesh \\ Background}

Smoking habit is often picked up at early ages. Therefore, studying the pattern of smoking prevalence among the youth is critical for tobacco control. This paper explores
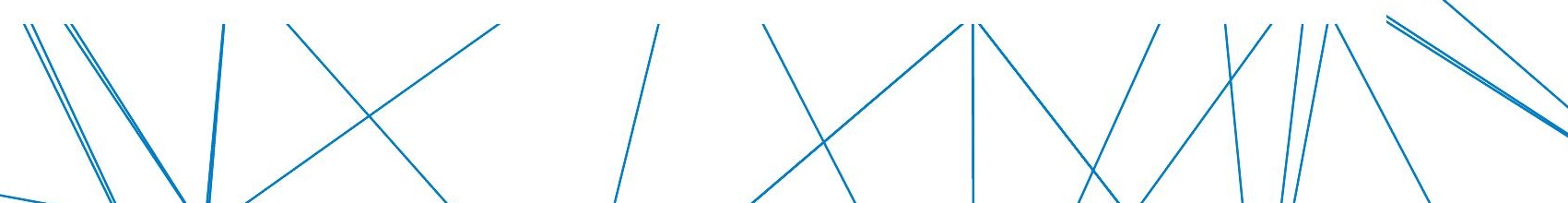
how perception of smoking changes over time among the youth in Nepal. The paper also analyzes how youth's perception of smoking and the surrounding environment influences youth's initiation of smoking.

\section{Methods}

The 2001, 2007 and 2011 Nepal Global Youth Tobacco Survey (GYTS) is used in this study. Logistic regression models are performed to examine various factors that affect initiation of cigarette smoking among the youth in Nepal.

\section{Results}

The three Nepal GYTS surveys demonstrate increasing trends in percentages of youth who find boys and girls that smoke more attractive and have more friends. In the same group, belief that smoking helps people feel comfortable in social gatherings has also gone up. Although an increasing proportion of youth believes smoking is harmful for smokers' health, a decreasing trend is observed regarding the harmful effects of second hand smoking. Results from logistic regression models reveal that any form of positive perception of smoking increases youth's chance of smoking initiation.

\section{Conclusions}

Findings of this paper demonstrate that over the years the perception of smoking has become more positive among the youth in Nepal. This is extremely alarming as positive perception of smoking leads to smoking initiation and eventually they become regular smokers at early ages. Awareness programs on harmful effects of smoking need to be designed to target the youth in order to educate them.

\section{Tob. Induc. Dis. 2018;16(Suppl 3):A95}

\section{DOl: 10.18332/tid/94544}

Effective use of Food Safety and Standards Act, 2006 to prevent the sale of tobacco products along with food items in supermarkets: A case study from Punjab

Areet Kaur ${ }^{1}$, Varun Roojam², Gurmandeep Singh ${ }^{1}$

${ }^{1}$ National Tobacco Control Programme, Punjab, India, ${ }^{2}$ Food and Drug Administration, Punjab, India

\section{Background}

In India, Tobacco products have been openly sold along with the food item such as candies, chips, biscuits and soft drinks etc., which are frequently used by children. Under Food Safety and Standards Act, 2006, a licensed food vendor can't sell the tobacco products along with food items to prevent children exposure to Tobacco products.

\section{Methods}

Based on the advisory issued by Commissioner-Food Administration regarding sale of tobacco products along with food items, a complaint was received by the District Tobacco Control cell, Punjab citing violation being done by the supermarkets in one district of state on 28th June 2017. On 29th June 2017, a meeting was held to constitute a special act enforcement team.

\section{Results}

After conducting the investigation, the enforcement team found the owner of the supermarket guilty of violation under Food Safety and Standards Act, 2006, thus Food License of the supermarket was suspended. Following this tobacco products were removed from all the supermarkets in the state of Punjab.

\section{Conclusions}

Strong interdepartmental co-ordination, regular enforcements drives have been the reinforcers in preventing the sale of tobacco products along with food items, thus reducing the probability child exposure to tobacco products.

\section{Funding}

National Tobacco Control Programme, Punjab.

Tob. Induc. Dis. 2018;16(Suppl 3):A96 DOl: 10.18332/tid/94545

\section{Strengthening the effectiveness of Indian Penal Code (1860) regarding spitting of tobacco at public places - A case study from North region of Indian subcontinent \\ Areet Kaur ${ }^{1}$, Gurmandeep Singh \\ 'National Tobacco Control Programme, Punjab, India \\ Background}

Smokeless tobacco use is on the upswing in many parts of the India. A high prevalence of smokeless tobacco use leads to a high prevalence of spitting, creating an unaesthetic and unhygienic environment. This may lead to the spread of diseases, including tuberculosis, thus posing a threat to the health of public. The study aimed to develop a mechanism to ban spitting Tobacco at Public places.

\section{Methods}

During the State level co-ordination Committee meeting of all the stakeholders, brainstorming was done to tackle the issue of public spitting of tobacco. The methodology was developed following a consensus-based decision was made by the expert panel to ban spitting under IPC, 1860 .

\section{Results}

A circular was issued by Additional Chief Secretary, Home affairs to all the Deputy Commissioners and Police Officials to implement ban on spitting tobacco at public places under sections 268,269 and 278 of IPC, 1860. The monetary penalty was included for the violators. Total 28 Police officers were appointed as Nodal Officers in all the 22 districts of the state to implement the ban.

\section{Conclusions}

Banning spitting of tobacco at public places would thus have a double benefit - it would aid in Swachh Bharat Abhiyan \& discourage the use of chewable tobacco, thus reducing the prevalence of Oral cancer.

\section{Funding}

National Tobacco Control Programme, Punjab.

\section{Tob. Induc. Dis. 2018;16(Suppl 3):A97 DOl: $10.18332 /$ tid/94546}

\section{Is ban on Hookah bars under Code of Criminal} Procedure ( $\mathrm{CrPC}$ ) effective in controlling the menace: A case study from Punjab, India Areet Kaur ${ }^{1}$, Gurmandeep Singh'

${ }^{1}$ National Tobacco Control Programme, Punjab, India

\section{Background}

Hookah is a waterpipe used for smoking Tobacco. Hookah smoking usually delivers a relatively huge amount Nicotine, a highly addictive and cancer-causing chemical. Till date there is no National level legal provision to ban Hookah bars running in various states of country. Section 144 of $\mathrm{CrPC}$, Which gives power to District authorities to issue order in urgent cases of nuisance of apprehended danger to human life, health or safety can impose a ban on hookah bars if promulgated. The objective of the study was to assess the effectiveness of CrPC for shutting down of Hookah bars in the state of Punjab.

\section{Methods}

This legal intervention approach was conducted during the period of April 2013 to May 2018. In 2013, Punjab Government instructed the Deputy Commissioners of state
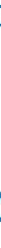
to promulgate section 144 of $\mathrm{CrPC}$ against the hookah bars. Health Advisory in public interest was also issued regarding ill effects of Hookah use. Permanent Task force was constituted to ensure strict enforcement of Law.

\section{Results}

Total 25 Hookah bars have been shut down in the State. FIRs have been lodged against Hookah bar owners by the Police department under section 144 of $\mathrm{CrPC}$. Since then, no complaint regarding a functional Hookah/Sheesha bar has been received anywhere in Punjab.

\section{Conclusions}

Orders of Section 144 of CrPC are subject to renewal every 2 months which is a short-term solutions thus, Tobacco control Act of India should be amended to include permanent on ban Hookah Bars in the State.

\section{Funding}

National Tobacco Control Programme, Punjab.

Tob. Induc. Dis. 2018;16(Suppl 3):A98

DOl: $10.18332 /$ tid/94547

\section{Should Ministry of Health ban manufacturing} and sale of Electronic Nicotine Delivery Systems (ENDS) popularly called E-cigarettes - result of an online poll

Rakesh Gupta1, Varun Roojam', Pradeep Mattu ${ }^{1}$ Department of Health and Family Welfare, Punjab, India

\section{Aim and objective}

E-cigarettes are highly addicting products. It is mostly being used by children and youth because these are glamorised by the tobacco industry. They are widely promoted and sold through E commerce. Sales are increasing sharply all over the world. These products are unapproved under Drugs and Cosmetics Act of India. Punjab, Maharashtra, Karnataka, Kerala, Bihar, J\&K, Mizoram etc. have already declared these products as unapproved for sale.

\section{Methods}

An online poll to facilitate line of action by Government of India to deal with E-Cigarettes was conducted from 21/3/18 to 30/3/18. National and International public health specialists, State Nodal Officers National Tobacco Control Programme, health administrators, psychiatrists and eminent doctors were requested to participate in the online poll.

\section{Results}

571 persons participated in the online poll. Out of these 364 people $(63.75 \%)$ were in favour of banning the manufacturing and sale, $94(16.46 \%)$ in favour of regulating under Anti-Tobacco/ Nicotine Laws, 59 (10.33\%) in favour of providing guidelines to manufactures for self-regulation and the rest $54(9.46 \%)$ wanted it's sale to be regulated under Drugs and Cosmetics Act for Cessation purpose.

\section{Conclusions}

An overwhelming majority of Public health specialists and others who participated in the online poll are of the opinion that Ministry of health should deal with growing menace of E-Cigarettes by banning the manufacturing and its sale. This line of action by the Government of India will open the way for other countries to declare these products as unapproved.

\section{Tob. Induc. Dis. 2018;16(Suppl 3):A99 DOl: 10.18332/tid/94557}

Tobacco use of the healthy aging individuals Neslihan Özcelik

'Department of Chest Disease, Kaçkar State Hospital, Rize, Turkey Aim

Cigarette smoking is major cause of diseases as heart disease, stroke, chronic lung disease and lung cancer, which causes of death in elderly. But, regardless of the age of the patients, the likelihood of these illnesses declining in the period following the release of cigarette.

\section{Methods}

35 patients were included to study older than 65 age and independent in daily life activities were admitted to Kackar State Hospital with nonspecific complaints and unknown chronic illnesses. Vital signs, saturation, ECG findings, smoking and alcohol dependence, sleep quality, BMI, bone densitometry, minimental test and geriatric depression scales were evaluated. Data analysis was performed with SPSS.

\section{Results}

Of patients were $48.5 \%$ male, $51.5 \%$ female, mean age was 82 and mean BMI was 19.5. Additional diseases diagnosed after the examination of our patients were $45 \%$ $\mathrm{HT}, 8 \%$ COPD and $28 \%$ osteoporosis disease. The average saturation was 94 and the heart rate was 75 . When smoking status was assessed, $68 \%$ of patients never smoked in their life and there were no patients currently ongoing. $95 \%$ of COPD patients had previous history of smoking.

\section{Conclusions}

When the concepts of healthy and super aging are considered, smoking is seen an important risk for additional diseases in old ages. In our country, significant progress has been made in smoking cessation policlinics in recently. To raise awareness about healthy old age and especially to question the situation of smoking in patients 65 aged and to inform smokers to encourage them to quit smoking.

\section{Tob. Induc. Dis. 2018;16(Suppl 3):A100 \\ DOI: 10.18332/tid/94558}

\section{What is necessary to fight against tobacco} vaporizers in Japan?

Kazunari Satomura', Suketaka Iwanaga', Keiko Kusaka', Megumi Noami', Mai Masuda', Toshitaka Nakahara' ${ }^{1}$ Kyoto University, Kyoto, Japan

\section{Introduction}

In Japan, recently not only smoking rates but also the consumptions of cigarettes are decreasing. Raising problem about tobacco is increasing users of tobacco vaporizers. To clarify points of problems, present situation of tobacco vaporizers was investigated.

\section{Subjects and Methods}

Data of tobacco vaporizers are collected from internet, newspapers and so forth.

\section{Results}

Tobacco vaporizers are a kind of e-cigarettes. Three vaporizers are available in Japan. They are IQOS, ploom TECh and glo. Most popular vaporizer is IQOS in Japan. One of the reasons that cigarette smokers change to IQOS is that it is allowed to use in some non-smoking places and restaurants. And it is advertised that negative health effect for the circumstance is smaller than that of cigarette smoking. As there are small evidences about negative health effects, regulations are depend on the local governments. The Ministry of Health, Labour and Welfare has not yet presented any policy for the vaporizers because of almost no evidence for their negative health effects.

\section{Discussion}

IQOS began to be sold since 2016 all over Japan. $80 \%$ of its users all over the world is Japanese. The number of its user are rapidly increasing in Japan.

Some of the users believe that using vaporizers is not
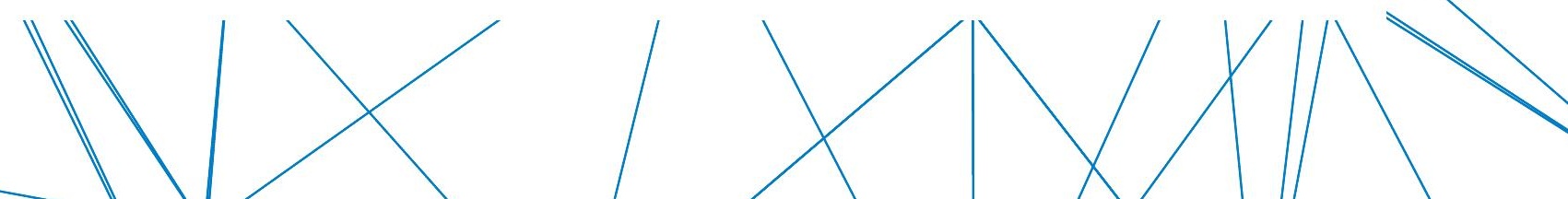
Students reported the perceived approval of smoking from good friends (disapprove/neutral/approve) and the perception of whether most secondary school students accepted smoking (no/yes). Smoking susceptibility referred to the lack of a firm intention not to smoke in the next 12 months, when good friends smoked in front, or when a good friend offered a cigarette. Logistic regression yielded adjusted odds ratios (AORs) of smoking susceptibility for injunctive norms in never smokers, adjusting for sociodemographic characteristics and school clustering effect.

\section{Results}

Overall, $1.3 \%, 21.1 \%$ and $77.5 \%$ of students perceived approval, neutral response and disapproval of smoking from good friends, respectively. Some (5.8\%) perceived that most students accepted smoking. In never smokers ( $n=6472,92.5 \%)$, compared with perceived disapproval from good friends, perceived neutral response (AOR 3.58, $95 \% \mathrm{Cl} 2.86-4.50)$ and approval $(5.41,2.93-9.97)$ were associated with smoking susceptibility. The perception that most students accepted smoking was also associated with smoking susceptibility $(2.73,2.02-3.71)$.

\section{Conclusions}

Injunctive norms were associated with smoking susceptibility in Hong Kong never smoking adolescents. Addressing misperceptions of others' approval or acceptability of smoking may help prevent adolescent smoking.

\section{Funding}

General Research Fund (17629016), Research Grants Council of Hong Kong Special Administrative Region, China.

\section{Tob. Induc. Dis. 2018;16(Suppl 3):A104}

DOI: $10.18332 /$ tid/94565

\section{Public poll for support $100 \%$ smoke free area} regulation to protect children from secondhand smoke exposure in big city on 8 provinces in Indonesia

Tri Ningsih ${ }^{1}$

IIndonesia Institute For Social Development, Jakarta, Indonesia Objective

Support Goverment and parliament to enact a national regulation about $100 \%$ smoke free area for protect children from smoke exposure on all place.

\section{Methods}

1. The study design was cross-sectional with data collection conducted during the months of May and June 20132. Case study on 8 provinces in Indonesia: Jakarta, West Java, East Java, Yogyakarta, Bali, South Sulawesi, South Sumatra, West Kalimantan 3. Direct interviews conducted on 1555 respondents 4 . Instruments used in the form of semi-structured questionnaires demography

\section{Results}

1. Respondents know that cigarette smoke other (Arol) detrimental to the health of children as much as $95.5 \%$, and those exposed to secondhand smoke are particularly susceptible to the effects of smoking $88 \%$. 2. Regarding exposure to cigarette smoke Respondent often expose in the workplace are $33 \%$, Public places $63.2 \%$, Public transport $43.9 \%$, at home $21.6 \%$ respondent always exposed to secondhand smoke. 3. Respondent agreed regulations to ban smoking in public places and enclosed workplaces $55.9 \%$ and $55.7 \%$ agrees in all enclosed public spaces such as public transport and shopping centers

\section{Conclusions}

1. Secondhand smoke exposure is danger for the health of the Children 2. Public Place are the higher place exposure to the cigarette 3 . Public agreed about the regulation for $100 \%$ smoke free area on all place 4 . The government and Parliament to be more open to the voice of victims exposed to secondhand smoke by review the Health Law related to $100 \%$ smoke Free Area.

\section{Funding}

The Union.

Tob. Induc. Dis. 2018;16(Suppl 3):A105 DOI: 10.18332/tid/95142

\section{Correlates of quit attempts among smokers in} Nigeria

Iken Oluwatomi ${ }^{1}$, Cadmus Eniola ${ }^{2}$

${ }^{1}$ University College Hospital, Ibadan, Nigeria, ${ }^{2}$ University of Ibadan, Ibadan, Nigeria

Many smokers who have tried to quit are unable to do so at the first try and many give up after multiple attempts. Behavioural theories such as the trans-theoretical model have been shown to assist in the development of targeted interventions to assist quit attempts and eventual quitting. There is little evidence about quit behaviour among adults in the Nigerian context. This study aimed to explore the correlates of quit attempts among the current tobacco smokers in Nigeria using the Transtheoretical model.

A cross-sectional secondary data analysis of the 2012 Global Adult Tobacco Survey in Nigeria was carried out using SPSS version 23 at a level of significance $p<0.05$. A total of $429(22.8 \%)$ respondents were current smokers mostly males (96.0\%). Most smokers were in precontemplation stage $(64.7 \%)$, with $14.9 \%$ in preparation stage. Only a few of the respondents $(20 \%)$ had access to cessation therapy, none to a quitline. Exposure to antitobacco media messages was associated with increased in quit attempts. Other correlates of quit attempts were male gender [OR: 9.615 (Cl: 1.449-1.478)], younger age [OR: $1.126(95 \% \mathrm{Cl}: 1.108-1.144)]$ unemployed status [OR: 2.223 (95\% Cl: 2.122-2.329)], and lower level of education [OR: 2.991 (95\% Cl: 2.930-3.053)].

While global attention in tobacco control focuses on prevention of initiation and cessation support, most smokers in Nigeria are not considering quitting. There is a need for targeted interventions to reach smokers at various stages, across the geopolitical zones as well as provision of necessary support to assist quitting among users.

\section{Tob. Induc. Dis. 2018;16(Suppl 3):A106 DOI: 10.18332/tid/94566}

\section{Biochemical profiling of smokeless tobacco} product Kiwam at different processing steps Ravi Mehrotra', Anshika Chandra², Vishwas Sharma', Amrita Nandan ${ }^{3}$, Ravi Kaushik ${ }^{1}$

'ICMR- National Institute of Cancer Prevention and Research, Uttar Pradesh, India, ${ }^{2}$ WHO FCTC Global Knowledge Hub on Smokeless Tobacco at ICMR- National Institute of Cancer Prevention and Research, Uttar Pradesh, India, ${ }^{3}$ Society of Life Sciences and Human Health, Uttar Pradesh, India

\section{Introduction}

Kiwam (Qiwam) is a partially fermented tobacco product consumed with Betal Quid (Paan). The major constituents of this product are tobacco, saffron (Zaffrani) and some additives. It contains Tobacco-Specific Nitrosamines (TSNA) which is considered as a cancer-causing agent. To elucidate the carcinogenic property of Kiwam, biochemical profiling of its constituents at different stages of processing is needed. The major processing steps involved in the
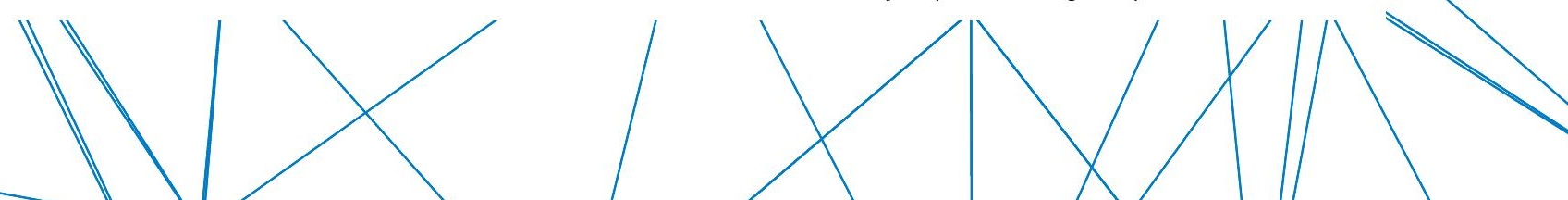
formation of Kiwam and biochemical profiling/changes at each processing step is still unknown.

\section{Aim}

To describe the major processing steps and biochemical changes that occurs at each processing step during the preparation of Kiwam.

\section{Method}

Tobacco leaves and stems were boiled in water followed by filtering of the constituents to remove the leaves and stem residues. The filtrate is again boiled to form a thick paste residue. The resultant paste was partially fermented through sun curing, and lastly saffron along with some additives were added. The samples from each step were analyzed for biochemical profiling through Continuous Flow Autoanalyzer (CFA) using Flow View Solution 3700 Analyzer (version 1.2.2) software.

\section{Results}

The biochemical changes at TSNA levels were observed at each processing steps. The detailed chemical profiling will be presented during the meeting.

\section{Conclusions}

Processing of Kiwam involves four major steps i.e. (i) boiling of tobacco leaves and stem (ii) filtration of product (iii) re-boiling of the filtrate till the paste is formed (iv) partial fermentation through sun curing. Kiwam is rich in TSNA and hence its use should be avoided.

\section{Tob. Induc. Dis. 2018;16(Suppl 3):A107}

\section{DOI: 10.18332/tid/95190}

Biochemical profiling of areca nut product Dohra Ravi Mehrotra', Amrita Nandan², Vishwas Sharma1', Anshika Chandra ${ }^{3}$, Ravi Kaushik

'ICMR- National Institute of Cancer Prevention and Research, Uttar Pradesh, India, ${ }^{2}$ Society of Life Sciences and Human Health, Uttar Pradesh, India, ${ }^{3}$ WHO FCTC Global Knowledge Hub on Smokeless Tobacco at ICMR- National Institute of Cancer Prevention and Research, Uttar Pradesh, India

\section{Introduction}

Dohra is a locally produced areca nut preparations used with or without tobacco in Allahabad, Jaunpur and Pratapgarh districts of Uttar Pradesh (UP), India. Different varieties of Dohra exist such as Sukha Dohra, Geela Dohra, etc. Evidence suggests that it causes Oral Potentially Malignant Disorders and Oral Cancer. It contains arecoline which is a well-known carcinogen. In order to understand the potential role of Dohra in causing cancer biochemical profiling of different varieties of Dohra is needed.

\section{Aim}

To describe the biochemical profile of different varieties of Dohra.

\section{Methods}

Different varieties of Dohra were collected from Allahabad, Jaunpur and Pratapgarh districts of UP. All the varieties of Dohra were analyzed for biochemical profiling through Continuous Flow Autoanalyzer (CFA) using Flow View Solution 3700 Analyzer (version 1.2.2) software.

\section{Results}

The biochemical changes at arecoline levels were observed in different varieties of Dohra. The detailed chemical profiling will be furnished in the meeting.

\section{Conclusions}

Different varieties of Dohra preparations are produced and each of them have a different biochemical profile. The Dohra is rich is arecoline and hence its use should be banned/avoided

\section{Tob. Induc. Dis. 2018;16(Suppl 3):A108}

DOl: 10.18332/tid/95191

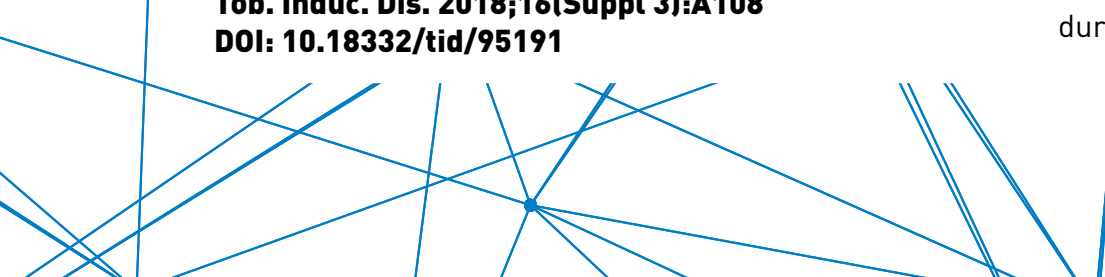

The globalized tobacco industry interference The Brazilian tobacco additives ban case Diogo Alves

'World Health Organization, Brazilian Country Office, Brazil

\section{Background}

Tobacco industry (TI) interference is one of the key challenges to the creation and implementation of tobaccoreduction regulation. It continues to undermine control efforts globally. One example is the Brazilian proposal to ban additives in 2012. Recent files show how a Dutch tobacco industry were planning to bring the case to World Trade Organization (WTO) and block the Mercosur European Union Free Trade Agreement negations.

\section{Intervention}

Bring awareness of how articulated the Tl is, ahead of many Governments. Use the Brazilian case to show how a Cigar Company based in Netherland was planning to convince/lobby other European Governments to prosecute Brazil internationally.

\section{Methodology}

Explore the TI library, held by the University of California in San Francisco. Display the WTO fulfilled forms they pretend to use, the exchange of documents between tobacco industry CEOs and how they were planning undermine FTA negations.

\section{Results}

The Netherlands are the biggest exporter of tobacco to Brazil, in particular of cigars. Together, Belgium and Netherlands imports $22 \%$ of all Brazilian tobacco. There is evidence of the close relation between tobacco industry and former Dutch Interior Minister. The TI did not followed with the process because meanwhile, the Brazilian resolution was pledged in Supreme Court, where it remains. The focus swift to Australia and they used all previous legal basis, prepared to suit Brazil, in the Australian case.

\section{Conclusions}

In response to these claims from the $\mathrm{TI}$, Governments may rely on their sovereign right to regulate in the interests of public health. Specifically in relation to tobacco control measures, which aim is to protect human health.

\section{Tob. Induc. Dis. 2018;16(Suppl 3):A109 \\ DOI: 10.18332/tid/94567}

Sex patterns of lung cancer mortality in Russia over a 16-year period, 2000-2015

Irina Zarubina', Yehuda Neumark'

${ }^{1}$ Hebrew University of Jerusalem, Jerusalem, Israel

\section{Objective}

Much has been published about tobacco smoking consumption in Russia, though tobacco-related mortality remains unexplored. This study aims to describe national and regional sex patterns of lung cancer (LC) mortality (as a marker for tobacco-related mortality) in Russia in 2000-2015.

\section{Methods}

Age-adjusted LC mortality (AALCM) rates by gender and for eight federal districts and 83 regions were calculated based on mortality and population data extracted from the Russian Fertility and Mortality Database. Annual percentage changes in AALCM on the national and federal district levels were estimated; average AALCM rates were mapped. Two-way ANOVA was applied to assess timedistrict interaction effects on LC mortality.

\section{Results}

At the national level, a monotonic decline in LC mortality during the 16 -year period was noted among men lannual $\%$ 
change $=1.9 \%$ J, while among women, national LC mortality rates remained unchanged for most years. Sex differences in AALCM rates across federal districts and regions were noted. Among men, AALCM rates were consistently higher in northern, central and Far Eastern regions of Russia, while among women, AALCM rates increased moving from west to east over Russia. A strong time-district interaction for age-adjusted LC mortality male-to-female ratio $(F=3.267, p<0.001)$ was found.

\section{Conclusions}

Giventhesignificantincrease in tobaccosmoking prevalence among Russian women that began in the 1990s, female LC mortality will continue to rise in the coming decades, with a disproportionate burden on those regions located far from the federal centres with insufficient health services. Additional work is needed to identify factors underlying the regional and sex differences.

\section{Funding}

Invariable LC mortality among Russian women follows the observation of increasing tobacco smoking consumption in the past and predicts growing challenges to the national healthcare system in coming decades.

\section{Tob. Induc. Dis. 2018;16(Suppl 3):A110}

DOI: 10.18332/tid/94646

\section{Use of tobacco products among a Turkish} foundation university students, Izmir 2018 Gönül Horasan' ${ }^{1}$, Dilek Soysal', Șenay Yıldız², İlgi Șemin ${ }^{1}$ Faculty of Medicine, Izmir University of Economics, Izmir, Turkey, ${ }^{2}$ Vocational School of Health Services, Izmir University of Economics, Izmir, Turkey

\section{Aim and objective}

The study is conducted to obtain the use of tobacco products and its related factors among a Foundation University Students.

\section{Methods}

The study sample consists of 346 first and fourth year students in 2018 in Izmir University of Economics. The sample was chosen randomly. The students filled a structured self reported questionaire before an educational activity.

\section{Results}

Of the study group, $38.8 \%$ are males, $37.6 \%$ were $18-20$ years old. Approximately 1 in 3 of the students (33.7\%) were daily smokers while $14.1 \%$ were occasional smokers and $4.4 \%$ were quitters. Regular or occasional smoking percentages are quite similar in males and females $(p>0.05$, chi square test). Smoking is more prevalent in older age group $(33.7 \%$ and $53.4 \%$ respectively), ( $p=0.001$, chi square test). The use of other tobacco products such as hookah, cigars and pipe, is $27.6 \%$ while it is $3.4 \%$ for e-cigarette with a similar pattern in all tobacco products according to gender and age ( $p>0.05$ for all comparisons, chi square test). Use of tobacco products except e-cigarette are similar according to parental education. E-cigarette use is more common among students whose fathers' have an educational level of postgraduate degree $(2.6 \%$ vs $13.0 \%, p=0.034$ Fisher's exact test).

\section{Conclusions}

We found smoking cigarettes and other tobacco products are quite common among university students. Smoking pattern of males and females in University students is similar on the contrary of Turkish adults' pattern. The study also reflects the growing use of e-cigarette among Turkish young people especially in students from upper social class.

Tob. Induc. Dis. 2018;16(Suppl 3):A111 DOl: 10.18332/tid/94647
Breast cancer and smoking: A comparison of 955 breast cancer patients according to their smoking status

Raika Durusoy ${ }^{1}$, Baha Zengel ${ }^{2}$, Ahmet Aykas²

'Department of Public Health, Ege University Medical School, Izmir, Turkey, ${ }^{2}$ Department of General Surgery, Izmir Bozyaka Research and Training Hospital, University of Health Sciences, Izmir, Turkey

\section{Aim and objective}

Smoking is among the risk factors of breast cancer. The aim of this study was to compare breast cancer patients characteristics according to their smoking status.

\section{Methods}

This study is a retrospective evaluation of all breast cancer patients treated at the General Surgery Department of University of Health Sciences, Izmir Bozyaka Research and Training Hospital, between 1982 and 2018. A total of 1459 breast cancer patients' charts were reviewed and 955 contained data on smoking and were included in this study. There patients were classified as ever versus never smokers. Pack-years data was available for $32.3 \%$ or ever smokers. Chi square, t test, Spearman's correlation, Kaplan Meierand Cox Regression were used for analyses.

\section{Results}

Among the 955 breast cancer patients, 30.5\% ( $n=291$ ) were ever- and $69.5 \%(n=664)$ never smokers. According to years of diagnosis, the ratio of smokers was significantly increasing with $21.6 \%$ before $2000,21.9 \%$ in $2000-2004$, $31.1 \%$ in $2005-2009,32.1 \%$ in $2010-2014$ and $41.5 \%$ in $2015-2018$ ( $p$ trend $<0.001$ ). Ever smokers were diagnosed at a younger age $(49.9 \pm 11.8 \mathrm{vs} .54 .1 \pm 13.5, p<0.001)$. This was not confounded by year of diagnosis, since age at diagnosis significantly increased with increasing year of diagnosis ( $r=0.161, p<0.001)$. ER positivity was higher among ever smokers $(70.5 \%$ vs.63.2\%, $p=0.040)$ and with significant changes according to pack-year groups. No difference was found in PR positivity, mean CEA, ER\%, PR\%, p53\%, Ki67\% values and number of positive sentinel or axillary lymph nodes of ever and never smokers, while the mean CA15-3 values were significantly lower among ever smokers (17.4 \pm 10.1 vs. $24.5 \pm 27.8, p<0.001$ ). Never smokers had a higher ratio of metastasis overall $119.5 \%$ vs. $13.7 \%, p=0.040$ ) and among sites, of bone metastasis $(12.7 \%$ vs.6.8\%, $p=0.039)$. After adjustment for age at diagnosis, there was no significant difference in mean overall survival of ever and never smokers.

\section{Conclusions}

Among breast cancer patients, ever smokers are diagnosed at a younger age compared to never smokers. More detailed evaluations could provide deeper insight in smoking-induced breast cancer.

\section{Tob. Induc. Dis. 2018;16(Suppl 3):A112 DOI: $10.18332 /$ tid/94648}

Association of tobacco industry denormalisation beliefs with smoking cessation and nicotine addiction in adolescent smokers Jianjiu Chen'1, Sai Ho', Lok Leung ${ }^{1}$, Man Wang1', Tai Lam¹ 'The University of Hong Kong, Hong Kong

\section{Aim and objective}

To investigate the associations of tobacco industry denormalisation (TID) beliefs (ie, negative perceptions of the industry) with smoking cessation and nicotine addiction in adolescent smokers.

\section{Methods}

In 2012/13, a cross-sectional survey was conducted in 
45857 secondary school students Imean age 14.8 years, $54 \%$ boys) in Hong Kong. TID beliefs (score range: $0-6$ ) were measured by two questions: "Do you think the tobacco industry is respectable?" and "Do you think the tobacco industry tries to get youth to smoke?" Each question had 4 options ("probably yes" to "probably no"), which were assigned scores of $0-3$, with larger scores indicating stronger TID beliefs. Also measured were smoking status, smoking cessation lyes/no; defined as cessation for $\geqslant 4$ months), morning smoking (yes/no), cigarettes smoked per day, etc. Associations were examined with adjustment of sociodemographic characteristics, peer smoking, and numbers of co-residing smokers.

\section{Results}

In ever smokers loccasional or daily smoking either now or in the past; $n=4544$ ), TID beliefs were associated with an adjusted prevalence ratio (PR) of $1.04(95 \% \mathrm{Cl} 1.02,1.07$ $\mathrm{p}=0.001$ ) for smoking cessation. In past 30-day smokers $(n=3250)$, TID beliefs were associated with an adjusted PR of $0.98(0.96,1.00 ; p=0.04)$ for morning smoking and an adjusted $B$ of $-0.27(-0.44,-0.10 ; p=0.002)$ for cigarettes smoked per day.

\section{Conclusions}

In Hong Kong adolescents, TID beliefs were associated with smoking cessation in ever smokers, and inversely associated with nicotine addiction in past 30-day smokers. A TID component may strengthen cessation interventions in adolescent smokers.

\section{Funding}

Food and Health Bureau of the Hong Kong Government.

\section{Tob. Induc. Dis. 2018;16(Suppl 3):A113}

\section{DOl: 10.18332/tid/94649}

\section{Outcomes of University Hospital Outpatient}

Smoking Cessation Clinic in İzmir

Merve Uygunsoy ${ }^{1}$, Ayșe Altın', Vildan Mevsim ${ }^{1}$

'Department of Family Medicine, Dokuz Eylul University, İzmir. Turkey

\section{Aim and objective}

The aim of this study is to determine characteristics, smoking habits, therapy for quitting and smoking cessation success who applied to the university hospital, outpatient smoking cessation clinic in İzmir.

\section{Methods}

This descriptive study was carried out using the records in the outpatient electronic health record system of the patients who applied to Dokuz Eylul University Smoking Cessation Outpatient Clinic between January 2014 and August 2017. Demographic data, smoking habits, type of therapy and follow-up data were evaluated from these records. Later, all patients were assessed for smoking cessation by telephone interview.

SPSS 22.0 program was used for mean, standard deviation of descriptive continuous variables. It was also evaluated frequency and percentage of categorical variables.

\section{Results}

The mean age of participants was $41.4 \pm 12.8$. $39 \%$ of participants were women, where $60.3 \%$ were men. $64.1 \%$ of participants was married. The cigarette

consumption (package/ year) was $26.9 \pm 21.6$. The mean score of Fargerstrom Test for Nicotine Dependence was $5.96 \pm 2.5$. According to the Hospital Anxiety and Depression scale, $67.6 \%$ of participants had anxiety, where $56.2 \%$ had depression. As a smoking cessation therapy, 25.1\% of participants treated with vareniclin, $2.5 \%$ participants treated with nicotine replacement therapy and $34.3 \%$ with bupropion. All of the patients received cognitive behavioural therapy. $24.4 \%$ of participants quit smoking.

\section{Conclusions}

Pharmacotherapy was given to the majority of patients who applied to smoking cessation outpatient clinic. The cessation of smoking is also high. Smoking cessation outpatient clinic have an important role in being successful in smoking cessation.

\section{Tob. Induc. Dis. 2018;16(Suppl 3):A114 DOI: 10.18332/tid/94667}

\section{Prevalence of cigarette smoking and cessation} among 15 years old and older people in

Kayapınar district of Diyarbakır Mehmet Gördük', Günay Saka², Selcuk Kolsuz ${ }^{2}$

${ }^{1}$ Sağlık Bakanlığı, Ankara, Turkey, ${ }^{2}$ Dicle University, Diyarbakır Turkey

Smoking addiction is among the most important research areas of public health science because of its preventable nature. To prevent this addiction and to overcome its harms to public health, economy and the environment, scientists should be aware of the answers what is the prevalence of smoking and what is the cessation rates. This crosssectional research studies the prevalence of cigarette smoking and cessation among 15 years old and older people registered at 17th Family Health Center in Kayapınar district of Diyarbakır. 309 people sampled systematically among universe of 5880 people in this region. The survey results show that 30.4 percent of the participants do smoke, while 14.6 percent are ex-smokers and the remaining 55 percent has never smoked. \%62,3 of men smoked in one part of their life or still smoking while this percent is $\% 24,6$ for women $(p=0,000)$. This study shows that education level is also associated with starting smoking. \%57,3 of people who went primary school at most had smoked or still smoking; for people who went college at least this percent is $\% 35,9(p=0,014)$. Fortunately, 52.1 percent of smokers has stated that they are planning to quit smoking. Since there is expanding awareness about the dangers of cigarette among the public and most of the smokers do want to quit smoking, the researches should identify the factors affecting smoking initiation and cessation and consequently precautionary measures should be taken to protect the public from cigarette addiction.

\section{Tob. Induc. Dis. 2018;16(Suppl 3):A115 \\ DOl: 10.18332/tid/94679}

\section{Smoking status of oncological patients}

Hatice Önder

'Department of Radiation Oncology, Faculty of Medicine, Bulent Ecevit University, Zonguldak, Turkey

Smoking is a major risk factor and main cause of many cancer types and death related cancer.lt is the foremost cause of cancer mortality in the United States accounting for $98 \%$ of all tobacco related deaths. Smoking is the main preventable cause of lung cancer, it also affects the treatment.

We investigated smoking status of our oncological patients. 372 patients information obtained from their files retrospectively.

The $64.5 \%$ of patients were male $(n=240), 35.5 \%$ were female $(n=132)$ and mean age was 60.9. 144 patients were nonsmoker (38.7\%),148 patients were $(39.8 \%)$ smoker and 80 were ex-smoker (21.5\%). Mean consumed tobacco amount was 40.37 packet/year. $37.5 \%$ of the group was lung cancer, $18.6 \%$ of the group was breast cancer, $9.7 \%$

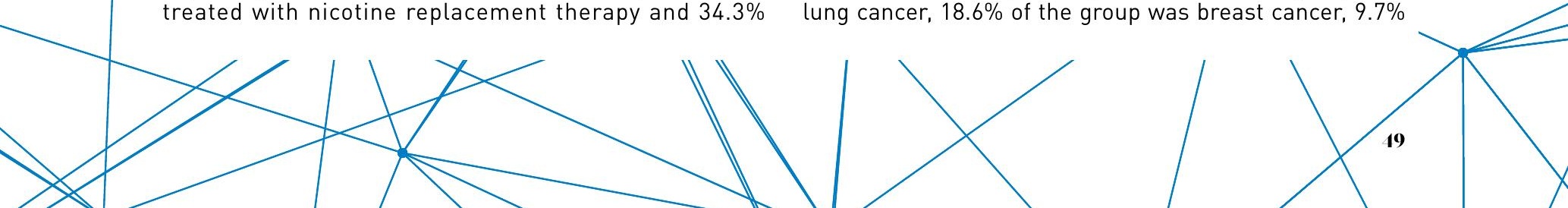


of the group was head and neck tumors. Only $916.4 \%$ ) patients from all lung cancer patients were nonsmoker, $60 \%$ were active smoker and $33.6 \%(n=47)$ were ex-smoker. Only 12 patients (33.3\%) with head and neck cancer were nonsmoker, $22.2 \%$ were ex-smoker, $44.4 \%$ were active smoker. $38.1 \%$ of gastric cancer patients were nonsmoker $(n=8), 42.9 \%$ were smoker and $19 \%$ were ex-smoker. Colorectal tumor group had a lower smoking ratio; $55.2 \%$ were nonsmoker and $10.3 \%$ were ex-smoker. The least tobacco using ratio was at breast cancer group, $83.8 \%$ of the breast cancer patients were nonsmoker.

According to world health organisation, one third of cancer releated death is about basic behaviours as; high body mass index, poor fruits and vegetables in nutrition, poor physical activity and using cigarette and alcohol. We can change all of these situations. Because of strong relation between many kinds of cancer (not only lung cancer as common consideration) and tobacco, firstly we must conceive awareness about this relationship.

\section{Tob. Induc. Dis. 2018;16(Suppl 3):A116}

\section{DOl: 10.18332/tid/94680}

\section{Tobacco consumption among high school} students in Kathmandu, Nepal

Bhakta Bahadur ${ }^{1}$, Laxmi Oli², Durga Pahari ${ }^{3}$

${ }^{1}$ National Health Education Information and Communication Center, Ministry of Health, Kathmandu, Nepal, ${ }^{2}$ Nepalgunj Medical College and Teaching Hospital, Nepalgunj, Nepal, ${ }^{3}$ Department of Community Medicine and Public Health, Institute of Medicine, Kathmandu, Nepal

\section{Introduction}

Tobacco use both in smoking and non-smoking form has been the leading global cause of preventable death, contributing to seven million people deaths each year. This study aims to find the tobacco use status among students and their family members and similarly the objective of the study was to assess the tobacco use prevalence among students of public schools in a municipality of Kathmandu, Nepal.

\section{Methods}

The study was school based survey that used two stage cluster sampling method. 378 students participated in the study. Global Youth Tobacco Survey (GYTS) selfadministered questionnaire was employed to collect the data. Descriptive analysis was performed by determining frequencies and percentages. Ethical clearance for the study was obtained from Institutional Review Board of Institute of Medicine, Nepal.

\section{Results}

The study revealed that students who were ever used any tobacco were $31.7 \%$. Boys $(23.3 \%)$ are three times more likely than girls (8.5\%) to ever use any tobacco products.

\section{Conclusions}

Tobacco use was high prevalent among the high school students, so it is a public health problem among school students in Nepal. These finding alarms the need of school based interventions to reduce tobacco use behavior among students.

\section{Tob. Induc. Dis. 2018;16(Suppl 3):A117 DOl: 10.18332/tid/94681}

Determination of cigarette drinking curriculum and investigation of some demographic effects of grade 1 students of Dicle University Faculty of Medicine

Bilal Yildiz', Gözde İsen', Günay Saka

${ }^{1}$ Public Health Department, Faculty of Medicine, Dicle University, Divarbakir, Turkev

\section{Objective}

Determination of cigarette drinking curriculum and investigation of some demographic effects of grade 1 students of Dicle University Faculty of Medicine.

\section{Methods}

Research planned by application form of survey for graduate students. 156 students received between 200 students. Analyzes were done with spss program.

\section{Results and conclusions}

$61(39.1 \%)$ women 95 (60.9\%) male participated to study. $80(51.3 \%)$ person lives with family. $46(29.4 \%)$ person's economical condition is very good, 104 (66.7) person's good, 6 (3.9) person's bad. 22 (14.1\%) person's mother, $65(41.7 \%)$ person's father smokes. 66 persons never smoked, 49 persons tried but not continued, 35 persons smokes actively, 6 person quitted smoking. Average age of smoking is 16 ( $3 \mathrm{sd}$ ). 12 persons of $71(16.9 \%)$ smoked first cigarette at faculty of medicine. 36 persons of 47 $(76.6 \%)$ who smokes tried to quit smoking. 16 persons of $64(25 \%)$ who smokes started smoke because of close friend, 15 persons $(23.4 \%)$ stress, 12 persons $(23.4 \%)$ curiosity. Cigarette drinking occurrence of male was higher according to women $(p<0.05)$. Cigarette drinking occurrence was high whose mother smokes.

\section{Tob. Induc. Dis. 2018;16(Suppl 3):A118 DOI: 10.18332/tid/94682}

Nicotine down-regulates the proliferation of the cementoblasts (OCCM.30)

Sema Hakki', Buket Bozkurt ${ }^{2}$

${ }^{1}$ Department of Periodontology, Faculty of Dentistry, Selcuk University, Konya, Turkey, ${ }^{2}$ Research Center, Faculty of Dentistry, Selcuk University, Konya, Turkey

\section{Aim}

Smoking is a well known risk factor for periodontitis and it has definitely negative impacts on the results of periodontal therapies. Nicotine, which is the main active component of tobacco, affects cell functions including proliferation, adhesion and differentiation of the cells. The aim of this study was to explore the effects of nicotine on the proliferation of cementoblasts.

\section{Methods}

Immortalized mouse cementoblasts (OCCM-30) were treated with different concentrations $(0.001,0.01,0.1$, $1,10,100,1000,10,000,100,000 \mathrm{nM}, 1 \mathrm{mM}, 10 \mathrm{mM}$ ) of nicotine and analyzed for proliferation using a real-time cell analyzer (xCelligence; RTCA-SP) for 130 hours and the cells were photographed after different concentrations of nicotine applications.

\section{Results}

Findings demonstrated that immediately after $10 \mathrm{mM}$ nicotine application, OCCM cells were not alive. $10 \mathrm{mM}$ concentration of nicotin was severely cytotoxic. Other concentrations of nicotine even when it was used picoM level, significantly inhibited proliferation of cementoblasts at $72 \mathrm{hrs}(\mathrm{p}<0.05)$. Inverted microscopy images exhibited rounded dead cells at highest concentration of nictoine parallel with the proliferation findings.

\section{Conclusions}

Results of this study displayed that nicotine suppressed proliferation potentials of OCCM.30 cells which is critical for new cementum formation. Further studies are warranted to understand whether nicotine affects the gene expressions profile of the cementoblasts.

Tob. Induc. Dis. 2018;16(Suppl 3):A119

DOl: 10.18332/tid/94684
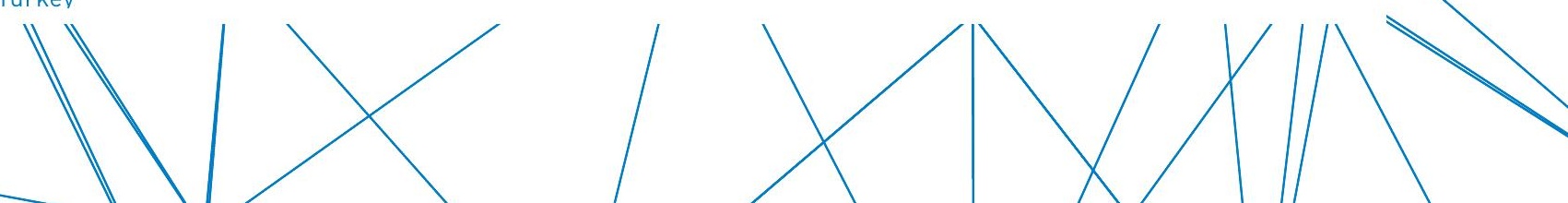
SCIENCE \& TECHNOLOGY PARK of CRETE (STEP-C)

100, N. Plastira str., Vassilika Vouton, 70013, Heraklion, Crete

00302810.3917 .14 | editorial@tobaccoinduceddiseases.org www.tobaccoinduceddiseases.org

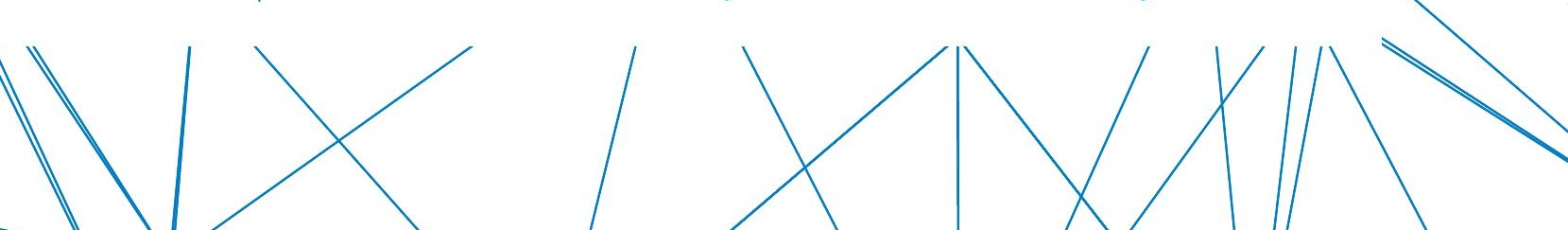

